Portland State University

PDXScholar

$1-1-1979$

\title{
Adoption of children in foster care: a comparison of processes leading to adoption by foster parents and adoption by others
}

Janet Lahti

Portland State University

Follow this and additional works at: https://pdxscholar.library.pdx.edu/open_access_etds

Let us know how access to this document benefits you.

\section{Recommended Citation}

Lahti, Janet, "Adoption of children in foster care: a comparison of processes leading to adoption by foster parents and adoption by others" (1979). Dissertations and Theses. Paper 878.

https://doi.org/10.15760/etd.878

This Dissertation is brought to you for free and open access. It has been accepted for inclusion in Dissertations and Theses by an authorized administrator of PDXScholar. Please contact us if we can make this document more accessible: pdxscholar@pdx.edu. 
ADOPTION OF CHILDREY IN FOSTER CARE: A COPPARISON OF PROCESSES LEADING TO ADOPTION BY FOSTER

PARENTS AND ADOPTION BY OTIERS

by

JANET LAHTI

A dissertation submitted in partial fulfillment of the requirenents for the degree of

\author{
DOCTOR OF PHILOSOPIY \\ in \\ URBAN STUDIES
}

Portland State Uhiversity 
AN ABSTRACT OF THE DISSERTATION of Janet Lahti for the Doctor of Philosophy in Urban Studies presented June 10, 1979.

Title: Adoption of Children in Foster Care: A Comparison of Processes Leading to Adoption by Foster Parents and Adoption by Dthers

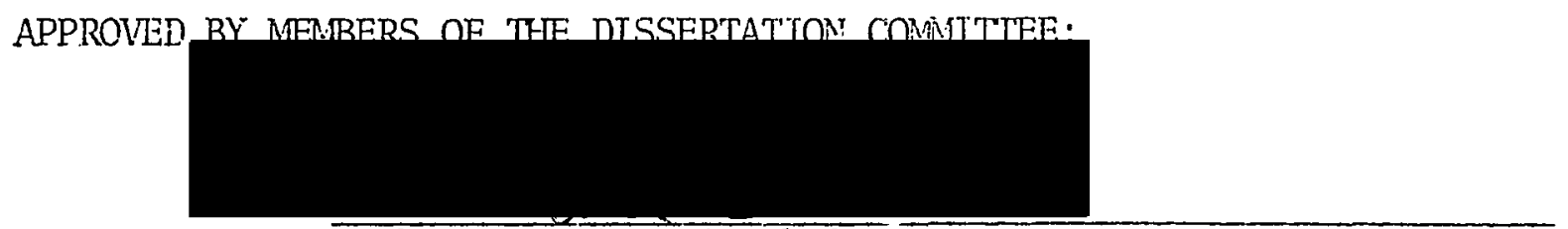

Arthur C. EmIen, Co-Chairman.

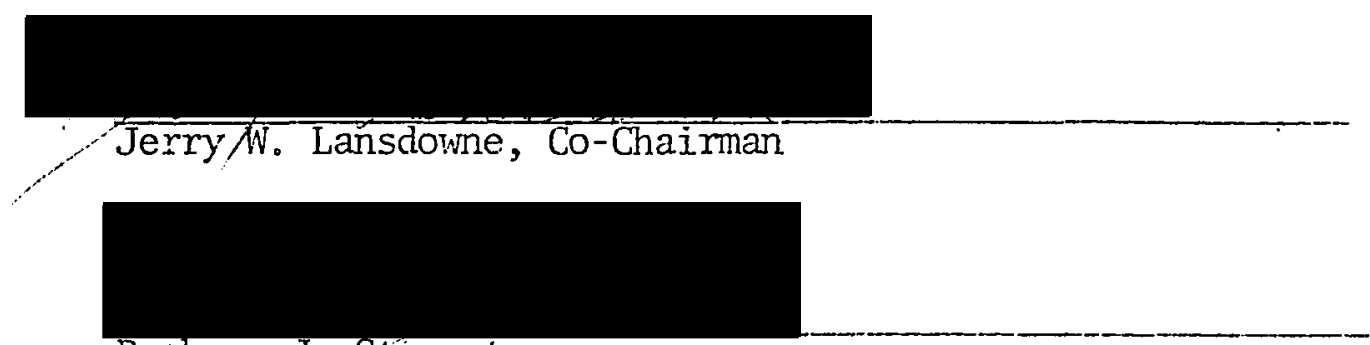

Barbara J. Sxewart

This research evaluates the results of: a change in policy by Oregon's ChiJdren's Services Division permitting foster parents to adopt their foster child. A comparison was made between two groups of children, both of whom were seen by their caseworkers as not 1.jkej.y to return home and adoptable. One group was believed likely to be adopted by foster parents and the other believed likely to be adopted by new parents. Process and outcome of placement efforts for the two groups are described and compared. The study sample, comprised of 155 children, were followed for 28 months from the time the decision was made that they were not likely to return home and were adoptable. Decisions necessary to reach 
the adoption goal were identified, and the time they took were sunmarized for the sample. An assessment lias made of the extent to which variables having to do with characteristics of the child, his history with the agency and the influence of the agency and court accounted for decisions made and time.

From the results of this study it appears that adoption by foster parents is a viable option for permanent placement. It can be accomplished as quickly, for as many children, and with no more risk than adoption by new parents. No difference was found in the proportion of the sample who were adopted by new parents and those adopted by foster. parents. It took approximately one year, no matter what the outcome. Children who might not otherwise be placeable were adopted by foster parents. These were the older children who had been in foster care longer and were considered less placeable. This provides a placement option for those most difficult to place.

Though adoption was seen as likely, half of the saup]e (74 of 155) remained in foster care. Of these, 31 percent (23 of 74) were freed from parents but not adopted. Children who remained in foster care are the oldest and the least placeable in the sample. For these children the options for exit from foster care are limited, and this seems to call for an intensive effort to find adoptive homes. Also needed is a closer monitoring of cases from entry into foster care to assure that the case is resolved as quickly as possible.

Children were more likely to be placed in a permanent home if they were part of a demonstration project which assigned special caseworkers to work intensively toward the goal of finding a permanent home for the child. Return to parents had the highest priority; or, if 
this was not possible, adoption. Eleven percent of the sample returned to their parents, though they had been thought not likely to return home. Children chosen for the project efforts were younger and more placeable. Hethods used by the project caseworkers should be made available for every case to facilitate their early resolution.

Several findings point to a need for some formal case review process. Some case decisions which should have been made on the facts of the case were accounted for, at least in part, by caseworker attitude. Such bias might be reduced by basing decisions on the consensus of several informed people. 
TO THE OFFICE OF GRADUATE STUDIES AND RESEARCH:

The members of the Committee approve the dissertation of Janet Lahti presented June 10, 1979.

Arthur C. Enlen, Co-Chaiman

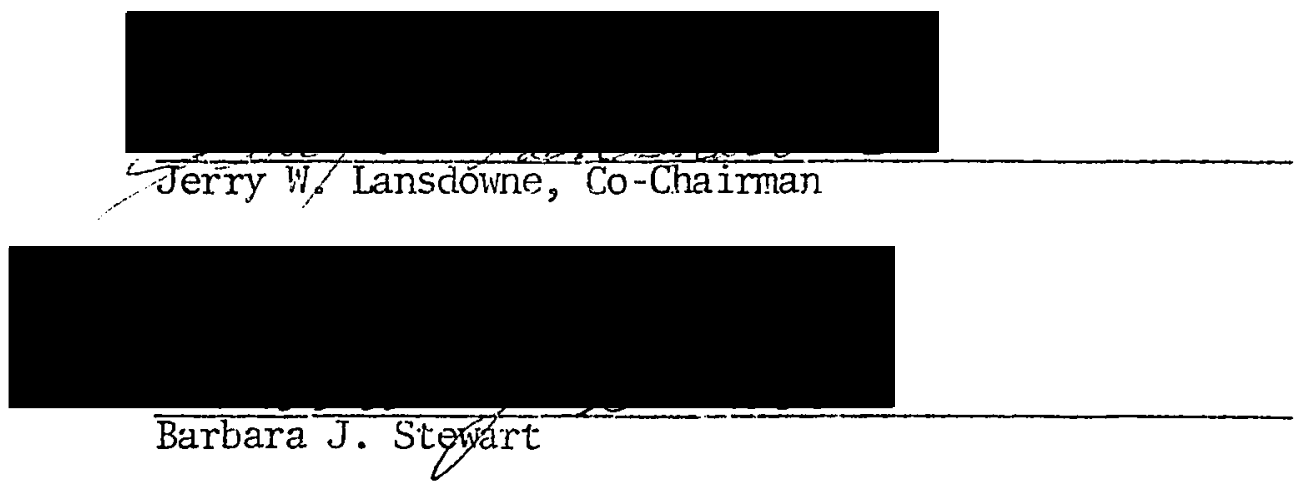

APPROVED:

Charles D. Bolton, Acting Dean, School of Urban Affairs

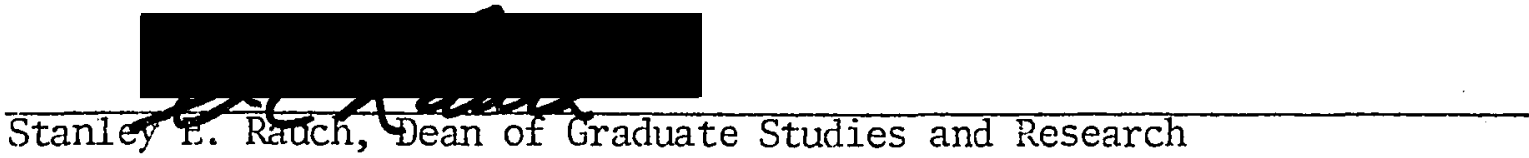


ACKNONLEDGESENTS

This study is the product of the efforts, ideas, and commitment of many individuals. Without their generous support it would have been impossible to complete this venture.

Credit is due to Arthur C. Emlen for his sound advice throughout the project. His consistent good will and support has been a valuable contribution. I would like to thank Jerry Lansciowne for his willing and perceptive help in the area of policy analysis. Barbara Stewart contributed much to my enthusiasm for research and guided me as I put together the results.

I owe a particular debt to the Children's Services Division caseworkers and administrators who furnished the data and in so many vays cooperated to make this study possible. This study was conducted in connection with a three-year demonstration project of the State of Oregon, Children's Services Division, supported by a grant from the Office of Child Development, Department of Health, Education, and Welfare (CB-OCD-\#481). I especially appreciate the encouragement and help of Lois McCarthy, CSD Program Manager who had administrative responsibility for the project and Vic Pike, Project Director. Under the grant, the research and evaluation of the project was conducted by the Regional Research Institute for Human Services at Portland State University. The principal investigator was Arthur Emlen, Professor of Social Work and Director of the RRI. The data for the dissertation were collected as an integral part of the RRI's study throughout which I served as a co-investigator. 
During the period when I vas finishing this work, Snirely Kernedy, Professor of Anthropology at Portland State University, died. She served on the advisory comittee through completion of comprehensive examinations. I gratefully acknowledge her valuable contribution to me personally and to my education.

I want to thank my husband and children for their patience and encouragement with what seemed like a never-ending task.

Many others have contributed to the completion of this work and I am grateful for their help. The Regional Research Institute staff have assisted in so many ways. Jim Casciato and Darey Shell did the computer programming. Appreciation must also be extended to Mary Troychak, Katie Liedtke, and Linda Devereaux for their help with the manuscript. Many others have given their encouragenent and help. I am particularly indebted to the foliowing people: Narie Kuehnel, Karen Reid Green, Susan Downs, Catherine Taylor, Glen Downs, and Lori Stahl. 
TABLE OF CONTENTS

PAGE

ACKNOWLEDGENENTS ....................... . . iii

LIST OF TABLES . . . . . . . . . . . . . . . . . . ix

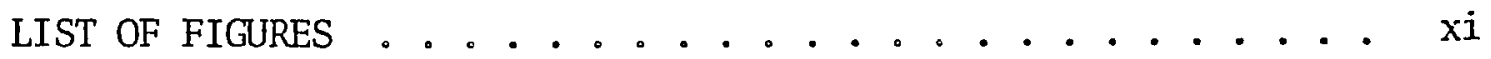

\section{CHAPTER}

I INTRODUCTION ................... I

Foster Care and Adoption . . . . . . . . 2

The Project ................ 5

Specific Research Objectives and Methods . . . . 6

Literature, Methods and Conclusions . . . . . 9

II REVIEW OF THE LITERATURE . . . . . . . . . . . 11

Adoption by New Parents . . . . . . . 12

Adoptive Parents

The Adopted Child

Adoption by Foster Parents . . . . . . . . 21

Foster Care ............. 28

The Foster Parents

The Foster Child

Summary . . . . . . . . . . . . . 33

III METHODS . . . . . . . . . . . . . 35

Subjects . . . . . . . . . . . . 36

Data Sources

Attitude Survey

Child Placeability lieasures

Interviews

Fxpert Ratings (The "Pike Ratings") 
Analyses ................. . . 42

IV CASE STUDIES .................. . 44

Polk County ............... . . 46

Foster Care Placement and Initial Assessment

Casework with Father

Casework with $!$ lother

Petition for Termination

Termination of Mother's Rights

Termination of Father's Rights

Aftermath

Multnomah County . . . . . . . . . . , 57

Casework Services

Placement with Father

Review Hearing

Permanent Planning Project

Review Hearing

Return to Foster Care

Termination Hearing

Sumnary . . . . . . . . . . 65

V THE PROCESS OF ADOPTION . . . . . . . . . . . 68

Decision Results ............. 73

The Outcome ............... 77

VI ACCOUNTING FOR THE DECISIONS . . . . . . . . . 80

Is a Child, Iho is Not Likely to Return Home, Adoptable by lew Parents or Foster Parents? 85

Discussion

Should This Child tho Was Predicted to be Adoptable by New Parents be Chosen for the Project? . . 93

Summary 
vii

PAGE

CHAPTER

Should This Child, Tho Was Predicted to be Adoptable by Foster Parents, be Chosen for the Project?............ 99

Discussion of Project Selection

Is Adoption Pursued for Children Likely to be Adopted by Foster Parents?. . . . . . . . 106

Discussion

Is Adoption Pursued for Children Likely to be Adopted by New Parents? . . . . . . . . 112 Discussion

What Is the Outcome for the Child . . . . . . 114

Should This Child be Adopted by New Parents, Adopted by Foster Parents, Remain in Foster Care, or Return to his Parent? . . . . . . 117

Is the Outcome for the Child: Foster Parent Adopt or New Parent Adopt? . . . . . . . . 119 Discussion

VII TIIE ...................... 126

Accounting for Time ............. 130

Discussion ................ 132

VIII CONCLUSIONS AND POLICY CONSIDERATIONS . . . . . . 133

Numbers Adopted . . . . . . . . . . 133

Time . . . . . . . . . . . . . . 135

Who is Adopted . . . . . . . . . . . 137

Legal Safeguards for Parental Rights . . . . . 139

Unexpected Results . . . . . . . . . . 140 
vi i

PAGE

CHAPTER

Other Considerations. . . . . . . . . . . 147

Conclusions . . . . . . . . . . . . . . 143

REFERENCES CITED . . . . . . . . . . . . . . . . 146

REFERENCE NOTES. . . . . . . . . . . . . . . . . . . 151

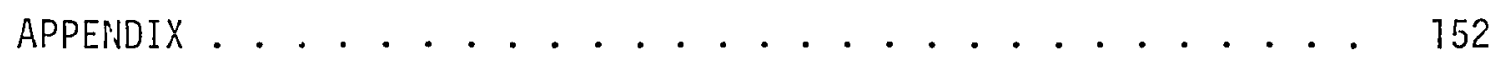




\section{LIST OF TABLES}

TABLE

PAGE

I Correlations Between Two Raters of Barriers to Child Placement Scales ........... . 41

II Number Freed from Parent $I$ by Number Freed fron Parent 2 in Foster Parent Plan ........ 75

III Number Freed from Parent 1 by Number Freed from

Parent 2 in New Parent Plan ......... 75

IV Number of Children in Each Outcome by Likely Outcome and Project ............. 79

V Variables and Measurement Scales Included in the Analyses ................ 81

VI Discriminant Analyses . . . . . . . . . . 84

VII Means for Variables Significant to the Decision:

"Who is Likely to Adont the Child?" . . . . . . . . 90

VIII Means for Variables Significant to the Decision:

Should a Child Likely to be Adopted by New Parents be in the Project? ............. 97

IX Means for Variables Significant to the Decision:

Should a Child Likely to be Adopted by Foster

Parents be Chosen for the Project? . . . . . . 103

$X$ Means for Variables Significant to the Decision:

Is Adoption Pursued for the Foster Parent Adopt Sample?. .................. 109 
XI Means for Variables Significant to the Decision:

Is Adoption Purused for the New Parent Sample? . . 115

XII Means for Variables Significant to the Decision:

What Placement Is Made? . . . . . . . . 120

XIII Means for Variables Significant to the Decision:

Is the Placement Adoption by Foster Parents or

Adoption by New Parents? . . . . . . . . . . 124

XIV Miean and Standard Deviation of Time, to Reach

Placement . . . ............ 127

XV Mean and Standard Deviation of Time to Reach P1acement

by Method of Freeing the Child . . . . . . . . 128 


\section{LIST OF FIGURES}

FIGURE

PAGE

1. Flow Chart of Decisions Made for Sample Mildren

Seen as Likely to be Adopted by Foster Parents . . 71

2. Flow Chart of Decisions Made for Sample Children

Seen as Likely to be Adopted by New Parents . . . 72

3. Discriminators (Client, Non-client and Service History)

of Caseworker Decision of Who is Likely to Adopt:

Foster Parents or New Parents . . . . . . . 91

4. Discriminators (Client, Non-client and Service History)

of Cases Seen as Likely to be Adopted by New

Parents into Two Groups: Project and Non-Project

Cases ................... . 98

5. Discriminators (Client, Non-client and Service History)

of Cases Seen as Likely to be Adopted by Foster

Parents into Two Groups: Project and Non-Project

Cases .. . . . . . . . . . . . . 104

6. Discriminators (Client, Non-client and Service History)

of Cases Seen as Likely to be Adopted by Foster

Parents into Two Groups: Adoption Pursued and

Adoption Not Pursued . . . . . . . . . . . 1110

7. Discriminators (Client, Non-client and Service History)

of Cases Seen as Likely to be Adopted by New

Parents into Two Groups: Adoption Pursued and

Adoption Not Pursued . . . . . . . . . 116 
3. Discriminators (Client, Non-client and Service History) of Actual Outcome :for Four Groups: Adopted by New Parents, Adopted by Foster Parents, Returned to Parents and Remained in Foster Care . . . . . . 121

9. Discriminators (C1ient, Non-client and Service History) of Actual Outcome for Two Groups: Adoption by Foster Parents and Adoption by New Parents . . . . . . . 125 


\section{CHAPTER I}

\section{INTRODUCTION}

This study evaluates the introduction in Oregon of a policy permitting foster parents to adopt foster children in given circumstances. When a child cannot return to his parents for reasons justifying termination of parental rights, adoption offers the prospect of permanent family relationships. Yet adoption is a child welfare policy that traditionally has not been considered appropriate for the relationship between foster parents and the children in their care, Foster care and adoption were designed as mutually exclusive alternatives, one temporary, the other permanent. If the intent of foster care is temporary placement, then it is not appropriate to allow an opportunity for adoption by foster parents to interfere with a child's prospects for return to his parents.

Pressure to institute a policy permitting foster parents to adopt came in part because the policy of foster care did not accomplish what it set out to do. Though designed to be a temporary planned arrangement, foster care turned out to last for many years for many children, often until they were emancipated at age 18. Over time some children formed strong ties to foster parents. When return to parents was not possible and grounds existed to terminate parental rights, the agency sought to honor the emotional bonds formed in foster care and permit foster parents to adopt. 
In order to evaluate the new policy, this study compares it to an older widely accepted one: adoption of children by parents new to them. For years this policy has been fimly in place. Therefore a cwearison is made between a group of children designated by their caseworkers as candidates for adoption by their foster parents and a group designated as candidates for adoption by parents nev to them. The comparizon of these two groups permits an assessment to be made of how implementation of the new policy measures up to an established one having the same outcome, namely adoption. By examining process and outcome, the study evaluates the feasibility of the new policy: Does the policy actually produce results, that is, adoption in substantial. numbers? Is the policy efficient with respect to the length of time required for the process to the point of adoption? Does the policy serve a different population and thus create permanent placements for children not served by other options? In general, does the policy create a viable option in providing family permanency for children in foster care?

FOSTER CARE AND ADOPTION

To permit a better understanding of the implications of this study for agency policy and practice some knowledge of the operation of foster care and adoption programs is presented.

The adoption of children by parents new to them has been a common practice in our society for some time. Traditionally this meant that parents, often young and unmarried, voluntarily relinquished their rights to their child, usually a newborn baby, and the child was placed by a public or private agency in a permanent adoptive home. Parents 
had no further contact with the child and usually were not aware of his whereabouts. Adoptive parents vere carefully screened and helped through the adjustment period by an adoption caseworker (Iahti, et al., 1978). Within the last two decades a change has taken place. Fewer babies are available for adoption leading both agency staff: and potential adoptive paients to explore the possibility of adopting older children. These children were considered more risky as adoptive placements. Even so as adoptive parents were willing to take them, adoption caseworkers began to work with these potential parents in an attempt to secure lasting placements. Studies discussed more fully in Chapter J.J indicate that these efforts have been successful.

Understanding adoption by foster parents and how it became an option for children requires a look at foster care; what it: is supposed to be, what it really is and of efforts to remedy the differences between the intention and the reality. Foster family care is a child welfare service which provides substitute family care for a plamed period for a child when his own family cannot care for him for a temporary or extended period when adoption is neither desirable nor possible (American Public Welfare Association, 1975). The assumption on which foster care is instituted is that it should be a planned arrangement and exist for as short a time as possible. In 1959 Maas and Engler studied foster children, with starting results. Of all. children studied better than half gave promise of spending a major part of their childhood years in foster care. Since then similar results have been obtained by other researchers (Jenkins, 1969; Chi.d and Family Services of New Hampshire, 1972). Large numbers of foster children 
grow up in an arrangement which is neither planned nor temporary. As children lived in foster care for long periods some developed strong ties to their foster parents and in some cases these parents were permitted to adopt.

Generally the process by which a child is adopted by foster parents occurs in the following way.' The child's parents do not provide adequate care and he is placed in a foster home. Special services and a concentrated effort are provided to parents in an effort to help them reach at least a minimum sufficient level that would permit themi to care for the child. The biological parents cannot make changes which would permit the child to be returned and it is determined that adoption is appropriate. Enotional bonds to foster parents are formed before the child is adopted, not after as would be the goal when parents adopt a child new to them. Agency staff decide that the foster home would be a good permanent placement and ask foster parents if they would like to adopt the child. If they agree, adoption takes place and this i.s usually with minimum involvement of the adoption caseworker.

A prime condition for the policy of adoption by foster parents to be implemented is that the court must detemine that the child's parents cannot care for him. No matter how strong the child's ties to his foster parents seem, adoption cannot take place until that child is legally free from his parents. The society values and the court protects the rights of parents. 
THE PROJECT

In an effort to alleviate this problem a special demonstration project was begun in Oregon. The project was based on the belief that a permanent home is important for a child's well being. The highest priority was to return the child to his parents, or, if this was not possible, the choice was adoption. Through a federal grant from the Office of Child Development of the Department of Health, Education, and Welfare a demonstration project (hereafter referred to as "the project") "Freeing Children for Permanent Placement" was set up within Oregon's Children's Services Division to deal with the problem of children who seem destined to remain in limbo in foster care. The project staff believed that the phenomena of foster care drift could be largely attributed to a failure to place in adoptive homes children who could not return to their parents and it was these children who were the project's focus.

The project provided a unique opportunity to describe and compare adoption by new parents with adoption by foster parents, because of the large numbers of children for whom the later option seemed the best choice. Children chosen as project cases, those not likely to return home and adoptable, had often lived in their foster home for some time and a bond between the parents and child had developed. The project found large numbers of such children and sought for them adoption by foster parents. Until about the time the project began, foster parents had been discouraged from adopting, in the belief that they had been 
chosen and groomed to provide a temporary home and that permitting them to adopt interfered with their effectiveness in providing short-term care. During the project when foster parents wanted to adopt they were encouraged to proceed, if the child's parents could not provide a home for him and the placement was considered to be a good one. Foster parent adoption was the permanent placement for approximately half of the children who were adopted in the study, providing a chance to assess the effects of the policy change.

\section{SPECIFIC RESEARCH OBJECTIVES AND METHODS}

In order to evaluate the policy of adoption by foster parents, a comparison was made with new parent adoptions. Five specific objectives have been defined for this comparison.

1. Describe the process by which each type of adoption takes place.

2. Identify the decisions which can be pinpointed for all cases and follow and compare each group of children as the identified decisions are made for them.

3. Account for group differences with the following sets of variables: client (measures of characteristics of the child), non-client (agency and court measures), and service history (measures of child's association with the agency).

4. Account for the time taken to achieve the outcome with selected client, non-client, and service history variables.

5. Consider the findings as they contribute to an understanding of urban-rural differences. 
The methods used to accomplish these objectives were: interviews, particirant observation, case studies and statistical analysis of caseworker and supervisor attitudes and ratings and demographic data. A case study method was chosen to describe the process. These results are reported in Chapter IV, in which the reader can see the case events from beginning until the case was resolved. The efforts of the caseworker and biological parent to reunite the family are described as well as the detail of court hearings and finally termination of parental rights and adoption. Two cases were chosen; one from urban Multnomah County and the other from rural Polk County. Each case was selected by the project caseworker because it contained a variety of typical events which would give the reader an idea of what adoption was like in that county. The case studies capture the flow of events and the remainder of the study examines cross sections of time at several points. Rural-urban differences are examined through the case studies as well as in the analyses reported in Chapters VI and VII.

The sample study consists of children designated by their caseworkers as not 1ikely to go home and adoptable by either (1) foster parents or (2) new parents. Where appropriate, comparisons are made between these two groups. Some of the comparisons are between outcomes, that is, between those actually adopted by new parents and those adopted by foster parents.

Chapter $\mathrm{V}$ identifies the decisions made and tracks each case to its final conclusion. A flow chart of events is presented and comparisons are made between adoption by new parents and adoption by foster parents. 
Results of efforts to account for group differences, both by predicted outcome and actual outcome are found in Chapter VI. Sets of variables (client, non-client and service history) were entered in discriminant function analyses to assess the extent to which these measures account for the various decisions made for a child. The client set consists of child-measures such as his placeability, his ability to cope emotionally and his relationship with his parents. The non-client measures are agency, court and county variables not directly associated with the child but possibly influencing his fate. Included in the service history set are measures having to do with the child's past such as length of time in foster care and number of foster care placements.

In Chapter VII time comparisons are made between the time it takes to accomplish adoption by foster parents and by new parents. The results of efforts to account for differences in time are presented. Selected variables from the client, non-client and service history sets are independent measures in a regression analysis with time as the dependent. variable.

A knowledge of the length of time taken to implement an acloption can be critical to the child and to decision making by the caseworker. As children grow older they become more difficult to place in an adoptive home and the caseworker may need to choose a different optjon (Unger, Dwarshuis \& Johnson, 1977). As the time taken to accomplish the goal of adoption increases the chances of reaching this goal decrease. For a child the growing up years seem long (Goldstein, Freud, and Solnit, 1974) so while an adult may think of a year or two as a 
short time to implement an adoptive placement for a child it could seem end1ess.

In summary, Chapters IV, V, VI, and VII present the results of analyses addressing the objectives of this study. The remaining chapters described below are designed to assist in the understanding of the objectives and the conclusions that can be drawn from them.

LITERATURE, METHODS AND CONCLUSIONS

Chapter II contains a summary of other efforts to understand adoption by new parents and adoption by foster parents. A discussion of the development of the foster parent adopt policy is presented. While the outcome of adoption by new parents has been evaluated in many ways few studies look at the process of adoption by foster parents or adoption of a child who is no longer an infant.

Chapter III contains a discussion of the methods used in the attempt to reach the objectives of this study. It contains a discussion of research methodology used as well as a discussion of sources and means of obtaining data.

Conclusions and policy implications of the findings are presented in Chapter VIII. Adoption by foster parents is compared with new parent adopt and the adequacy of adoption by foster parents as a policy option for permanent placement of children is assessed. This study looks at a process. Its focus is on children who are older than the infants who have been the subject of most adoptions. The research looks at adoptions during a time of change. Fewer babies are available and agencies are beginning to focus on the older child as an answer to 
parents' desire for children to adopt. While most adoption studjes address problems related to reasons parents adopt or the quality of the adoptive home, this study deals with processes by which a child's status changes froin foster care where the parents still have permanent custody to an adoptive home where adoptive parents have full. parenta]. rights. 


\section{CHAPTER II}

\section{REVIEW OF THE LITEPATURE}

Since 1850 (Bremner, 1970), it has been a policy in this country to place in adoptive homes children whose narents cannot or will not provide care. Adoption, with all its legal sanctions and protections, represents the removal of a child from his parents to willing, guardians in its most permanent sense. When this arrangement has been completed it is legally the same as if the child had been born to these adoptive parents. This practice, which in the past has usually involved infants or very young children, was carried out smoothly and with little interference.

Early in the last decade several changes took place which had an impact on adoption practice. One was a decrease in the number of infants who could be adopted. This resulted from the increasing availability of birth control methods, and abortions and of a tendency on the part of parents, particularly unwed mothers, to keep their child. Adioption caseworkers and prospective adoptive parents began to consider the older child. This would provide a supply of children for adoption. Wost of these older children had been placed in foster care temporarily and later became available for adoption. The advisability of placing these children in adoptive hones was cuestioned by some in the belief that a family adopting an older child would experience severe problems (Kadushin, 1970a; Unger, et a1., 1977).

A second change was a movernent to remedy foster care drift, the tendency to permit children who had been placed in foster care on a 
temporary basis to remain there during all their childhood years (Enlen, et al., 1977). The demonstration project described earlier was a major component of this movement. As project cases were closely examined the decision that adoption was appropriate was made for many of them (Emlen, 1976). This movement impacted on adoption practice in two ways; foster parents were seen as an option for adoptive placement and the numbers of older children available for adoption increased.

The availability of these children made it possible to correct the imbalance created by the decrease in the number of infants. Also ties children had formed to their foster families were honored and they were permitted to remain in the home through adoption.

What follows is a report of studies of adoption by foster parents, adoption by new parents and of foster care. The focus is on information which will assist in an understanding of the status, the process, and outcome for children most like those in this study.

\section{ADOPTION BY NEW PARENTS}

\section{Adoptive Parents}

In studies extending from the late 1940's through the eariy 1970's in wide-ranging areas of the United States, the characteristics of adoptive parents were strikingly similar. Adoptive parents were preponderantly white, middle class, in their thirties, Protestant, educated to twelfth grade and beyond, and holders of professional, independent, or skilled positions. They were adopters of white infants (Brenner, 1951; Fairweather, 1952; Jaffee \& Fanshe1, 1970; Haas, 1960; Shireman \& Watson, 1972; Skodak \& Skeels, 1949). 
The picture of adoptive parents was resoundingly uniform, considering their numbers, perhaps because this was not a sample of a11 people who would or could adopt children. Adoptive parents were those who had been selected by adoption agencies. The selection criteria of these agencies, then, must have been remarkably similar. However, some new trends have made their appearance. Adoptive parents have been approved outside of the white middle class, including single parents, especially in the black community and for hard-to-place chi]dren (AIdridge, 1974; Falk, 1970; Fanshe1, 1957, 1972; Herzog, et a1. , 1971; Kadushin, 1970b; Neilson, 1976; Shireman \& Johnson, 1976).

The literature on adopters of the older child is the most pertinent here. Kadushin (1970a), in taking a close look at such a group in Wisconsin, found that they met the standard socio-economic norms of most adoptive parents in this country, but they were generally older. The mean maternal age was 40; the mean paternal age was 41.5 . Many had experience with children, either voluntarily or occupationally; but, most importantly, 37 percent were already parents. This is in marked contrast to the younger adoptive parents of infants and presents a significant complicating factor in the adjustment of the older adonted child. Kadushin notes that few such parents initially express preference for an older child. A follow-up "satisfaction-dissatisfaction: ratio showed 73 percent of the adoptions to be successful in terms of parental satisfaction, and Kadushin carefully demonstrated this to be within the normal success rate for adoptions in general. 
The Adopted Child

Adoption in America today is a child-centered process. Resources, in the form of time and personnel, are devoted to it in the hope that the parentless child will find happiness, security, and adult success. Many studies have been conducted to determine how well the adopted child actually fares.

For a general statement one need only to look at the results Kadushin charted in 1974 of 19 studies stretching from 1924 to 1972 that follow up the adoption of white, non-handicapped infants five to ten years 1ater. Of 2,440 placements, 17 percent were judged failures. Seven studies covering more than 436 placements of "chiJdren with special needs" showed a poor result in eight percent of the cases. This leads to the conclusion that adoptions are more frequently successful. Some studies compared adoptees as a group to other groups and found that they functioned at average or above average levels. Seglow, Pringle and Wedge (1972) studied a cross-section of children born in England, Wales and Scotland during March 1958. Using a Iongitudinal study, information was gathered on these children during four intervals of their first 13 years. They compared the children who had been adopted with a general population of children (cohort) and with illegitimate children who were cared for by their biological mothers. The general aims of the study were to determine what kind of start in life adoptive children have, how they compare with other children by the age of seven, and what their "risk" factor is. The study concluded that at age seven the adoptive children were equal to or superior to the cohort children with regard to physical development, general abilities and educational 
attainments. The sample of illegitimate children who remained with their biological mothers, thereby experiencing no parental separation or shifts in family placement, were at a significant disadvantage on a.11 measures.

A similar conclusion was drawn by Tizard and Rees (1974) when they compared $4 \frac{1}{2}$ year olds who had spent their first two to four years institutionalized. At the time of the study, the group of 65 subjects had either been adopted, returned to their families, or remanded to the institution. They were assessed in terms of response to strangers, scores on psychological tests (Wechsler Preschool and Prinary Scale of Intelligence), behavior during resting, and breadth of experiences. The results were compared across the three groups as well as against a natural family group of London working-class children. The adopted children had the highest intelligence scores and were least distracted and restless while testing. They were also above average on all other points.

Earlier studies have reflected that the adopted child turns out more "normal" and less maladjusted than anticipated (Addis, Salzberger \& Rab1, 1954; Borgatta \& Fanshe1, 1965; Pringle \& Bossive, 1965; Skodak \& Skeels, 1945).

Elonen and Schwartz (1969) reported that adopted children adjusted as successfully as non-adopted children, but they pinpointed the parents' reactions to the child's questions and feelings about his past and their attitude toward providing information about the child's background as a potential source of problems. 
Triseliotis (1973) studied 70 adoptees who had gone to the Register House in Edinburgh, Scotland, to see their birth registrations. The majority of the adoptees were between the ages of 20 and 34 . Eighty percent of them were under a year old at the time of adoption. Triseliotis found that 44 of the 70 perceived themselves in fairly negative terms and had a poor self-image. They also perceived their adoptive home life as depriving and maintained that they were given no information or only negative information about their origins. It is possible that adoptees having problems may be more motivated to seek infonnation abuut their past.

Jaffee and Fanshel (1970) found that the adoptive children who had the most problems were also the children most likely to want more information about their biological parents. Stephenson (1975) avowed that "Those who attribute extreme vulnerability to the adopted state have made the unfortunate mistake of making assumptions about the adopted population as a whole from (a) very skewed sample of people" (p. 365).

Actually, the problem of genealogical bewilderment does not usually exist for the older adoptee, since he knows and remembers who his natural parents are.

Often the initial experience of separation from the natural parents has been repeated and reinforced several times through replacements at the hands of his parents or in agency foster homes. The end result of these experiences is a child who is old in years, but has suffered tragic interruptions in his physical and emotional development. He is a child who has invested in love relationships and been disappointed. (IlcCoy, 1961, pp. 14).

Few would deny that the child experiences some trauma when he is moved from one placement to another. Rutter (1971) investigated 
parent-child separation in depth and found that much clepended on the nature of the separation experience. His results seem to show that the amount of discord surrounding a separation was the damaging element to the child.

Since the older child may arrive at his adoptive home after many discordant separations, the prognosis does not seem very bright. However, contrary to what might be supposed, studies do not show that multiple pre-adoptive placements necessarily doom the child to poor life adjustment. Jaffee and Fanshel (1970) studied the outcome of 100 adoptions made between the years 1931-1940. The population consisted of Caucasian children under the age of three at the time they were adopted and in their 20's to $30^{\prime} \mathrm{s}$ when the study was conducted. Data were obtained by interviewing the adoptive parents. They found that 40 percent of the parents saw no major limitations in the adoptee with respect to his or her current functioning. These children had experienced a mean number of 3.2 pre-adoptive placenents but the authors concluded that pre-adoptive placement bore little relationship to their subsequent life adjustment.

Bohman (1970) followed 168 children in Sweden, who represented all the children born within a period of two years, and placer in adoptive homes by the Adoption Agency of the Child Welfare Committee of Stockholm City. The children ranged from 10 to 11 years of age at the time of follow-up. A control group consisted of classmates of the same sex and age. Bohman found that pre-adoptive placements had no significant effect on adoptive outcome. 
In his follow-up study of older child adoptions, mentioned above, Kadushin (1970a) evaluated 91 children placed for adoption between the ages of five and 12, considered to be older children by adoptive standards. The children were removed from their natural homes at a mean age of 3.5 years and placed for adoption at the mean age of 7.2 years. They had experienced an average of 2.3 pre-adoptive placements. At the time of the follow-up, 10 years after removal, the mean age of these children was 13.9 years. The children had lived in socially deprived conditions characterized by poverty and pathology. The mean number of specific social and personal pathologies exhibited by each of the natural families from which these children came was 5.7. In spite of this background, Kadushin found that "The group as a whole. . . showed a greater degree of psychic health and stability than might have been anticipated given the nature of their backgrounds and developmental experiences" (pp. 208).

In a follow-up study of children in the demonstration project "Freeing Children for Permanent Placement" (the project from which the sample was drawn for this study) Lahti, et al. (1978) found no adoptive failures in a group whose average age at interview was seven and who had been in their adoptive home an average of 27 months. In a discriminant analysis attempting to account for the children's well being, age was not significant to the adoptive child's well being. Children who were in a high scoring group on factors measuring a broad spectrum of the child's life experiences were seen as permanently entrenched in the adoptive home and where doubt existed about the likelihood of the home being permanent the well being scores were lower. The high scoring 
children were those who also got along we1l when they first entered the home. If the decision to seek adoption had been less straightforward, i.e., there was a chance that the biological mother could have had the child returned to her, scores tended to be lower. The number of foster care placements and the length of time in foster care did not account for significant portions of the variation in the child's well being. Variables related to the adoptive home appear more related to the child's well being than those associated with the more distant past.

The question of siblings also figures in a special way with regard to dealing with the older adoptee. Chema, et al. (1970) pointed out that sibling groups are most often separated because a home to accommodate all of them is unavailable. Ideally, the groups should remain intact but Chema says that for the older child, "There may be the possibility of separate placements with continued contact, which can be a healthy 'second best"' (p. 453). Bell (1959) illustrated the occasional need of the older child to carry over one or two deep past relationships with the case history of an eight-year-old who maintained contact with an affectionate aunt.

Most adoptions work, and the factors that can predict a successful adoption have received a great deal of scrutiny. Brenner (1951) contended that a stable marriage was the factor most closely associated with successful adoptive outcome. Lawder, et al. (1969) found that "'satisfaction in parental role' and the parents' 'warmth and affection toward the child' showed the strongest positive relationship to adoptive outcome, with 'acceptance of adoptive role' a close third on 
degree of relationship" (p.96). Witmer, et al. (1963) found that

"Parent satisfaction is one of the major criteria of adoption outcome" (p. 393).

Background factors, for either child or parent, don't seem to correlate strongly with success, nor do age, length of marriage, religious affiliation, or other children in the home. Kadushin's summary (1974) of the work done in this area found only one negative factor: the child's sex. Adopted boys seemed much more likely to be maladjusted than adopted girls or non-adopted peers. His general conclusion about factors related to successful adoptions is that

Acceptance of, and satisfaction in, adoptive parenthood -coupled with warmth toward, and acceptance of, the child -were invariably associated with adoptive success. Conversely, the factor most clearly related to difficulty is parental rejection, although it is not clear whether the rejection causes the difficulty or the difficulty causes the rejection. (p. 581)

In summary it might be said adoption is a well studied phenomenon with a long cultural history. The number and variety of studies available show it to be very complex, as any such intimate human relationship is bound to be. Studies show that typical adoptive parents are white, thirty, educated and prosperous; they usually adopt white infants. Yet there are reports of new trends to accommodate both parents and children outside this group in the conviction that every child deserves the commitment of permanent parents. Studies are presented dealing with some special problems inherent in the adoption of the older child. The general view given in the studies discussed here, of adoption as a positive alternative for the parentless child, seems to justify it as a permanent plan. 


\section{ADOPTION BY FOSTER PARENTS}

Until recently, foster parents were rarely considered as part of the adoption picture. Allowing, or even encouraging, foster parents to adopt a child who had been in their care for several years and had formed strong ties to the foster family was not a common practice, even though the possibility existed and is discussed in child welfare texts as early as 1957 (Glickman, 1957)。

The reason for this stenmed from important differences between foster parents and adoptive parents. The purpose of foster care, the temporary provision of a substitute home for a child while a permanent solution is being found for the problems causing his removal from his home, seemed to preclude adoption within the foster care setting. Since the purpose of foster care differs so dramatically from adoption, so do the criteria for choosing foster parents and adoptive parents. Foster parents are selected for their ability to provide this temporary care. Many, in fact, specialize in a particular aspect, such as providing care for teenagers or for infants. The feeling within child welfare agencies was that the foster home selected might not necessarily be the optimal permanent placement for the child, since urgent family problems and emergency situations sometimes require rapid placement (Pike, Note 1) before an adequate study can be done.

The Oregon adoption unit staff believe that much attention should be placed on matching the child and his prospective permanent family and preparing all parties in advance. Clearly, the steps leading to 
foster care and adoptive placements are quite different. In the past in the State of Oregon, adoption by foster parents sirnply was not considered (Pargeter, Note 2). Oregon law, however, did not prohibit the practice.

Adoption by foster parents is rarely mentioned in the adoption literature. Foster parents who adopt apparently have not been singled out for study. The only article specifically dealing with this topic is one by Albert J. Neely, Director of the Children's Division, Cook County Department of Public Aid, of Chicago (1969), in which he very briefly reported on the work of his agency during 1967. Of the 92 children for whom adoptions were completed that year in Cook County, most were adopted by foster parents. Neely's report is of particular interest because he emphasized the role of the agency in exploring the possibility of adoption with foster parents, stating that the initiative is the responsibility of agency staff rather than of the foster parents. "Foster parents who have had the same children for extended periods of time are entitled to our making known to them and exploring with them the idea of adoption" (p. 163). Neely also notes the savings for the taxpayer brought about by the adoption of children in foster care. He estimates that completion of the 92 adoptions mentioned above eliminated approximately $\$ 1,133,000$ in foster care costs for those children had they remained in care until age 18.

In 1969, a national survey was published on attitudes and practices in foster care (Stone, 1969). Questionnaires were sent to 596 agencies and institutions. Stone pointed out that permanent foster care was part of a trend toward the dissolution of the previously clear distinction 
between foster care and adoption. She reported that many agencies were now permitting foster parents to apply for adoption of the child for whom they had been caring if and when he became available for adoption. When asked about adoption of a foster child, 50 percent of the agencies responding affirmed that agency policy allowed foster parents to adopt; 42 percent allowed it under certain circumstances; 7 percent said it was not at all possible under present policy. Stone noted that for onefourth of the affirmative respondents this constituted a change in policy over the last 10 years.

As the number of babies and young children available for adoption has diminished in recent years, attention has focused more and more on the so-called "hard-to-place" children: the older child, the physically, emotionally or mentally handicapped child, the child who is a member of a sibling group, or the minority child. To enable such children to become legally adopted, various states began to enact legislation to provide adoption subsidies. It is in the literature on subsidized adoption that we find most mention of adoption by foster parents, since those parents have often developed strong attachments to the children in their care and in many cases have been deterred from adoption for financial reasons. Private agencies have long provided short-term subsidies for specific reasons, but New York, in 1968, was the first state to enact legislation to provide regular payments to certain parents who adopt. Initially, New York's statute limited the availability of subsidies to foster parents who wanted to adopt children who had been in their homes as foster children. New York agencies had generally encouraged foster parent adoptions even prior to the existence of subsidies (Gentile, 1970). 
New York later amended its subsidy legislation to include new parents for children who couldn't be adopted by foster parents.

Andrews (1971) addressed the issue of choosing between 1ong-term foster care and subsidized adoption in terms of the benefits to the child. With regard to adoption, she mentioned a sense of belonging to a family, the right to use the family name and have an amencled birth certificate, Social Security benefits, and the right to inherit. She went on to say, "Adoption prevents the uprooting of the child should the biological parents seek to reclaim him. These factors are important ingredients in a child's security and sense of belonging" (p. 197). On the other hand, she noted that adoption causes a child to Iose his birth name and may cause him to lose contact with siblings and relatives.

In 1972, Watson noted in reference to subsidized adoption that the general thrust of the legislation seemed directed at converting into adoptive placements those situations in which a child is rooted in a satisfied foster family that has been unable to adopt for financial reasons.

By 1975, 39 states had passed subsidized adoption laws. (Oregon's law was passed in 1971). The Model State Subsidized Adoption Act (U.S. Department of HEW, 1976) stipulated special conditions which qualify a child for subsidized adoption. The first is "because he has established significant emotional ties with prospective adoptive parents while in their care as a foster child" (pp. 1-2). Other conditions proposed were physical or mental disability, emotional disturbance, recognized high risk of physical or mental disease, age, sibling relationship, racial or ethnic factors, or any combination of these conditions. 
The Child Welfare League of America (1973) discussed the use of foster homes as adoptive homes and stated that many foster families may become interested in and capable of adoptive parenthood and should be encouraged.

In Boston, the New England Home for Little Wanderers, a child welfare agency, has revolutionized its approach to findjng permanent homes for older or handicapped children. The agency no longer distinguj.shes between potential foster and adoptive homes, but rather deals with all applicant families as "family resources." It aggressiveJy seeks guardianship of a child with the right to place him for adoption or custody in order to protect a permanent plan when adoption i.sn't possible. Then, through a program of educational meetings with the interested families and peer group and agency support, the New England Home attempts to select families who will provide all children, even those considered non-adoptable and who will be raised in a foster home, with a sense of permanency and security. The underlying idea is that an open, nontraditional approach to chijd placement allows, and even stimulates, families to consider several alternatives. Thus, parents whose intent. was adoption may find it possible to provide a permanent home for a child who will never be legally free. Conversely, parents who planned to provide a foster home may decide to adopt their foster child (Hegarty, 1973).

Another rather distinct type of foster parent adoptive placement was described by Gill. (1975). The Lutheran Child and Family Services in Iilinois had a special program designed to place children not yet free for adoption with foster parents whose intent from the start was adoption 
of the child if he became free. The purpose is to spare the child from interim moves and the upset often caused by being in limbo. Placements resulting from this program differ from traditional foster care placements which end in adoption since the initial intent and the cormitment are to adopt the child.

In his text on child welfare services, Kadushin (1974) dealt with the subject of adoption by foster parents. He pointed out that an initial placement in foster care first may be desirable for hardto-place children, since it allowed the parents to develop an attachment to the child without feeling obligated to make the child part of the family. After an attachment developed, adoption may follow, Kadushin also comnented that most of the children adopted because of the availability of subsidization had been foster children in their adoptive home. He reported that New York's law required that the foster parents be given preference in applying for adoption if a child became available after having been in their home for two years.

All of this tends to make foster and adoptive homes less distinctively different and more conceptually interchangeable. The trend toward permanent or long-term foster care has blurred the previously sharp distinction between foster care and adoption; subsidized adoptions tend to obscure it further. (p. 599)

Brieland (1974) addressed the issue of trends in his forecast of future developments in the child welfare field. He predicted that foster parents increasingly will be selected as potential adoptive parents, with financial subsidies provided when necessary. "The bulk of agency adoptive placements will be of foster children, with 'quasi' or 'cormon- 
law' adoptions typical. Later, after the placement proves to be a success, the agency will approve the adoption" (p. 575).

With regard to foster parent foster child relationships, foster parents have actually brought agencies to court, placing under national scrutiny the procedures involved in foster care placements. The case of Smith v. Organization of Foster Families for Equality and Reform (OFFER) (1977) is perhaps the most striking example. OFFER and individual foster parents alleged that the statutory and regulatory procedures of the state and city of New York regarding removal of a foster child from a foster home violated the Due Process and Equal Protection Clauses of the Fourteenth Amendment. The District Court ruled in OFFER's favor, declaring that the state's pre-removal procedures were constitutionally defective and that the child was entitled to an administrative hearing before being pre-emptorily transferred from one foster home to another, suffering "grievous loss." The case was appea1ed to the Supreme Court, which, on June 13, 1977, reversed the District Court's ruling, stating that New York's procedures were adequate to protect the interests of the foster families.

One study (Lahti, et a1., 1977) referred to above describes the child and family who adopts him and assesses their adjustment. The children in the study had lived in their adoptive home an average of $5 \frac{1}{2}$ years with a range of two to 12 years. Ninety-three percent of these adoptions remained intact. At interview 94 percent of the families consisted of both a mother and father and an average of two children. During the time a decision about the permanent placement was being made, 46 percent of the children had visits from one or both biological parents 
and 68 percent of the visited children displayed behavior problems such as lying, bedwetting and temper tantrums after the visit. The adjustment at the time of the interview of children adopted by foster parents was no different from those adopted by parents new to them. However some other differences were noted. Children adopted by foster parents tended to be older, had spent a longer time in foster care and were less healthy when they entered their present home than those adopted in the traditional way. The foster parents tended to have a lower income level, did not feel as well prepared for the child's arrival. However they felt that the initial adjustment to the child was easier for them than did parents adopting children new to them. In spite of the presence of factors usually considered detrimental to the success of an adoption, these children fared as well as other adoptees.

In summary, while evaluative studies of adoption by foster parents are virtually nonexistent, legally these parents are able to adopt their foster children if the child is free from his parents and increasing numbers are taking this action. Past constraints have been due to agency policy rather than legal prohibitions. The availability of subsidized adoption has facilitated adoption by foster parents.

\section{FOSTER CARE}

The children who were subjects of this study were in foster care during the time period traced. Following is a compilation of other research addressing what life is like for this child. While the studies are by no means definitive they shed some light on characteristics of foster parents and the child's adjustment during care and in adult life. 
The Foster Parents

Socio-economic status has not been widely studied, but the existing ing literature seems to agree that, over a wide geographical area, foser parents are largely middle-aged, white, Protestant, working class people who own their homes and are high school educated (Babcock, 1965; Cautley, Aldreidge \& Finifter, 1966; Fanshe1, 1966; Jaffee \& Fanshel, 1970; Mande11, 1973; Peterson and Pierce, 1974; Rein, Nult \& Weiss, 1974; Wolins, 1963). Further investigations present descriptions of other foster parent characteristics that add to our picture. Babcock (1965), in a psychiatric evaluation of 25 foster families participating in an intensive three-year study in Pittsburgh, reported very little marital conflict. Foster parents in this study were also relatively isolated from their communities except for kinship and religious ties. A study by Paulson and Grossman (1974) described characteristics of. foster mothers. This study assessed child rearing attitudes of 233 licensed, full-time foster mothers and compared them to attitudes of 70 biological mothers. Foster mothers were reported to be strict and conforming in parenting and discipline, dedicated to the maternal rewards of the mothering role, and gratified by the emotional closeness of family ties with children and spouse. Fanshel (1966) noted that foster parents had the values and behavioral characteristics of "folk people." He observed that foster fathers tended to be passive where fostering functions are concerned, but strong and assertive in other areas, such as work. Foster mothers, Fanshel observed, tended to receive much role satisfaction from having close contact with children. 
Kraus (1971) reported that successful foster parents seemed to be motivated by a general interest in helping children. Cautley and Aldridge (1975) observed that most successful foster parents came from families with two or more siblings and that they were among the oldest siblings. Older siblings, in most American families, generally have the responsibility of caring for younger siblings. It is implied here, then, that older siblings tend to develop parenting skills.

\section{The Foster Child}

Several investigations have been conducted to study the behavior and adjustment of children in foster care. Much of the research has involved follow-up studies of adults who had been in foster care as children. A few observations have been made regarding the behavior and adjustment of children while in foster care.

Several authors have speculated about the general consequences of foster care on children. Maas (1969) reported that 40 to 60 percent of the foster children he studied revealed symptoms of psychological disturbance. However, in reporting the results of their longitudinal, descriptive study of 624 children in foster care in New York City, Fanshel and Shinn (1978) stated that foster children did not regress while in foster care. School achievement as measured by teacher ratings improved for 47 percent of the children during the first $2 \frac{1}{2}$ years of care but the decline for the remaining 53 percent resulted in a net group decline for this time. During their second $2 \frac{1}{2}$ years in foster care, 58 percent showed sufficient gains to result in a new marked improvement for the group. The group as a whole was then within nine percent 
of their age appropriate grade level. They were still performing below grade level but the gap had been reduced during the 5-year study period. Evidence on IQ suggests that the longer children remained in foster care, the more likely they were to show IQ gains. They fared significantly better than children who returned home. In general the authors found that "continued tenure in foster care is not demonstrably deleterious with respect to IQ change, school performance or the measures of emotional adjustment" (p. 491).

Then caseworkers rated observable behavioral reactions of the children some 30 days after they entered care, the majority of the subjects showed little overt indication of stress. Three years after entering foster care, 82 percent of the children were quite solidly entrenched in their foster care setting. Twenty-five percent were not aware that the foster family was not their biological family. Overall, the data suggested that children who entered foster care after five years of age found it more difficult to accept being placed away from their natural families than did toddlers or infants.

This same study reveals some interesting reactions to patterns of parental visitation. Children who were frequently visited seemed to show less attachment to their natural mothers, as well as less security in their foster care placement. Fanshel and Shinn state that

The presence of two sets of parental figures in the child's life can be a source of strain. Although parental visits may nevertheless have benefits with respect to the child's inner view of his own worth, such visiting is obviously not an unalloyed blessing. . . It seems obvious that the best approach to sparing the child the experience of conflicting loyalties while in foster care is to seek to forestall long-term placements. (pp. 411-412) 
Some follow-up studies have been conducted in an attempt to determine what happens to these children when they leave foster care and adjust to adult life. Meier (1965) conducted an interview study of 61 adults between the ages of 28 and 32 who had been in foster care at least five years. Criteria used by Meier included interviewer ratings of the respondents' level of social effectiveness and feeling of wellbeing. Meier found that in most areas of adaptation, current functioning compares favorably with that of the general population. An early study by psychologists Roe and Burks (1945) was a follow-up of 36 former foster children. They reported "most of these subjects have established reasonably satisfactory lives, including adequate personal and community relationships and most of them are married" (p. 8). A more recent commentary by Jacobson and Cockerum (1976) reported the majority of their sample of former foster children in Idaho were married, had children, and were employed. These few follow-up studies, then, seem to point out that former foster children can, and usually do, adapt satisfactorily to adult life.

The true nature of the foster care experience can be rather difficult to delineate from the literature. We have some information on the socio-economic status of foster parents, what makes for success as a foster parent, and what effects foster care has upon the children. However, studies on the life adjustment of the children have been conflicting and inconclusive. 
SLIAIAY

The few studies on children returned from foster care to their biological parents show that they do not necessarily return to improved situations, nor do they fare as well as children in other placements. Yet, the moral obligation for child service workers to effect this primary reunification whenever possible is practically undebatable in our society.

The large body of literature on new parent adoption depicts a carefully selected and tended union of adoptees and adopters, with a high rate of success for the families and the children. It also includes many articles on problems peculiar to the adoptive state. Another body of articles exists to debunk the assertions of the latter. Similarly, evaluative studies of foster care point to malaajustment in children or adults on the one hand and normal functioning on the other, in an almost even split.

The policy permitting adoption by new parents has been widely used and certain aspects have been studied. The process of adoption by new parents has been generally described but has not been measured for either this or those adopted by foster parents. Descriptions of adoptive parents and children are available as are studies evaluating the outcome. In the past adoption by foster parents has usually not been legally pronibited but has been discouraged by agency policies. The trend with- 
in the past two decades is toward the increasing use of this option. Some beginning attempts are being made by a few agencies to re-design agency policies to make a place for this alternative in permanent planning for children. In the single study comparing the well being of children adopted by new parents with those adopted by foster parents the latter group was found to score as high as the former. 


\section{CHAPTER III}

\section{METI IOISS}

To evaluate the policy permitting foster parents to adopt, a sample of children in Oregon's Children's Services Division foster care who were seen as unlikely to return home and adoptable were followed for 28 months. Five specific objectives have been defined for this evaluation.

1. Describe the process by which each type of adoption takes place.

2. Identify the decisions which can be pinpointed for a11 cases and follow and compare each group of children as the identified decisions are made for them.

3. Account for group differences with the following sets of variables: Client (measures of characteristics of the child), nonclient (agency and court measures) and service history (measures of child's association with the agency.

4. Account for the time taken to achieve the outcome with selected client, non-client and service history variables.

5. Consider the findings as they contribute to an understanding of urban-rural differences.

Decisions were defined, and variables associated with decisions and the time it took were identified. 


\section{SUBJECTS}

The study group was comprised of a 50 percent sample of foster care children from 16 counties in Oregon designated by their caseworkers as unlikely to return home and adoptable. The sample was randomly chosen. This sub-group of adoptable children unlikely to return home was identified as part of a screening of foster care children in project counties (Emlen, 1976). Caseworkers were asked to designate the likely outcome for each child in their caseload. Three hundred sixty-five children were considered unlikely to go home and adoptable. For 310 (85 percent) complete data were available and from these a sample of 155 was chosen. For the 55 cases not included in the study the data missing were scores on the attitude survey for each child's caseworker.

Two problems complicate the assessment of the value and relevance of the sample as a cross sectional sample. The total number of children moving through the foster care system, the turnover, will be underrepresented (Emlen, 1976). Overrepresented will be children who might end up in long term foster care. This study is aimed more at the 1atter group than at the short term foster care residents so the sampling is appropriate.

Computing the sample loss for the total screening effort was a second issue. The number of children in project counties at the time CSD lists were generated could not be positively ascertained. Conputer printouts from which the sample was taken listed 3,607 children in foster care in project counties as of December 10, 1973 and official CSD reports (Note 3) 1ist 2,815 in January 1974, a difference of 792 
cases. This difference affected calculations of the sample loss. The number of cases screened was 2,283 and if the foster care population was 2,815 the percentage screened would be 81 percent and if the nopulation was 3,607 the percentage drops to 63 percent. A subsequent check with CSD staff and supervisory personnel led us to believe 81 percent was the best estimate of the percentage of cases screened (Emlen, 1976).

\section{Data Sources}

Data used for the study came from eight sources: (I) a caseworker attitude survey, (2) an assessment of the placeability of each child by the caseworker, (3) a screening of all foster care cases (mentioned above), (4) data on the foster care population of each county, (5) ratings of the court and agency within a county as barriers to developing permanent plans for children in foster care, $(6)$ interviews with agency personne1, (7) examination of case records and (8) visits to court hearings. A discussion of the use of each of these follows.

\section{Attitude Survey}

The questionnaire was designed to assess caseworker attitudes toward termination of parental rights as child welfare practice and their perception of the county as a barrier to termination of parental rights. Twenty-eight attitude items on a four point scale from strongly agrce to strongly disagree along with one item reflecting the amount of caseworker experience in handling termination cases comprised the questions in the instrument. In addition a variable was created by counting the number of questions left unanswered and this measured the level of uncertainty. The questionnaire was developed 
by interviewing several CSD staff members to assemble a groun of statements typically made by caseworkers about the issues being assessed. From these Regional Research Institute staff and project staff selected itens for the survey.

The survey was completed between January - June of 1974 by 279 (90 percent) of the Oregon foster care caseworkers. A factor analysis of 28 items was conducted using a varimax rotation and eight factors emerged (Emlen, 1976): (1) Court barriers to terminations in this county, (2) negative attitude toward temination, (3) CSD/court interagency communication perceived as favorable, (4) willingness to terminate despite possible unavailability of adoptive homes, (5) approval of restoration efforts, (6) lack of experience doing teminations, (7) willingness to predict that the child will not return home and (8) time for decision. County climate scores were generated from the factor scores by calculating for each county the percentage of workers who scored above the mean of all those completing the survey. For each factor a climate score was calculated. Climate scores for a child are scores of the county in which the child lived. Each child had eight factor scores and eight corresponding climate scores.

\section{Child Placeability Measures}

Assessment of the obstacles to placing the child was made by asking caseworkers to complete the form Barriers to Child P1acement. Questions assessed the extent to which the parents were seen as an obstacle to the child's return home, the placeability of the child, and the extent to which the child had bonds to significant other people. The mother and father barrier questions on a six-point scaie from no 
barrier (one) to high barrier (six) assessed whether the parents were seen as likely to be able to have the child returned to their care. The placeability rating, on a five-point scale with one equalling no problem in placing the child and five meaning major problems, was an overall assessment of how the qualities of the child facilitated or inhibited finding a permanent home for him. A six-point scale going from no barrier (one) to high barrier (six) was used for measures of child's physical condition, coping ability, and expenses as a barrier to placement. A five-point scale from no bonds (one) to strong bonds (five) was used for ratings of the child's relationship to parents, siblings and others. Questions designed to provide demographic information were also included.

The "Barriers to Child Placement" instrument was developed by first reading case records, then formulating questions, testing them with caseworkers and supervisors and finally revising them. The barriers form was completed by caseworkers from October to necember, 1975. Workers were asked to make the rating of the conditions existing at the time placement decisions were being made for the child. By October 1975, two years had passed since the earliest beginning date of this study. The date was chosen in the belief that sufficient time had passed to permit placement decisions to be made for most cases so workers could make the judgments requested.

To appraise the extent to which two caseworkers familiar with the case would make similar judgments a test was made of rater reliability. For 20 cases a second caseworker was located who was familiar with the lacts of the case and this worker was asked to indenendently complete the Barriers to Child Placement form for a case which had already been 
rated by the regular worker. A Pearson product movement correlation was calculated for the 10 rating scales on the form. The results are presented in Table $I$. It can be seen that correlations were high for every rating except the one assessing the child's bonds to his siblings. Caseworkers rating the sane case tend to agree in their evaluations of the child's relationship to others and to his placeability.

\section{Interviews}

The flow chart (Figure 1) showing the decisions on the route to adoption and case studies were developed by reading case records and by interviewing caseworkers, supervisors and administrators, and by attending court hearings. First a preliminary flow chart was developed from interviews and reading case records. This was tested on several cases in the study, to see if the necessary data irere available. Revisions were made and it was retested until a set of decisions made for each child on the route to adontion was identified.

Case study material was formulated by reading the case record, through taped interviews with the caseworkers, and by attending termination of parental rights court hearings. A draft of each case study was read and checked for accuracy by the caseworker. A bias in the case study presentation is created by the fact that it was not possible to interview the parents or children for their perception of the events. While an effort has been made to reduce bias by omitting data that was not objectively verified, the absence of input from parents and children is a shortcoming. The case studies do present the kinds of events which occur and the sequence in which they take place though there may be a difference among the involved parties in their understanding of 
TABLE I

CORREIAATIONS BETIVEN TTO RATERS

OF BARRIERS TO CIIILD

PLACENENT SCALES

Scale

Correlations $^{a}$

Condition as a Barrier to the Child's Return

Nother

.88

Father

.93

Child Placeability

Physical

.86

Coping

.70

Financial

.93

Overall

.99

Child's Bonds to:

liother

.77

Father

.92

Siblings

.44

Foster Parents

.73

$a_{N}=20$ 
the meaning of these events.

Expert ratings (the "Pike ratings")

At the beginning of project activity, lic Pike, project director and his assistant, who were familiar with all counties, made expert ratings of the extent to which each county was a barrier to the termination of parental rights in three domains; the county judges, the district attorney and the agency staff of Childrens Services Division.

\section{ANALYSES}

Wethods of analyzing these data to answer the questions asked by the study included stepwise multiple discriminant function analyses, stepwise regression analyses, analyses of variance and tests of mean differences. The discriminant analyses has two comonon uses: (1) given two or more groups and an unlnown individual, the unknown individual is placed in a group with minimum probability of misclassification by developing a weighted sum of known variables so that differences among groups are maximized, (2) given two or more groups of individuals, variables are examined to deternine which measures are the most useful in distinguishing among the two groups. The method of analysis is identical in the two cases but interpretation is different. In the first case correctly identifying an unknown individual is the goal. In the second, assessing the importance of the discriminating variables is the objective. Our focus was on the second type. Of interest was accounting for the group a child was in by the service history, client and non-client variables. This analysis was used to account for which variables and to what extent they accounted for grouping for each 
decision in the process and the final outcone. A stepwise regression analysis was used in an effort to account for the time it took for a child to achieve adoption by foster parents or by new parents. This method was used to see which variables would best account for time. Developing a prediction system, another common use of the regression analysis, was not the primary goal. Additional information about how the discriminant function, the stepwise regression analysis of variance and other analyses are used will be presented as their results are discussed.

It is important to remember that this study does not compare the process of adoption by foster parents with that of new parents as it would occur for comparable groups of children. No randon assignment to groups was possible nor would it have been desirable. The placement made for a child was that which was seen as best suiting his needs and those of the family with whom he was placed. Measured here is the extent to which relevant variables account for decisions made in achieving the goal and the steps along the way, as we].] as the time it takes for children for whom one or the other option is chosen. This comparison is most useful from the policy viewpoint. If the process and outcome of adoption by foster parents were found to present service problems as an option for placement of children for whom it was deemed appropriate then it would not likely survive as a policy alternative. 


\section{CHAPTER IV}

\section{CASE STUDIES}

The case studies presented here detail the corplexity of the process of adoption of foster children and contrast events of a case in an urban setting with those of a rural case. By dealing with specific case events the richness of the meaning of the experience can be depicted in more detail than is possible when looking at numerical data for the total sample. One purpose here will be to make possible a deeper understanding of the difficulty, complexity and urgency of decisions in the adoption process. A second purpose is to conpare and contrast the manner in which foster care children become adopted in an urban setting with this experience in a rural area.

The determination that a child should be removed from one set of parents and placed in a totally new family is not made lightly. This action dissolves one of society's most cherished institutions, the family. Both the court and the child welfare agency view this as a most serious decision to be made on $1 y$ under the weight of compelling evidence. Ii is made only after the parents' inability to achieve a minimum sufficient level of parental function is established to the satisfaction of the court.

Actors in the drama are the child, caseworker, the parents and the court. The caseworker representing the social service agency is responsible for managenent of the complex procedure. Actions taken must be kept sensitive to the needs of the child, his parents and society. The 
parents interact with the caseworker who manages the reunification effort and may direct them to appropriate community services in an attempt to reunite the family. The court acts in several ways; first, when the child is romoved from his parents' home the court may make him its ward with temporary custody to the agency. In some counties the court conducts review hearings to establish the conditions under which parents can expect to have the child returned to their care. Finally in cases where reunification is not possible and unless the parents voluntarily relinquish their rights to the child, the court decides to terminate parental rights. The child whose future is at stake usually remains in foster care until parental rights are terminated. This can be a long period of uncertainty and conflict for the child. Parental visits may focus the child's attention on his unsure future.

The rural-urban comparison is one of a large complex system contrasted with a small informal one. While both are state administered with identical procedural guidelines, differences are evident in their manner of conducting business.

A child can be adopted only after he has been legally freed from both parents. As will be noted in the case studies, before this can occur a thorough and careful exploration is made of parental resources which might permit the child to be returned. When return is not feasible, activity is centered upon preparing to legally free the cliild from his parents. Once this has been accomplished adoption can take place. Adoption was by no means certain for the children in this study. Even though their caseworker had indicated that adoption was likely, 11 percent returned to their parents and 47 percent remained in foster care (see Chapter V). Adoption was not an immediate 
decision and took place only after the caseworker and court determined that the parent could not provide adequate care.

The cases presented here were selected by their caseworker because the events were typical and represent most of the kinds of activity engaged in as case resolution was sought.

In the smaller county caseworkers cooperated to provide case continuity and informal networks were used to locate clients and in other ways facilitate case resolution. The court was considered to be a barrier to termination of parental rights. Courts in the larger county were more involved in case activity and more community resources were readily available. Agency personnel did not cooperate to facilitate case resolution.

\section{POLK COUNTY}

On October 3, 1975, two groups of people gathered in the lobby of the Polk County Courthouse for the beginning of a two-day hearing which would decide whether or not Lillian Hoover's (clients' names have been changed) parental rights to her four children should be terminated. One group consisted of this mother, her sister, her court-appointed lawyer and a psychologist. In the second group were three social workers, among them Joy MCGavock, assigned to the project, David Slader, an attorney from the Portland Public Defender's office representing the interests of the children, the district attorney, another psychologist, and a former landlord of the mother.

Termination hearings, unlike other civil proceedings which involve the interests of only tivo parties, consider the interests of three parties; the parents, the state, and child. Each party may have legal representation. Lillian hoped the court would decide that she 
could be an adequate parent to her children. The child's attorncy would argue that it was in the best interests of these four children that the mother's rights be terminated and they be placed in adoptive homes; and in this case the state agreed that Lillian's rights should be terminated.

It would be a difficult hoaring for everyone. The pro-tem judge was faced with what another judge has called "one of the most drastic actions a state can take." State v, Jamison, 251 Or. 114., 117, 444 P. $2 d$. 15 (1968). Lawyers know that it is difficult to evaluate whether in any given case the grounds for termination can be proved or disproved. Joy, the cascworker who had tried to lielp Lillian become an adequate mother, would now have to testify publicly and in detail about Lillian's repeated failures to make a home for her children. Lillian faced the possibility of permanent loss of her children and knowledge that she had been judged an inadequate mother by society.

Foster Care Placement and Initial Assessment

The Hoover children's first experience with the Children's Services Division took place on July 20, 1971, when they were picked up and placed in substitute care. At 10:30 a.m. on that day officials of the Polk County Health Department found the four children, ages five, three, two and two months, at their home alone. The children were described as very dirty, and having various skin rashes and burns, and without adequate clothing. Of particular concern was the two-month old baby who had no bottle or diapers. The parents were believed to be at a drinking party. Three days later when the parents contacted CSD they did not deny that they had been involved in such parties, nor that they had left the children unsupervised during these times. 
The condition of the house was described by the landlord as totally unlivable. The garbage consisted of "unused abundant foods, beer and wine bottles (some half full), and all kinds of junk and clothing. The upstairs rugs had to be discarded because they wore hopelessly soiled with paint, ketchup, and syrup. All the matresses... had to be taken to the dump because they were totally soiled with blood and urine. Dirty diapers were thrown all over the house and outside in the yard. They had plugged the toilets with clothing and used the whole house as a bathroom."

The children were macle wards of the court with care, custody, and supervision awarded to CSD. They were placed in foster homes; the baby in one home and the three older children in another. The Hoovers agreed to foster care as a temporary plan and expressed a willingness to make the necessary changes so the children could be returned.

During the following year, the parents visited the children three times and would often miss appointments. In August of 1972 the Hoovers separated. After his separation from Lillian, Sam never saw his children again. Lillian disappeared until early in 1973, when she asked to visit the children and indicated she was going to divorce her husband and wanted to make a home for the family. Plans were made to accomplish this goal but Lillian's efforts to follow through were sporadic, and in July she disappeared again. She contacted the agency in December with the request that the childiren be released so she could take them to live with their grandmother in another state. An investigation of the grandparents' home led caseworkers to reject this as an unacceptable plan. In December, 1973, the Hoover case was transferred to Joy, the special permanent planning caseworker, as the children were considered 
likely candidates for adoption. They had been in foster care for more than two years and were thought likely to renain in foster care throughout their childhood if a permanent plan was not made for their future. Their orm parents repeatedly failed in their efforts to be reunited with the children, but the children were young enough to be adointed by other parents.

The task of dealing with the court on issues related to child custody is complex, requiring special casework skills and astute supervision. Joy was trained to handle court matters and other prob].ens encountered in moving children into permanent homes. First, intensive services were provided to parents. If they could not demonstrate that they could provide an adequate home, voluntary relinquishment or court action to terminate parental rights was the goal.

Soon after Joy had received the case the former caserrorker took her to meet both of the foster families and the Hoover children. Caseworkers in this small county typically cooperate in this way to smooth the transition from one worker to another. Even though each worker is responsible for his caseload, consultation on cases and cooperation among workers is the rule.

Joy relied on the local knowledge and the cooperative attitude of the other workers in her first task with the Hoover case -- locating the parents. One of the caseworkers reported that she heard Mrs. Hoover was working at a nursing home and that Mr. Hoover was in jail. With these leads Joy succeeded in finding Mr. Hoover but it took a month to locate Mrs. Hoover. 
Casework with Father

By the time Joy called the jail, Mr. Hoover had been released. Letters sent to his now address elicited no response. As active pursuit of elusive parents was a standard procedure for the project, Joy visited the address she had been given by the jail and talked with Mir. Hoover who indicated an interest in having his children retumed. When a month had gone by with no word fron him, Joy again wrote and asked what plans he had to visit and to achieve the other goals which would result in return of the children. Another month passed with no response, so she made a visit.

Even though transportation was available for M.Mr. Hoover, by August 1974, he had missed every opportunity to behave in a way that would result in the return of the children. Early in 1975, it became clear that a petition would be filed to teminate his parental rights.

Casework with Mother

Locating the Mother. Locating Mrs. Hoover was not easy. A check of all the nursing homes in the area determined that she was not employed at any of them. The next lead came from Lillian's sister whose children were also in foster care, and she reported to her caseworker that Lillian was living in a town nearby. Joy wrote a letter and Lillian came immediately to the CSD office. She stated that she very much wanted her children back and was interested in a program for restoration. A plan was made for Lillian to visit the children regularly, to seek employment, and to obtain professional counseling. Counseling was considered essential because Lillian had continued to drink heavily and realized that she could not care for her children when she was 
frequently involved in drinking parties lasting several days.

Visits. For the first eight months of project activity Lillian kept half the scheduled visits with the children. When she came the visits were considered successful, as Lillian was affectionate and responded well to children. However, Jim, age two, screamed during part of each visit, and afterward became more obstinatc and experienced some loss of appetite. Richard, age five, wet the bed for several nights after the visits. Susan, age four, began clinging to her foster mother and asked if she did not "born" her, and Barbara, age eight, became hostile and overly assertive. Even though the children's behavior caused a problem for the foster parents, they were cooperative and seemed to understand that the outcome was uncertain and that visits were necessary. By this time the children had been in their foster homes for three years, and the three younger children hardly knew their mother. Employment. Lillian's efforts to find employment were erratic, and the jobs she found were short-lived. She worked a few days as a babysitter and a couple of weeks in a tavern.

The caseworker referred Lillian to the Department of Vocational Rehabilitation, but she missed all appointments. She did see the DVR counselor once, however, when the CSD caseworker supervisor noted that both Lillian and the DVR counselor happened to be in the CSD office at the same time and asked him to interview Lillian then. The process of investigating the possibility of this service was speeded up by the helpfulness of Joy's colleague.

Other Services. Lillian indicated an interest in parenting classes. In this small, rural county classes were conducted weekly and a newcomer could only enter at the beginning of the session. Lillian 
was enrolled but did not attend.

Lillian also missed two aippointments for counseling at the Mental Health Association, prompting the counselor to write a letter stating that no more appointments would be scheduled.

During the seven months of caserork activity all efforts to help Lillian meet the minimum requirements to obtain the custody of the children had not been successful. Visits to the children had been sporadic, employment fitful, and appointments for counseling and parent education classes had been missed. Lillian continued to move frequently and her housekeeping was as unsatisfactory as when the children were originally placed in foster care.

Written Agreenent. In Jume 1974, Lillian moved to the State of Washington to live with her parents and planned to enroll in a rehabilitation progran through the Indian agency. She was part Indian and therefore qualified for help through the agency.

In September a contract was written and signed by CSD and Lillian as a last ditch effort to motivate her to make at least the mininum changes necessary. If she failed at this, Joy planned to move ahead with a termination of parental rights petition. The contract listed what each party would do. Lillian Hoover would: (1) Actively seek employment, and once this was obtained she would budget money to provide adequate food, shelter, and clothing for herself and pay child support of $\$ 5$ per child per month; (2) visit the children tivice a month at the CSD office and notify the caseworker one day in advance if unable to come; (3) participate in family counseling and in the alcohol rehabilitation clinic; (4) participate in medical appointments for her children; (5) remain at one address; (6) maintain adequate housekeeping standards. CSD would: 
(1) Work with Lillian in any reasonable way to regain custody of the children; (2) arrange visitation every tro weeks; (3) help Lillian get assistance from other agencies and arrange transportation.

During the weeks following the signing of this contract, Lillian's behavior did not change. Through the Indian progran, she entered an alcoholic rehabilitation facility for an 18-day stay. Three days before she was to complete the program Lillian left abruptly. Through her frequent moves Joy persisted in her efforts to keej track of Lillian and get her to fulfill the terms of the contract.

\section{Petition for Termination}

The target date of December 1974, passed without progress made toward meeting the contract terms. Joy decided to petition for termination of parental rights for both parents. She had discussed voluntarily relinquishment of their rights with them but they rejected it. The parental behaviors which had necessitated the children's foster care placement were not improved. In fact, during the years their children had been in foster care the chances of reuniting this family worsened. The decision to pursue termination was made only after reviewing the details of the case carefully with colleagues and Polk County caseworkers who knew the family. Joy began preparing the case for the court hearing. She had documented each step of the treatment program, including all efforts to contact the parents, to put them in touch with other agencies, and their repeated failure to respond. She found witnesses, helved then prepare their testimony, filed the termination petition drawn with the assistance of the lietropolitan Public Defender Attorney, and obtained a court date. Filing the termination petition was delayed several times it was not filed until July. 
With the filing of the petition, CSD's work with the court began. Polk County was seen by agency staff as presenting a high barrier to the termination of parental rights. The court rarely held either termination hearings or review hearings in the past. For the lloover case, this was the first contact with the court since the custody hearing four years before.

Until the advent of the project, termination of parental rights cases were rare in many Oregon counties and this was true of Polk County. Agency staff believed that the court actively blocked such cases. The judge was rumored to resist termination of parental rights and so would appoint a pro-tem judge to hear such cases. Caseworkers saw the court as obstructive and uncooperative. When CSD had a case in which temination of parental rights seemed appropriate, the case was scrupulously prepared, and taken to court only when compelling evidence was available.

\section{Termination of Mother's Rights}

As the two groups were waiting for Lillian's hearing to start, Joy left the group and went over to talk with Lillian. She had grown fond of Lillian after a year and a half of intensive work with her, but was convinced that she could not be an adequate mother to the children. The judge and lawyers found termination a radical and painful action, but for the caseworker it was doubly tormenting. She had to testify against a person with whom she had been intimately associated, whom she had encouraged and tried to help. Together they had worked toward a goal and failed.

Lillian's attorney argued that Lillian could care for her children with the help of scrvices offered by the Indian agency. A psychologist for Lillian testified that if she had psychological counseling, money 
due her for Indian inheritance, and family support, she could care for the children.

The state and the Public Defender, representing the children, argued that since no progress had been made toward reuniting this family. in the four years and three months the children were in foster care, enough time had been allowed and this mother's rights should be terminated.

A summary of Lillian's past behavior relevant to her ability to be a mother, including patterns of visiting, changes of residence, efforts to control drinking, attempts to find employment, attendance at parenting classes and counseling sessions and her level of ability to provide for the children's physical needs was presented. Lillian's former landlord testified to her poor housekeeping. A psychologist who had evaluated both the children and the mother testified for the state that it was his belief that Lillian could not be an adequate mother to the children.

A few days later a verdict was handed down terminating: the parental rights of Lillian Hoover to her four children. Joy heard the verdict and told the news to Lillian. She wept.

Termination of Father's Rights

In January, the temination hearing for Sam Hoover was held. The state and the children's attorney's position was that Sam's parental rights should be terminated since he had not made the changes necessary to permit the return of his children. The testimony inclucied evidence that visits were infrequent, financial support to the children nonexistent, attempts to find employment irregular, and that little effort 
had been made to care for the children's needs. Sain's attorney argued that he had re-married, settled down, and would soon be able to care for the children.

His parental rights were terminated but Sam decided to appeal the decision. The termination decision was upheld in the appellate court.

The three older lloover children were adopted by their foster parents. At the time this was written, the fate of Jim was in doubt. He has lived with his foster parents since he was taken into foster care at the age of two months and was five years old at the time this was written. Adoption by these parents is unlikely since they are an older couple. It is possible that he will be placed in an adoptive home where he can visit with his present foster parents.

\section{Aftermath}

On November 11, in an interview published in the County newspaper, Joy accused the local court officials of delaying termination cases. Polk County, she said, has the worst record of the 36 counties in Oregon. "One ongoing case has been delayed for several months because the hearing dates have been continually rescheduled." In a letter to the editor the Juvenile Court Judge and the court director denied these charges and offered data to support their position. Before the dispute was over several additional articles had been written. Thereafter, comunication improved between the court and CSD. The county juvenile judge began to hear temination cases himself, instead of appointing a pro-tem judge. In conversations with David Slader, the public defender attorney, representing children interests, the judge indicated an interest in teminations and in becoming more acquainted with case law in this area. 
In assessing the situation in Polk County, David said, "The obstacles (to terminations) existed because they hadn't been tested."

\section{MULTNOMAH COUNTY}

Urban Hultnomah County, with over 100 caseworkers handling foster care cases, is divided into five separate districts. If a family moves from one district to another, the case is transferred to a new caseworker in that office. Such transfers make j.t difficult to provide service continuity, which was seen as important in Polk County.

The juvenile department of: the linltnomah County Circuit Court is considered helpful in case planning by CSD caser:orkers and project staff. The court and CSD staff hold monthly conferences to plan for cases which appear headed for some type of court action. The court routinely holds case review hearings to assess the progress of children in its temporary custody. In liultnomah County, temination of parental rights cases are regularly heard. The court is not considered an obstacle to achieving this goal.

\section{Casework Services}

Shelley Krause, born January, 1970, first entered foster care in November 1970. Shelley and her mother, Dorothy Krause, had been living with a woman who telephoned the police to report that she had found numerous scratches and bruises on Shelley's body. Shelley was picked up and placed in temporary shelter care and later the court ruled that she should remain in custody of CSD until the abuse charges were investigated. Child abuse could not be proved. At the time Shelley entered foster care, her parents had been separated several months and were in the process of obtaining a divorce. At the divorce hearing early in 1971 
custody of Shelley was awarded to her mother. Dorothy applied for welfare assistance.

Shelley's father, Bill Krause, spent a year in an institution for the mentally retarded. Because he is mentally retarded the caseworker questioned his ability to care for the child. Dorothy Krause had no diagnosed mental deficiency but her intellectual abilities are low. She is further handicapped by a hearing problem for which she uses a hearing aid. In 1968 , Dorothy had given birth to a child who died at the age of five days as a result of "injuries sustained in a fall", according to the caseworker. In view of the abuse charge concerning Shelley, the worker began to wonder whether this child really had died from a fa11.

Placement with Father

By October 1971, Dorothy Krause had remarried and given birth to a boy. On November 2, Shelley was picked up by the police as a battered child and a week later the new baby was taken in with similar symiptoms. As a result, Shelley was placed in the custody of her father, who was living in the home of a farily who could assist in her care. With this move Shelley entered her fourth home in the 21 months since her birth.

Shelley stayed with her father for almost a year. In October 1972, the family with whom he and Shelley were living asked him to move because of his "dirty habits, poor personal hygiene and drunkenness." Shelley remained in this home after Bill Krause left and it became a foster hoine for her. Shortly after he moved, Bill Krause expressed to the caseworker his willingness to release Shelley for adoption. He was not pernitted to release because the worker was optimistic about 
returning the child to her mother and wanted the child to maintain legal ties with the father.

\section{$\underline{\text { Review Hearing }}$}

At a review hearing in July 1973, Đorothy asked that Shelley be returned to her. In denying her request the judge pointed out that the court policy is to return children to parents if possible, but the court was not convinced that the mother was sufficiently stable. At this time Dorothy had been visiting the child regularly and had for several months successfully cared for the children of the man with whom she had been living. Another review hearing was promised in five months, at which time, if progress continued, Shelley could be returned to her care. The hearing set up guidelines for her behavior -- she was to increase her visits to Shelley and pay support, and continue to maintain a physical environment which would be acceptable for a child. In this way Dorothy could demonstrate by action that she really did want her child returned. She was warned that the court would not permit Shelley to remain in limbo forever.

Dorothy's caseworker was not as encouraged about her progress as the court appeared to be. Dorothy had seven known addresses during the 1.4 months preceeding the review hearing. Typically she would form a superficial liaison with a man, become his live-in babysitter or housekeeper for a few weeks, and then the relationship would dissolve. Her recent behavior showed no modification of this pattern. The caseworker saw Dorothy's current living arrangement as just another temporary liaison, and believed that it was not an acceptable environment for Shelley. 
In addition to Dorothy's nomadic 1ifestyle, there had been two occasions on which she had bcen accused of physically abusing Shelley. Counseling had been reconmended in tine hope of changing, her behavior, but she failed to meet appointments. The worker wondered whether Dorothy was willing to make the changes which would enable her to provide the minimun level of care necessary for Shelley's survival.

Permanent Planning Project

October, 1973, the case has reviewed with juvenile court personnel, and it was agreed that termination of parental rights and subsequent adoption was the best plan for Shelley. Dorothy visited regularly but continued to move often. She had been fired by the man whose children she cared for. She did almost nothing to demonstrate her interest in the child. So on October 29,1973 , the case was transferred to the Permanent Planning Project. The caserorker, Denise Case, like the Polk County worker, was trained to work vigorously to resolve cases as quickly as possible.

The previous caseworker made no effort to provide continuity by introducing Denise to significant people in the case or by otherwise easing the transition for workers or the family. Mulnomah County caseworkers don't cooperate in handling cases, according to Denise.

In assessing the Krause case, Denise recognized that there was at least a slight chance that Shelley could be returned to her mother. Dorothy had been visiting regularly, and while the mother-child relationship was not ideal, there was a possibility that it could become adequate. Dorothy had moved back to the hone of the man who had fired her earlier, and if this arrangement was successful there was some chance for 
reunification of Dorothy and Shelley. On the other hand, the history of possible physical abuse weighed heavily on Denise's mind as she evaluated the options for Shelley.

Another review hearing was schedulec: for January 1974, but was postponed until May at the recuest of Dorothy's attorney so that she could have a chance to improve her financial situation and to obtain a psychiatric evaluation.

In April, 1974, Denise and the permanent planning project director decided to risk returning Shelley to her mother. A psychiatrist had evaluated both Shelley and Dorothy, and felt that with a stable job and agency support, Dorothy could function as a mother to the child. Dorothy was visiting her daughter regularly, although she didn't show a great deal of affection for her. Investigations made on the children of the man Dorothy was 1iving with indicated they were doing well at school and were not being abused. So it appeared that he and Dorothy were doing well with his children, and his presence in the home might prevent Dorothy from again abusing Shelley. This placement would be a last ditch effort. If it failed, the worker would irmediately begin preparing for temnination hearing, and the documented evidence of the mother's failure to provide a home might be decisive to the outcome of the hearing.

Soon after Shelley retumed to her mother, Dorothy lost her job and applied for welfare assistance. She also needed immediate hel! finding a place to live. Denise decided that Dorothy should not be asked to look for work but should concentrate her efforts only on caring for her child. Her previous jobs as a 1ive-in babysitter had 
always been temporary, and Denise did not vant her to continue in these jobs, as the frequent changes would be upsetting to Shelley. Training for new kinds of employment had been offered to Dorothy and rejected nany times in the past. Any efforts at job training could wait.

$\underline{\text { Review Hearing }}$

A review hearing was scheduled for late lay, and events in the case made this hearing especially critical. A termination of parental rights hearing was a distinct possibility. At this review hearing, the case was carefully re-exanined, and specific parental behaviors necessary to perpetuate the mother-child relationship were set out in detail.

Specifically the court ordered that Shelley be continued under temporary comnitment to Children's Services Division, but she was authorized by the court to live with her mother if the following conditions were met: (1) Dorothy is to live alone without having a resident male to whom she is not married; (2) Denise Case is to arrange for parenting classes and Dorothy must attend; (3) Dorothy is to accept help on how to plan a budget and purchase her food and clothing and other supplies; (4) Dorothy is not to junish Shelley except on her bottom with her hand; (5) Dorothy is to accept any other conditions Denise may require; and (6) a review hearing is to be scheduled in four months.

From Denise's viewpoint, this review hearing was critical, as it set forth exactly what Dorothy would have to do in order to regain custody of her child. "It's almost as if it were decided at the review 
hearing. Yes, we will teminate if she doesn't do this", Denise said. The hearing served the additional purpose of impressing Dorothy with the seriousness of the situation. Sometimes a court order, enhanced by the solemn legal atmosphere of a hearing, was more persuasive to parents than a caseworker's exhortations.

After the review hearing in May, Denise tried to help Dorothy implement the agreenents. Dorothy and Shelley moved into a trailer house on August 2. On August 27 th, Denise visited Dorothy at the trailer and discovered that she and Shelley had been staying there only occasionally, since there was not enough money to have the gas turned on, and it was cold in the trailer. Denise had helped Dorothy work out a budget for the month of August which included this expenditure, but apparently Dorothy had spent the money for something else. On September 11th, Denise again went to the trailer and was told by a neighbor that Dorothy had not been there for several weeks. Denise discovered that she had stayed in three different locations during this time. Thus Dorothy continued her pattem of drifting and was umable to provide even minimun care for her child.

Shelley's attorney did not approve of her being moved from one house to another, and indicated he was considering filing a petition to remove Shelley from Dorothy's care. This warning had no effect.

No progress was made in helping Dorothy attend parenting classes. Services such as the parenting classes are readily available in thltnomah County. Classes are held daily, usually during both the afternoon and evening, and attendance can begin at any time. Couseling is available from several agencies and a variety of medical services are conveniently located and easily accessible. In Wultnomah County generally there are 
a larger variety of services for clients, and they are more accessible than in Polk County.

Return to Foster Care

She1ley changed "parents" seven times since birth and in addition had changed residence frequently while in the care of her mother. At the request of Shelley's attorney, in September the mother was asked to return Shelley voluntarily to foster care and she did. In the months since the review hearing no progress was made toward achieving the goals outlined by the court. Shelley's attorney felt that it was no longer in her best interest to remain with her mother. Denise felt certain that Dorothy's helpless drifting from man to man was not likely to change. She seened unable to adjust her life in such a way that she could regain custody of Shelley. After consulting with the court, the project director, and Shelley's attorney, a petition was filed to terminate the parental rights of Dorothy and Bill Krause.

\section{Termination Hearing}

The hearing was held in November 1974 seeking to terminate rights of both parents. The father, who had previously indicated a willingness to voluntarily surrender his parental rights, did not contest the action.

The attorney for Dorothy took the position that insurficient time was allowed to permit Dorothy to make the necessary changes that had been agreed to at the Ifay review hearing.

The child's attorney and the state presented evidence that Dorothy had never been an adequate mother to Shelley, and it was unlikely that she would ever become one. Three psychiatrists stated that Dorothy was 
unlikely to change her behavior. Denise testified specifically to Dorothy's repeated failure to provide a home for Shelley. In short, Dorothy had not made the changes in her behavior which she had promised to make at the lay review hearing. On Novemiver 20, the parental rights of both Bill and Dorothy Krause were terminated.

Before Shelley could be adopted, additional intelligence tests and physical examinations had to be completed so that the prospective adoptive parents would have sufficient information about her. Intelligence tests indicated that Shelly is not retarded, but she scored low. Physically she had a few problems which could probably be corrected. In November 1975, Shelley was placed in an adoptive home. By this time she was five years old, and had been in eight foster homes.

\section{SUIRIARY}

Case differences exist because of the unique characteristics of each case, the idiosyncratic way each worker does her job, the variation in the way the court and CSD cooperate to resolve cases, the

manner in which each CSD county unit conducts its business and the availability of services.

The method workers used to facilitate the movement of these foster children into a permanent plan is similar in all counties. First, the caseworker must locate the parent. Then if the parent wants his child retumed a plan must be made to bring this about. Then the caseworker assists the parent in carrying out the plan. Especially at this stage of the process the workers are alert to the danger of letting time pass without active efforts being made to move toward the agreed upon goal. 
When returning to the parents is not possible, caseworker energies are directed toward facilitating an adoption.

County differences center on variation in court activity, the availability of cormunity resources, cooperation of Children's Services Division staff and the use of helping networks to provide information about the case.

A variety of community resources were used by both workers as they sought to help the parent. In the more rural Polk county, counseling at the mental health association, parenting classes and vocational rehabilitation help were available but had to be carefully scheduled. Counseling was denied after several apnointments had been missed, and this was the only help available to Lillian Hoover. Her only other alternative was to seek helæ in a more urban center some miles away. Parenting classes were scheduled once each week and started every two or three months. If attendance did not begin early in one session the student must wait until the following class began several months hence. If specialized medical treatment was necessary, a trip of sixty miles to lfultnomah County, an urban center, had to be arranged.

Perhaps the most striking difference between Polk and Multnomah County was in the extent to which the court was involved. In Polk County, Children's Services Division staff and the client made plans to accomplish the return of the child. A contract was written and agreed upon and irmplementation begun. In lifultnomah County the court was involved from the beginning. The revier hearing conmared to the contract in Polk County. Both were written agreements between the state and the parent. However, the review hearing was more decisive. 
Monthly meetings were held in Multnomah County with court counselors and other court persoinel to discuss cases which needed court action. In Polk County the court got into the picture at the time termination action was sought whereas in Pultnomah County the court was involved from the beginning.

Another difference between Polk and Wultnomah County is in the way the staff works to do its job. In Polk County each worker is responsible for his own cases but others cooperate to help out when necessary. When a case is transferred, continuity is provided when the new worker is made acquainted with the case by the former caserworker. 


\section{CIAPTER $V$}

THE PROCESS OF ADOPTION

A child is adopted only after the court has established to its satisfaction that the child's parents cannot care for: him, and a suitable adoptive home has been found. Children jn thiss study were followed as efforts were made to achieve the adoption goal. Though they were thought not likely to to home and adoptable, the process involved a strict test of this prediction. First, a concentrated effort was made to return the child home. An adoptive home was sought only when all hope was gone that the parents could assume care.

Adoption-related events which occured during a 28 month period, beginning with the tine a decision was made that the child was not likely to return home and adoptable, are presented in this chapter. First, decisions in the adoption process are defined and discussed. The children are tracked through this process. Decisions made and the time taken between decisions are noted.

For the cases described, the process began with a screening of foster care cases in Oregon project counties. This innovation in Oregon child welfare practice was nade possible by the demonstration project. Conducted by the Regional Research Institute, the screening required that each caseworker handling foster care cases indicate the likely outcone for each child on a one page ruestionnaire. 
The screening and case selection for the project took place between November 1973 and June 1974 (En!1en, 1976). Outcome choices were: return to parents, adoption by foster parents or neri parents, remain in foster care or contractual long term foster care. After this screening, project staff reviewed the cases more closely with the caseworker and made the final selection for the project. The project sought cases where children were seen as not likely to return home and adoptable. Not all cases deemed by individual. caseiworkers to be likely candidates for the project were chosen. A limited nuriber of cases could be accepted for the project special effort. Basic to the ability to provide the special effort were reduced caseloads for the project caseiorker. Hore children were eligible for the project than could be included so other selection criteria were used. A case was not included if its resolution appeared to be straightforward with no difficult legal processes and could be handled by a regular caseworker. The project caseworker within a county unit could handle a limited number of cases and when slots were filled no more could be taken until others had been resolved.

Examination of case records, and interviews with caseworkers and administrators in foster care and adoption revealed that few routine decisions are made for all children in foster care. Some case records contain infornation about decisions made by the biological parents and caseworkers to cooperate in an effort to retum the child. Some contain a letter from the adoption unit stating that ai adoptive home could probably be found for that child if he were free. Some have records of court reviews and other clues as to 
decisions made about the child's future. However, no uniforn pattern for systematic assessment of the status of all foster cases existed at the time these data were collected.

Figures 1 and 2 contain flow charts indicating decisions made for each group: those likely to be adopted by parents new to them and those likely to be adopted by foster parents. Children were tracked from the caseivorker decision that the child was not likely to return home and adoptable or was chosen by the project, whichever came first. They were followed for 28 months, or until an outcome had been achieved. The decisions that could be identified for most children were whether or not they became a project case, whether the rights of their parents were legally ended and, if so, whether by termination or voluntary relinquishment, and whether adoption or return to biological parents took place. The decisions made for the study sample were noted.

Beginning with the screening decision or identification as a project case the next one identifiable for all children was when they were legally freed from one of their parents. Either the parent voluntarily relinquished rights to the child or the court terminated the parent's legal rights. The child could be freed from both parents in the same vay and at the same time or the method and time might differ. Sometimes one or both parents were dead. For the decision called "how freed from narent 1 " the first parent whose rights were ended was of interest regardless of whether the parent was the father or mother. For the decision "how freed from parent 2" the parent in question was the one remaining after the child 


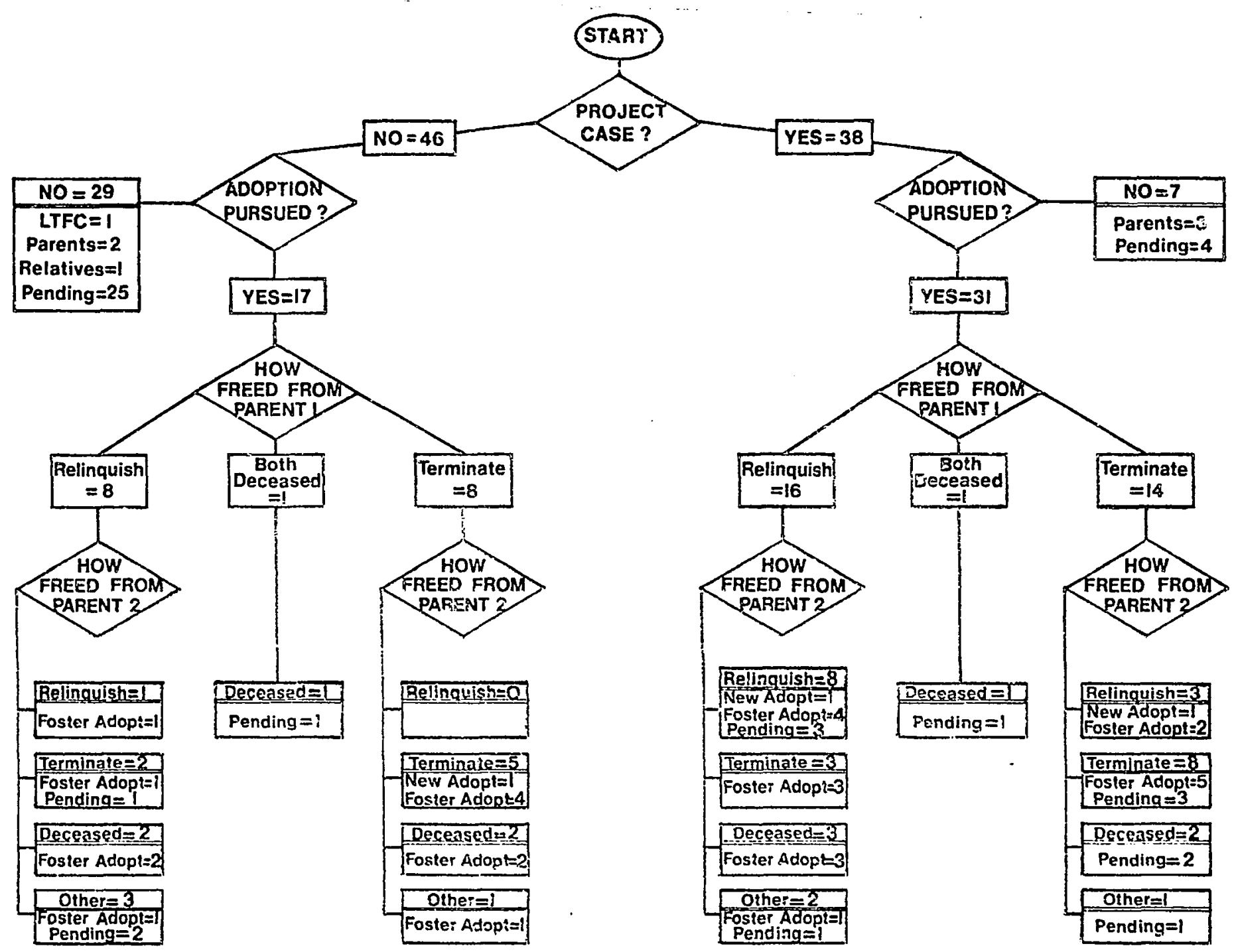

Figure 1. Flow chart of decisions made for samn]e children seen as likely to be adopted

by foster parents (ITFC = long term foster carc: ponding = foster carc). 


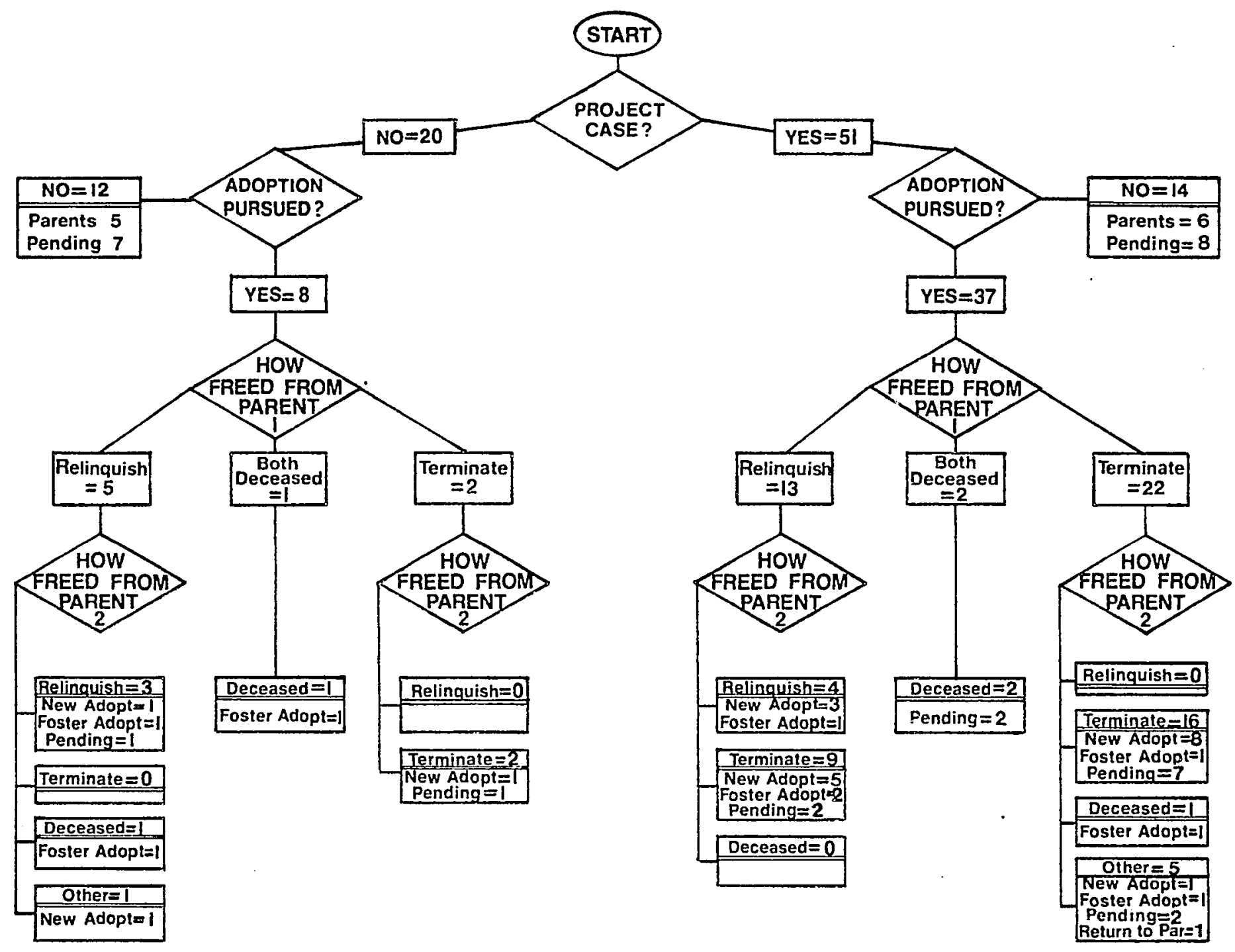

Iigure 2. Flow chart of decisions made for simble children seen as likely to be adopted by now parents (pending = loster care. 
was legally freed from the first. The final decision was whether or not the child was adopted by his foster parents, by new parents, or had another outcome such as continued foster care (noted as pending on the figure), returned to parents, placed with relatives or in long tem foster care.

\section{DECISION RESULTS}

There were some differences between those likely to be adopted by foster parents and those likely to be adopted by new parents in the nurnber of children for whom the various decisions were made. Al1 differences reported are statistically sicnificant at $\underline{\mathrm{P}}<.05$.

A larger proportion of children were chosen for the project from those thought likely to be adopted by new parents than from those in the foster parent plan. This might reflect the project case selection practice of choosing difficult cases, Since those likcly to be adopted by foster parents had been in foster care longer (Chapter VI), their parents were more likely to have lost contact with them. When this happened legal action to teminate the rights of parents was more straightforward. Project staff chose to leave these cases with the regular caseworker. The decision for those headed for adoption by foster parents was less complicated for another reason; for them an adoptive home was readily available and a search unnecessary. For these tivo reasons, they would be less likely to be chosen for the project effort.

The decision to pursue adovtion indicates whether or not a child was freed from one parent. Once a case became part of the project, adoption was just as likely to be pursued for those in the new parent 
plan as for the foster parent plan. This was also true of cases not in the project. They moved at the same rate until they were freed fron one parent, no matter which outcome was predicted. However, if a case was not accepted, the chance of adoption being pursued was less than if it was in the project. Thus, the likely outcome was not significant in determining whether adoption was pursued, but whether a case was in the project was important.

loving down the flow chart to the decision concerning how the child was freed from the first parent, the results show that more project children were freed by termination in the new parent plan than in the foster parent plan. The number of cases freed among those not chosen for the project is so small, especially in the new parent plan, that it is difficult to make a meaningful comparison.

To assess whether the way a child was freed from the first parent is predictive of the way he was freed from the second parent, data were combined within each of the plans (see Tables II and III).

If a child was freed from his first biological parent by termination. it is more likely that he would be freed from the second parent in the same way. This was the case for both those in the new parent plan and the foster parent plan. For the group headed for adoption by new parents, if the first biological parent relinquished his rights it is not more likely that the second parent will do the sarne. This was not true of foster parent adopt group. If the first parent relinquished it was more likely that the second parent would relinquish. While the way a child was freed from his first parent was sometwhat: preaictive of the way he was freed from the second parent, the patterns 
TABLE II

NUIBER FREED FROI PARENT 1 BY

NUIBBER FNEED FROM PARENT 2

IIJ FOSTER PARENT PLAV

\begin{tabular}{lccc}
\hline Viethod for Parent 2 & \multicolumn{3}{c}{ Wethod for Parent 1 } \\
\hline & Relinqui shinent & Termination & Total \\
Relinquishment & 9 & 3 & 12 \\
Termination & 5 & 13 & 18 \\
$\begin{array}{l}\text { Other: dead, no record or } \\
\text { not freed }\end{array}$ & $\underline{10}$ & $\underline{6}$ & $\underline{16}$ \\
Total & 24 & 22 & 46 \\
\hline
\end{tabular}

TABLE III

NURBER FREED FROI PARENT I BY

NUMBER FEEED FROM PARENT 2

IN NEE: PARENT PLAN

\begin{tabular}{lccc}
\hline W. hethod for Parent 2 & \multicolumn{3}{c}{ Misthod for Parent I } \\
\hline & Relinquishment & Termination & Total \\
Relinquishment & 7 & 0 & 7 \\
Termination & 9 & 18 & 27 \\
$\begin{array}{l}\text { Other: dead, no record or } \\
\text { not freed }\end{array}$ & $\underline{2}$ & $\underline{6}$ & $\underline{8}$ \\
Total & 18 & 24 & 42 \\
\hline
\end{tabular}


are by no means consistent. Tenination is more likely to occur for: both parents than is relinquishment.

The flow charts contain a total of thirteen children who were freed from their first parent, but for whon no record was available of action concerning Parent 2. Tho of the children vere returned to the remaining biological parent, five remained in foster care and six were adopted. It appears that six children became adopted without ever being legally freed from one of the biological parents, usually the father. While it is possible that some records have been lost, and thus the repeated searches for these data were not successful, it is more likely that adoption did take place without freeing the child from one parent. Until recently a child who was half free was sometimes adopted. Usually it was the absent or unknorm father from whom the child was not freed. The Supreme Court decision Stanley vs. Illinois, 405 U.S. 645 (1972), reaffimed the legal rights of the child's biological father. The court ruled that a child cannot be legally freed for adoption until there has been some disposition of the rights of the biological father. Following this decision, more care was taken to deal legally with the parental rights of an absent parent. All six of the children in this study were freed from their mother but not their father. The whereabouts of five of the fathers were unknown.

Even though a child was not freed from both parents, if adoption took place the rights of these new parents are clear. The Oregon statute dealing with the relationship between the adopted child and his natural and adoptive parents provides that the relationship ". . . shall be the sane to all legal intents and purposes after the 
entry of such decree as if the adopted person had been born in Iawful wedlock to his adoptive parents and had not been born to his natural parents". Oregon Revised Statutes 109.041 (1)

A total of 25 children were freed from both parents but were not adopted, 11 in the group were seen as likely to be adopted by foster parents and 14 from the group likely to be adopted by new parents. In. addition, six children were freed from one parent. While some of these children may have been adopted after the 28 months covered in this study, others may remain in foster care because no adoptive home is available.

\section{THE OUTCOAE}

Table IV contains sumaries of the actual outcome for the study sample 28 months after the study began. Data are presented by type of plan and within the plan by project and non-project.

Perhaps the most striking finding is that, though the caseworkers predicted otherwise, at the end of 28 months large numbers of children remained in foster care, a placement designed to be temporary. In fact, more children remained in foster care than achieved the plan that was predicted for them. The proportion of children adopted by foster parents did not differ from the proportion adopted by new parents. So no matter what the prediction, at the end of the study almost half of the children were in the same type of placement as they were in at the beginning. Of these children remaining in foster care, 29 (39 percent) were freed from at least one parent and 23 (31 percent) were freed fron both parents but were not adopted. Of those 
who did leave foster care, the caseworker generally made a better than chance prediction of the outcome.

Whether a child was part of the project made a difference for those headed for adoption by foster parents in that fever children remained in foster care among project cases. In the predicted new parent grour, no difference was found between numbers of project and non-project cases remaining in foster care.

The first priority of the demonstration project: and for foster care workers in general is to return the child to his biological. parents. This outcome, though not predicted for these children, was the placement for 11 percent of the cases. More children were returned from those who seemed headed for adoption by new parents than from the foster parent plan group.

To summarize, no differences were found between the proportion adopted by foster parents and by new parents. In this respect, foster parent adopt appears to be an acceptable placement. No matter which outcome seemed likely, almost half of the children made no change in the type of placement they were in. They remained in foster care. of the 74 children in foster care at the end of 28 months, 31 were legally free from at least one parent. Clearly the goal was adoption but they were stopped somewhere short of the goal. The goal is to make foster care a temporary arrangement for all children. These children had already been in foster care well over 28 months and efforts to move them into a permanent plan had not succeeded. Foster care had not accomplished its goal. 
TABLE IV

NUMBER OF CHILDREN IN EACH OUTCOME

BY LIKELY OUTCONE AND PROJECT

\begin{tabular}{|c|c|c|c|c|c|c|c|}
\hline \multirow[b]{2}{*}{ Placement } & \multicolumn{3}{|c|}{ Foster Parent Plan } & \multicolumn{3}{|c|}{ New Parent Plan } & \multirow{2}{*}{$\begin{array}{l}\text { Total for } \\
\text { Both Plans }\end{array}$} \\
\hline & Project & Non-Project & Total & Project & Non-Project & Tota1 & \\
\hline Long Term Foster Care & 0 & 1 & $1 \quad(1 \%)$ & 0 & 0 & & $1 \quad(1 \%)$ \\
\hline Return to Parents & 3 & 2 & $5 \quad(6 \%)$ & 7 & 5 & $12\left(17_{0}^{0}\right)$ & $17(11 \%)$ \\
\hline New Parent Ndopt & 2 & 1 & $3 \quad\left(4_{i}^{0}\right)$ & 17 & 3 & $20(28 \%)$ & $23\left(15^{\circ}\right)$ \\
\hline Foster Parent Adopt & 18 & 12 & $30(36 \%)$ & 6 & 3 & $9(1.3 \%)$ & $39(25 \%)$ \\
\hline Relatives & 0 & 1 & $1 \quad\left(\begin{array}{l}0 \\
0\end{array}\right)$ & 0 & 0 & & 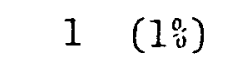 \\
\hline Foster Care & $\underline{15}$ & 29 & $44(52 \%)$ & $\underline{21}$ & $\underline{9}$ & $30(42 \%)$ & $74(47 \%)$ \\
\hline Total & 38 & 46 & $84(100 \%)$ & 51 & 20 & $71(100 \%)$ & $155(100 \%)$ \\
\hline
\end{tabular}




\section{GIAPTER VI}

\section{ACCOUNTING FOR THE DECISIONS}

The results of efforts to discriminate between groups of children for whom different decisions were made are presented here. A stepwise discriminant function analysis was the statistical tool used. Seven sets of analyses were done in an effort to understand which measures account for the decisions made in the process finding the nost appropriate placement for a child.

Three sets of variables were used to account for group membership at various points in the decision process; client, non-client and service history. A listing of variables included in each of the three sets is found in Table IV. The number of subjects available for some analyses was less than the total in the sample. When this happened, the number of variables within each set was reduced. This was done so that a ratio of at least four subjects to one variable could be maintained in each analysis. While differences of opinion exist on what this ratio should be, more than four variables to one subject is preferred. However, because this is an exploratory study in ari area in which little research has been done, this ratio was chosen to permit as full an investigation as possible of potentially important variables. Results are interpreted cautiously.

A summary of the nine analyses clone in an effort to account for differences in decisions made for specified groups is presented in Table V. Following this summary each analysis is discussed. 
VARIABLES AND ITISASUREMENT SCALES

INCLUDED IN THIE

ANALY'SES

Sets

Service History

Age

Number of placements

Time in foster care

Client llother barrier

Father barrier

Placeability ratings:

Physical

Coping

Financial

Overall (everything considered)

Bonds: to mother

to father

to siblings

to foster parents $5=$ strong bonds

to others

Non- Pike ratings:

Client

CSi

County DA

County Judge $\underline{\text { Scale }}$

$1=$ Project

$0=$ Non-Project

Expressed in total number of months from birth to October 1975.

The total number of different foster homes a child has lived in between the time he entered foster care and October 1975.

Expressed as the total number of months the child had been j.n care until October 1975.

Caseworker rating of the cxtent to which the biological mother was a barrier to the child being returned to her. 1 = minimal barrier to $6=$ high barrier.

Same as mother barrier but applied to the father.

The child's caseworker rated each of these four child conditions on the basis of whether it was Ji.kely to be a barrier to placing the child. 1 = placeable

5 or $6=$ not placeable

The child's caseworker made a rating of the extent to which bonds to various people were likely to influence the placement chosen.

$1=$ no bonds

Ratings of the institutional barriers to permanent planning. These ratings were made by Victor Pike, demonstration Project Director. 1 = low barrier to $5=$ high barrier. 
TABLE V (continued)

$\begin{array}{lr}\text { Sets } & \text { Variable } \\ \text { Non- } & \text { Foster care rate } \\ \text { Client } & \\ \text { (cont.) } & \end{array}$

Foster care population

Caseworker attitude factor scores:

I. Court barriers to termination in this county

II. Negative attitude toward termination.

III. CSD interagency communications perceived as favorable

IV. Willingness to terminate despite the unavailability of adoptive homes.

V. Approval or restoration effort

VI. Lack of experience doing termination

VII. Willingness to predict that a child will not return home.

VIII. Tine for a decision $\underline{\text { Scale }}$

Numbers of children in foster care per 1000 children under 18 in each county.

The total number of children in foster care in each county

The results of a survey of caseworker attitudes was factor analyzed and eight factors emerged. The child's score on each factor j.s hi.s caseworker's factor score. $-1.67=$ low barrier to $2.39=$ hi.gh barrier

$-1.39=$ ]ess negative attitude to $3.65=$ more negative attitude

$-2.25=$ less favorable communication to $1.73=$ more favorable communication

$-1.76=1$ ess willing to terminate to $2.00=$ more willing to teminate

$-2.23=1$ ess approval of restoration effort to $1.90=$ more approval of restoration

$-1.31=$ more experience to $2.35=1$ ess experience

$-1.98=1$ ess willingness to $2.06=$ more willingness

$-1.95=$ less time to $2.24=$ more time 
TABLE V (continued)

Sets

$\underline{\text { Variable }}$

$\underline{\text { Scale }}$

County Clinate Scores:

For each caseworker factor a county climate score was computed by calculating the percentage of caseworkers in that county who scored above the niean for 279 caseworkers surveyed.

I. Court barriers to $100=1$ igh barrier to $0=10$ w termination barrier

II. Negative attitude toward termination

$100=$ negative to $0=$ less negative

III. CSD interagency communications perceived as favorable $100=$ favorable to $0=1$ ess favorable

IV. Willingness to terminate despite the unavailibility $91=$ more willing to $0=1$ ess of adoptive homes willing

V. Approval of restoration efforts

$86=$ approval to $0=$ Iess approval

VI. Lack of experience $71=$ lack of experience to $0=1$ ess doing termination lack of experience

VII. Willingness to preaict that a child wijl not return home

$75=$ willing to $0=$ less willing

VIII. Time for a $82=$ time to $0=1$ ess time decision 
TABLE VI

DISCRIMINANT ANALYSES

Decision

Groups

1. Caseworker decision: Is the child not likely to go home and adoptable?

(1) Yes, by foster parents $(n=34)$

(2) Yes, by new parents $(n=71)$

2. Should this child who is likely to be adopted by new parents be selected for the project?

(1) Yes the child is selected $(n=51)$

(2) No the child is not selected $(n=20)$

3. Should this child who is 1ike1y to be adopted by foster parents be selected for the project?

(1) Yes the child is selected $(n=38)$

(2) No the child is not selected $(n=46)$

4. Is adoption pursued for children likely to be adoited by new parents?

5. Is adoption pursued for children likely to be adopted by foster parents?

6. What outcome was achieved? (Two analyses were done for this decision.)

(1) Pursued ( $n=45)$

(2) Not pursued $(n=36)$

(1) Pursued $(n=48)$

(2) Not pursued $(n=36)$

Analysis 1

(1) Adopted by new parents $(n=23)$

(2) Adopted by foster parents $(n=39)$

(3) Returned to biologj.cal. parent $(n=19)$

(4) Remained in foster care $(n=72)$

Analysis 2

(1) Adopted by foster parents $(n=39)$

(2) Adopted by new parents ( $\mathrm{n}=23)$ 
IS A CHILD, WHO IS NOT LIKELY TO RETURN HOAE, ADOPTABLE: BY NEV DAPF:ITS OR FOSTER PARENTS?

This decision took place when workers were asked to examine each case in their caseload and make a judgment about its likely outcome. One of the nine possible outcomes could be chosen (Emien, 1976). The two outcomes of interest here are: the child is not likely to return home and is adoptable by (1) foster parents or by (2) new parents. This analysis permits an exploration of the way caseworkers make judgments about whether a child is likely to be adopted by foster parents or by new parents.

Each of the three sets of variables, the client, the non-client and service history were entered in an analysis in the six possible orders. While the sets themselves were forced to enter the analyses in different planned orders, the variables within each set entered in a stepwise fashion, that is measures entered according to the amount of: variance they accounted for. This permitted an assessment of the relationship of the sets to each other and an evaluation of each variable within a set. The contribution of the three sets and the important: variables within each set will be discussed first. Finally the relationship of the sets to each other will be assessed.

Forty-four percent of the variance in the caseworker decision concerning whether or not the child was likely to return home and was adoptable by either foster parents or new parents was accounted for in this analysis. The largest contributing set was service history which accounted for 29 percent when it entered the analyses first. The child's age $(F(1,153)=55.28, \mathrm{p}<.01)$ and length of 
time in foster care $(F(1,152)=3.82$, $\underline{\mathrm{D}}<.10)$ were the two variables within this set accounting for significant proportions of the variance. (F values reported are those when the measure first entered the analysis.) Children who were older and had been in foster care longer were likely to be seen by their caseworker as adoptable by foster parents rather than new parents.

The correlation between age and length of time in care is $r=.50$, so the two variables are related. The variance accounted for by a measure entering an analysis second is that proportion of the variation which the second variable accounts for after that contributed by the first. Age entered first since it accounts for the largest proportion of the variation. Length of time in foster care and age hold variation in common so length of time in foster care by itself accounts for a smaller proportion of the variance than it would if age was not included.

The second most important set, client characteristics, accounts for 17 percent of the variation when it enters first. Bonds to foster parents was the most important variable here $(F(1,153)=19.18, \underline{L}<.01)$ with children who had stronger emotional ties to their foster parents among the group thought likely to be adopted by foster parents. Bonds to the mother was the other significant measure $(F(1,152)=5.53, \underline{p}<.05)$ in this set. Children who seemed headed for adoption by new parents were more likely to have some remaining attachnent to their mother than were those deemed adoptable by foster parents.

Non-client measures accounts for only 10 percent of the group difference when the set was entered first. One significant variable 
was negative attitude toward termination on the part of the caseworker $(F(1,153)=4.30, \underline{p}<.05)$. Caseworkers who had objections to the idea of terminating parental rights were more willing to say a child would be adopted by his foster parents than by new parents. Another variable accounting for a significant proportion of the variation was the county climate measure of the willingness of workers in the county where the child was living to terminate parental rights even though an adoptive home may not have been available $(F(1,152)=4.53$, $\underline{p}(.05)$. Workers from counties where such a willingness was more prevalent were likely to say that the child was adoptable by foster parents. The adontion process in Oregon is set up so that finding a home for children headed for adoption by nerv parents does not begin until the parents' rights are terminated. Children headed for adoption by foster parents are living with their potential adoptive parents at the time the adoption decision is made so that the availability of a home is clear to the child's worker and others involved in the decision. Then this situation existed caseworkers were more likely to be willing to teminate parents' rights in spite of a possible negative attitude toward the idea.

Foster care rate and foster care population were used as measures of the size of the group of foster care children in each county. It was expected that in the Iarger, more urban counties the process of achieving a permanent home for a child and the number of homes found would differ. However, in none of the discriminant analyses did either of these variables account for a significant pronortion of the variation. As will be further explained in Chapter VII, foster care 
population accounts for differences in time for those adopted by foster parents.

The relationship of the three sets of variables can be seen by examining Figure 2. The proportion of the variance accounted for by a set decreased as that set was forced to enter after others. Service history, the most important set no matter when it entered the analysis, drops until it accounts for 14 percent, entering after the other two. The importance of age in understanding the caseworker decision remajns even when service history entered after both other sets but length of time in foster care accounts for a significant part of the variation only when the set entered first. As discussed above, the correlation of age with lengtin of time in foster care could account for this decrease.

The stronger relationship of client measures to service history than to non-client variables can be seen on Figure 2 . When the client set entered after the non-client set it accounts for a slightly larger part of the variance but was reduced from 17 percent to nine percent when it entered after service history. Client measures have a higher correlation to service history than to non-client variables. When the client set entered second, a slightly larger proportion of the variation is accounted for. Variance is not shared by client and non-client measures as was the case with service history and client variables but the variance accounted for by the client set is improved by the non-client.

Caseworker perception of the child's emotional bonds to his foster parent accounts for a significant part of the variation no matter when 
the client set entered the analyses, but bonds to the biological mother are important only when the client set entered first and second. Hother bonds are not as strong a discriminator as foster parent bonds. Adoption usually would not be considered in the face of strong ties to the parent, but if adoption is considered, then bonds to foster parents receive strong attention. When non-client entered after client it accounts for a larger proportion of the variation than when it entered first. Again, the relationship of the client and non-client appears to enhance the predictability of the other. Here the predictability of the non-client is increased. When the non-client set entered after others, neither of the measures which accounts for a significant portion of the variation is important: factor II, negative attitude toward temination and county climate score IV, willingness to terminate despite the unavailability of adoptive homes.

In sunmary, while 66 percent of: the variation in caseworier decision remains unaccounted for, differences between the two groups are apparent. Service history, particularly age, is most germane to understanding the difference and in some analyses, length of time in foster care emerged. The other important variable is bonds to foster parents, a client measure. Others which account for smaller portions of the variance are bonds to biological parents, a negative attitude toward termination on the part of the caseworker, and the climate variable, willingness to terminate despite the unavailability of adoptive homes. 
TABLE VII

MEANS FOR VARIABLES SIGNIFICANT

TO THE DECISION: ITHO IS LIKELY

TO ADOPT THE CHILD?"

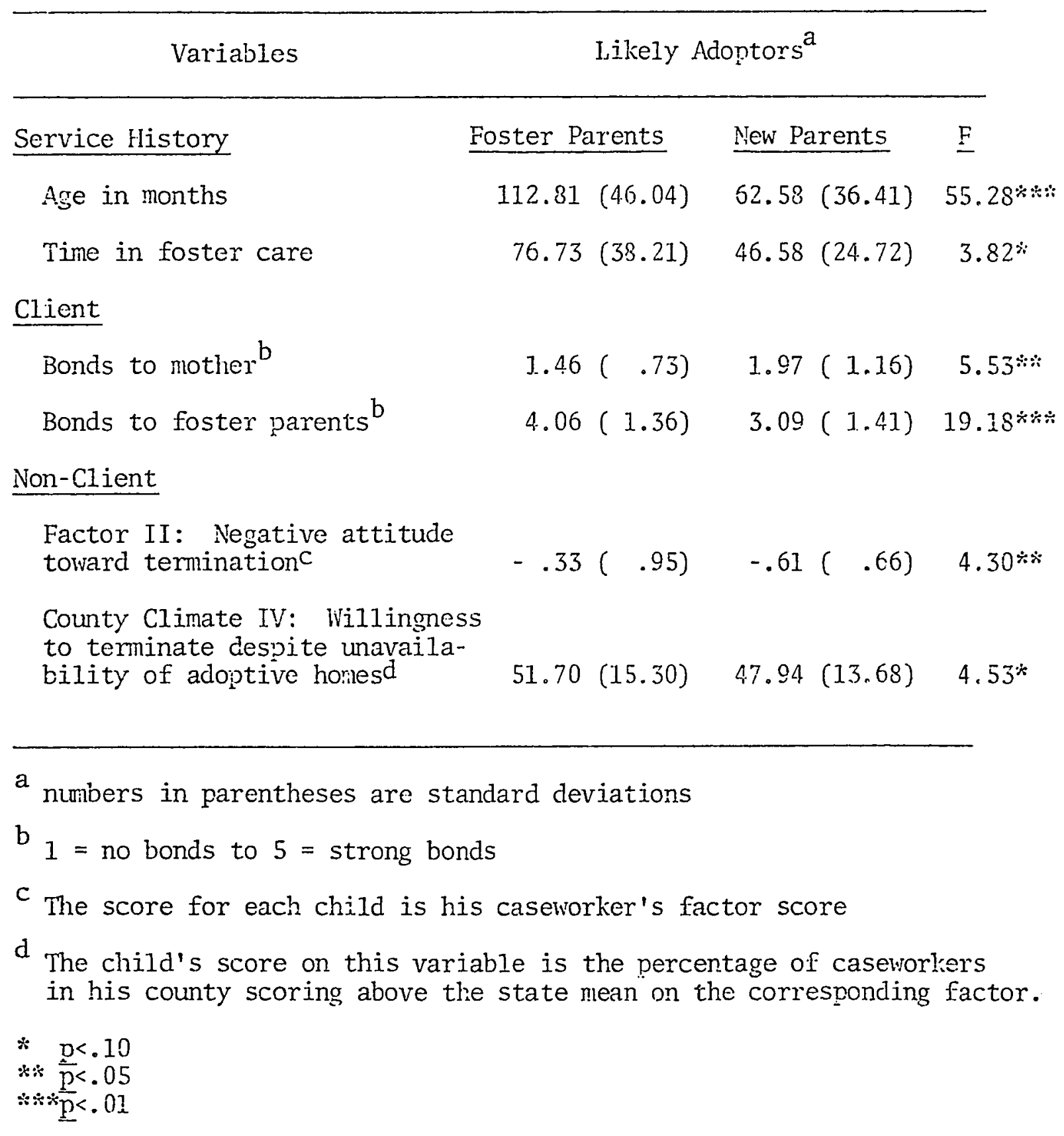


III) Client

I Non-Clisnt

Service tistory
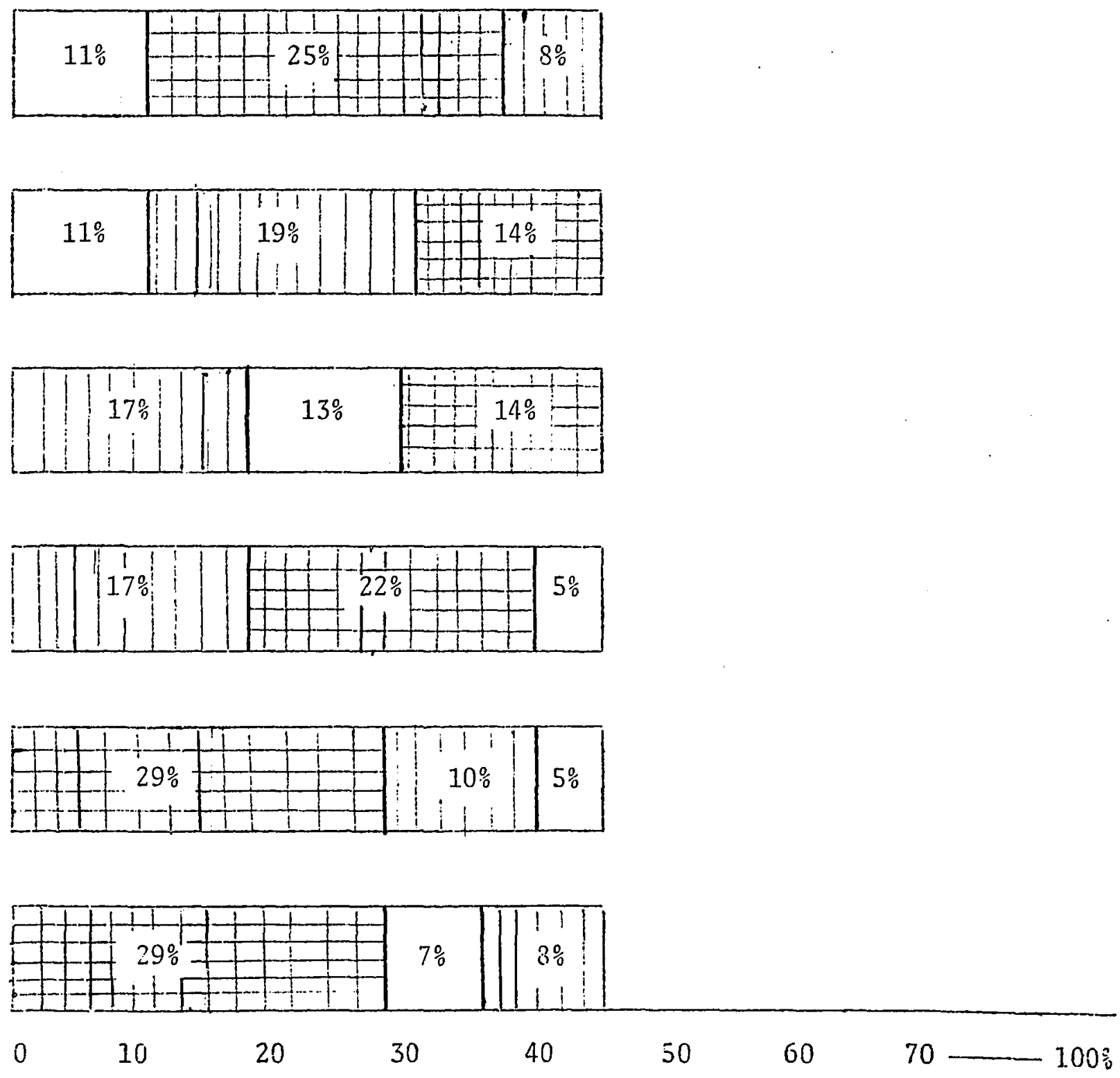

Percent of the Variance iccounted For

Figure 3. Discriminators (client, non-client and service history) of casetionicer decision of who is likely to adont: foster parents or nel: parents. Variance accounted for as sets entered in al1 possible orders. (Sets at the left of the Figure entered Iirst). 
Discussion

The caseworker decision about whether a child is Iikely to be adopted by foster parents is most strongly influenced by measures associated with the child. His age makes a big difference perhaps because an older child might be more likely to be adopted by parents who knew him and to whom he developed an attachnent, that is his foster parents. A child who has been in foster care longer had more opportunities to form attachnents to foster parents and therefore the probability of forning a lasting relationship would increase.

Caseworkers rated the mother-child bond stronger for those children who seemed headed for adoption by the new parents. Perhaps the additional time those 1ikely to be adopted by foster parents had spent aivay from their mother tamished the nother-child bond. They had been absent from this parent for a longer period than children likely to be adopted by new parents.

A negative attitude toward termination of parentaj. rjghts on the part of the caseworker influenced the decision as to likely outcome. The relationship between the non-client measures and the other sets indicates that the judgnent of a caseworker about characteristics of the child are influenced by this attitude. Caseworkers with a negative attitude toward termination of parental rights were more likely to say a child should be adopted by his foster parents. 
SHOULD THIS CHILD VIIO ITAS PREDICTED TO BE ADOPTABLE BY NEW PARENTS BE CHOSEN FOR TIE PROJECT?

After the caseworker had made a decisjon that the child was not likely to return home and was likely to be adopted either by new parents or foster parents, another review was done. This time the child's caseworker and project staff discussed the case in some detail to decide whether it was appropriate for the project effort. Criteria for project selection in addition to the ones used by the caseworker were: the case be among those seen as most difficult to move through the permanent planning process and the sipecial project caseworker should not have more than 25 cases at one time.

The two groups in this analysis are (1) those seen as adoptable by new parents who were chosen to be part of the denonstration project and (2) those who were not chosen. The three discriminating sets were reduced to a total of 19 variables for this analysis and the one following it.

Again here, as in all analyses, the three sets of variables were entered in all possible orders and variables within sets entered in a stepwise fashion. Each set will be discussed separately, then their relationship with each other will be considered.

The measures accounted for 56 percent of the variation in the decision to include a child in the project who was seen as not likely to return home and adoptable by new parents.

The non-client set is most relevant, accounting for 37 percent when entered in the analyses first. The four variables accounting for significant proportions of the variation in this set are (1) county 
climate VIII - time for decision $(F(1,69)=18.93$, p $<.01)$, (2) factor score VIII, time for decision $(F(1,68)=5.66, \underline{\mathrm{z}} \% .05)$, (3) county climate $I$, court barriers to termination $(F(1,67)=5.42, \underline{p}<.05)$ and (4) factor II, negative attitude toward temination $(F(1,69)=6.03$, $\underline{p}<.05)$. The last variable, negative attitude, accounts for a significant portion of the variation only when considered separately. Then entered in a stepwise fashion after the effects of other more important variables were accounted for, this measure was not significant.

Froli the time for decision variable we learned that children were more likely to be chosen by the project if the individual child's caseworker and caseworkers as a group in the child's county had time to deal with temination of parental rights and were comfortable with the idea. Also if the court in a child's county was seen as presenting obstacles to the temnination of parental rights the child was more likely to be chosen for the project.

Another variable accounting for a significant portion of the variation indicates that a child with a casevorker who had a negative attitude toward termination of parental rights was less likely to be chosen for the project.

Generally from these non-client variables we learn that caseworkers who could make a comnitment to the idea of termination of parental rights were more likely to furnish cases to the project. Evidence that the stated. project policy of taking only cases difficult to move through the permanent planning process was implemented is indicated by the finding that children chosen for the project were more likely to be from a county perceived as having high court barriers to the ternination of parental rights. Cases in these counties would be more difficult to 
resolve.

The other two sets of disciminators account for small portions of the variation. Client measures account for 13 percent and service history nine percent when each set enters first. The caseworker rating of the extent to which the father was seen as a barrier to the child's return home is the only variable from the client set accounting for a significant proportion of the variation $(F(1,69)=4.17, p<.05)$. A child whose father was seen as not likely to take him back was less 1ikely to be chosen as a project case. Fathers presenting the highest barrier to the child's return were generally those for whon parent-child reconciliation was least possible. These were the easier cases since temination of parental rights was more straightforward. They were less Iikely to be chosen by the project. The project selected difficult cases. Where fathers presented less of a barrier, case resolution was more difficult because of indecision about the outcome. The rural county case study presented in Chapter IV illustrates the effort necessary to determine the outcome where the father expresses an interest in having his children returned to his care. The effort required was greater and the case was more likely to be taken into the project if the father was actively involved with his children.

Age was the service history measure accounting for a significant proportion of the variation $(F(1,69)=6.17, \underline{p}<.05)$. Younger children were chosen for the project. For theril the risk was not so great that delays would result in their being too old for adoption by the time they were free.

By examining the relationships among the sets of measures it can be seen that, though there is some reduction in its effect as the non- 
client set entered near the end, its strong influence remains throughout. The one variable within the service history set which accounts for a significant portion of the variance no matter when it entered was the county climate measure VIII, time for a decision. Thus the best predictor of a case being chosen for the project was if the caseworkers felt comfortable with termination of parental rights and had time for a decision. The county climate variable I, court barriers to termination, was the only other measure accounting for a significant portion of the variation beyond step 1. The other two sets were of considerably less importance and this usually decreased as they were entered second and third. Age was not significant after the Service History set entered first. The father rating was important as the client set entered first and second. 
TAALE VIII.

IEANS FOR VARIABLES SIGNIFICANT TO TEE DECISION:

SIOULD A CHILD LIKELY TO BE ADOTED BY

IEEN PARENTS BE IN

THE PROJECT?

\begin{tabular}{|c|c|c|c|}
\hline \multirow[t]{2}{*}{ Variables } & \multicolumn{2}{|c|}{ Project Case ${ }^{a}$} & \multirow[t]{2}{*}{$\mathrm{F}$} \\
\hline & Yes & No & \\
\hline Age & $56.06(28.79)$ & $79.05(47.80)$ & $6.17 *$ \\
\hline \multicolumn{4}{|l|}{ Client } \\
\hline Father barrier ${ }^{b}$ & $4.61(1.13)$ & $5.20(1.01)$ & $4.17 \%$ \\
\hline \multicolumn{4}{|l|}{ Non-Client } \\
\hline $\begin{array}{l}\text { County Climate I: Court barriers } \\
\text { to terminationc }\end{array}$ & $42.37(39.61)$ & $22.15(16.85)$ & $5.42 *$ \\
\hline $\begin{array}{l}\text { County Climate VIII: Time for } \\
\text { decisior }\end{array}$ & $58.02(19.42)$ & $35.00(21.63)$ & $18.93 \div \%$ \\
\hline $\begin{array}{l}\text { Factor II: Negative attitude } \\
\text { toward termination }\end{array}$ & $-.72(.63)$ & $-.31 .(.66)$ & $6.08 *$ \\
\hline Factor VIII: Time for decision ${ }^{c}$ & $.47(.69)$ & $-.19(.61)$ & $5.66 \%$ \\
\hline \multicolumn{4}{|c|}{$\begin{array}{l}\text { a Numbers in parentheses are standard deviations. } \\
\mathrm{b}_{1}=\text { minimal barrier to } 6=\text { high barrier } \\
\text { c The child's score on this variable is the percentage of caseworkers } \\
\text { in his county scoring above the state mean on the corresponding factor. }\end{array}$} \\
\hline $\begin{array}{l}\text { C The child's score on this variable } \\
\text { in his county scoring above the sit } \\
\text { d The score for each child is his ca } \\
* \mathrm{p}<.05 \\
* * \mathrm{p}<.01\end{array}$ & $\begin{array}{l}\text { e is the percen } \\
\text { tate mean on th } \\
\text { aseworker's fac }\end{array}$ & $\begin{array}{l}\text { tage of casewor } \\
\text { e corresponding } \\
\text { tor score. }\end{array}$ & $\begin{array}{l}\text { rkers } \\
\text { g factor. }\end{array}$ \\
\hline
\end{tabular}


111 Client

$\square$ Non-Ciient

世ervice Histor;

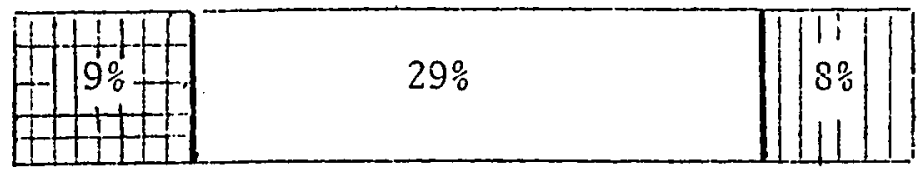
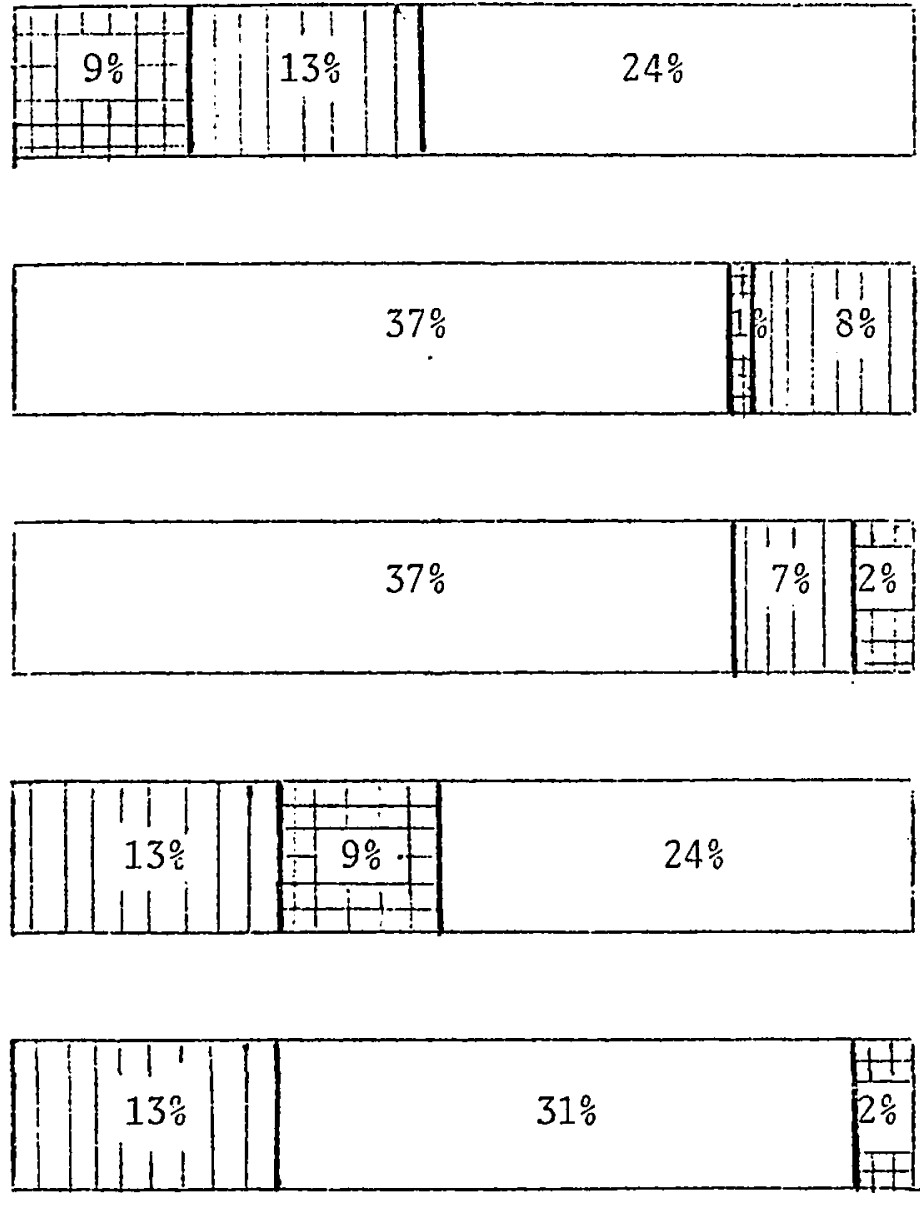

$\begin{array}{llllllll}0 & 10 & 20 & 30 & 40 & 50 & 60 & 70-100 \%\end{array}$

Percent of the Variance Accounted For

Figure 4. Discriainators (client, non-client and service history) of cases scen as likely to be adopted by ne: parents into tro groups: project and non-project cases. Varjance accounted as sets entered in all possible orders. (Sets at the left of the Figure are entered first). 
Surmiary

Drawing from a pool of children thought not likely to return home and adoptable each was considered and the project roster was chosen. From this analysis it can be seen that the best indicators of whether a child was taken into the demonstration project had to do, not with qualities of the child or his history, but with attitudes and conditions that were seen to exist among those in charge of the child's future.

Project cases were more likely to be from a millj.eu where agency staff viewed termination of parental rights as a viable option. This may reflect the greater willingness of staff with these attitudes to transfer cases into the project.

The importance of the degree to which the father was a barrier to the child's return home is probably an indicator of the project's tendency to take difficult cases. That the project took younger children points to a preference for those for whom an adoptive home could more easily be found. It appears that project staff were willing to accept difficult cases but they wanted to be certain an adoptive home could be found once the child was free.

SHOULD THIS CHILD, 朔O WAS PREDICTED TO BE ADOPTABLE BY FOSTER PARENTS, BE CHOSEN FOR THE PROJECT?

This decision is similar to the one discussed just before it but the group on which the decision was made is different. Considered here are the children which were seen as likely to be adopted by foster parents. The two groups are those that are seen as adoptable by foster parents and chosen for the project, and those that are seen as adoptable by foster parents and not chosen for the project. Project staff, in 
consultation with the child's caseworker made the selection, choosing as project cases those presumed to have the least straightforward path to adoption. The number of cases that was chosen by the project had to be within the limit of approximately 25 cases per caseworker.

The results of this analysis are similar to those in the new parent adopt decision. The total variance accounted for is similar, 49 percent here and 44 percent above. Also, the non-client set is most important in both analyses, with service history and client being relatively unimportant.

Thirty-four percent of the variation is accounted for by non-client measures when they entered first. Discriminators from this set accounting for significant proportions of the variation are; county climate score $\operatorname{VIII}(F(1,82)=22.15, \underline{p}<.001)$ and factor score $\operatorname{VIII}(F(1,80)=5.19$, $\underline{p}<.05)$, time for a decision; and county climate score $\operatorname{IV}(F(1,81)=$ $7.66, \underline{\mathrm{p}}<.01)$ willingness to terminate despite the unavailability of adoptive homes. County climate score II, negative attitude toward termination, accounts for a significant part of the variation only when considered separately $(F(1,82)=8.96, \underline{p}<.01)$, but not in combination with the other variables. The correlation between this variable and county climate IV is $r=.41$. Caseworkers who didn't like the idea of permanently removing a child from his parents were more willing to terminate in the face of the possibility that an adoptive home would not be found. County climate IV entered the discriminant analysis before county climate II. Because it accounts for a larger portion of the variance, it takes up variance the two variables hold in common. Entered after county clinate IV, the variance accounted for 
by county climate II is substantially reduced.

The curious relationship between county climate score II and county climate score $\mathrm{IV}$ deserves more attention. The correlation between these measures suggests that in counties where caselrorkers have a negative attitude toward temination of parental rights there is a tendency for workers to be willing to terminate parental rights despite the unavailability of adoptive homes. It might be expected that a negative attitude would result in less, not more, willingness. However, a look at the variables comprising these factors reveals that county climate II, negative attitude toward termination, is strictly an attitude measure, probing feelings without asking for a decision based on those feelings. County climate IV demands some intellectual assessment of real conditions concerning adoptability of children and availability of adoptive homes. These caseworkers seem to say that while they don't like the idea of termination of parental rights, they favor freeing adoptable children even though there is a risk that an adoptive home might not be available.

If the child's caseworker and caseworkers in general within a county believed that they had time to do a termination and were comfortable with the idea, then the project was likely to accept that case. These two variables were also inportant discriminators of the project, nonproject cases in the likely new parent adopt group, the analysis discussed just before this one. This factor seems to be a measure not only of a willingness to find time to make a decision but a recognition of the risk of the unknown and a certain anguish at having to move ahead.

Service history and client variables account for small percentages of the variation. The variable accounting for a significant portion of 
the variation for service history is age $(F(1,82)=7.00, \underline{\mathrm{p}}<.01)$ and for the client set overall placeability is the strongest $(F(1,82)=$ $7.96, \underline{\mathrm{p}}(.01)$. Children chosen for the project were younger and were seen by their caseworker as more placeable.

The placeability rating was correlated $(\underline{r}=, 4 \mathrm{~J}$ ) wi.th the variable assessing the child's bonds to his biological father. The more placeable the child, the weaker the bonds. The father bonds variable is significant $(F(1,82)=4.22, p<.05)$ when other measures are not considered. But: when entered in a discriminant analysis in a stepwise fashion it did not account for a significant portion of the variation. When placeabi].ity accounting for a larger proportion of the variation entered the discriminant analysis before father bonds, it absorbed the variation which was due to the relationship of the two measures.

Considering the relationship between the three sets of measures when they are entered in the analysis in all possible orders, it can be seen that non-client are predominant no matter when they enter. Except when it entered after service history, the cl.ient set accounts for the same or more of the variability when it goes in the analysis or third as when it is first. Client and non-client measures are related in such a manner that the predictability of each set is enhanced when the other set enters before it.

If caseworkers within a county and the child's particular worker felt they had time for a decision and were not bothered by the idea of terminating parents' rights then a case was likely to be a project choice. Also, if caseworkers in a county were willing to terminate parental rights, a case was a probable choice for the project. 
TABLE IX

IFANS FOR VARIABLES SIGVIFICANT TO THE DECISION:

SHOULD A CIILD LIKELY TO BE ADOPTED BY

FOSTER PARENTS RE CHOSEXI FOR

THE PROJECT?

\section{Variables}

Client

Overall placeability ${ }^{b}$

Father bond ${ }^{\mathrm{c}}$

Service History

$$
\text { Age }
$$

Non-Client

County Climate II ${ }_{\mathrm{d}}$ Negative attitude toward termination

$54.42(18.06) 45.85(6.53) 8.96 \% *$

County Climate IV: Willingness to terminate despite $\mathrm{d}^{\text {the }}$ unavailability of adoptive homes

County Climate VIII: Time for decision

Factor VIII: Time for decision ${ }^{e}$
Project Case $^{\mathrm{a}}$

Yes

No

$\begin{array}{ll}1.39(.86) & 2.15(1.46) 7.95 \% \\ 1.05(.46) & 1.37(.85) 4.22 \%\end{array}$

$59.21(24.96) 43.50(22.85) 7.66 * *$

$61.16(21.58) 38.22(22.76) 22.15 * *$

$.50(.77) \quad-.03(.70) 5.19 *$

a Numbers in parentheses are standard deviations

b. $1=$ placeable to $5=$ not placeable

c $1=$ no bonds to 5 = strong bonds

d The child's score on this variabie is the percentage of caseworkers in his county scoring above the state mean on the corresponding factor.

e The score for each child ishis caseworker's factor score.

$* p<.05$

$* * p<.01$ 
[i] Client

[I kon-Client

II Service History
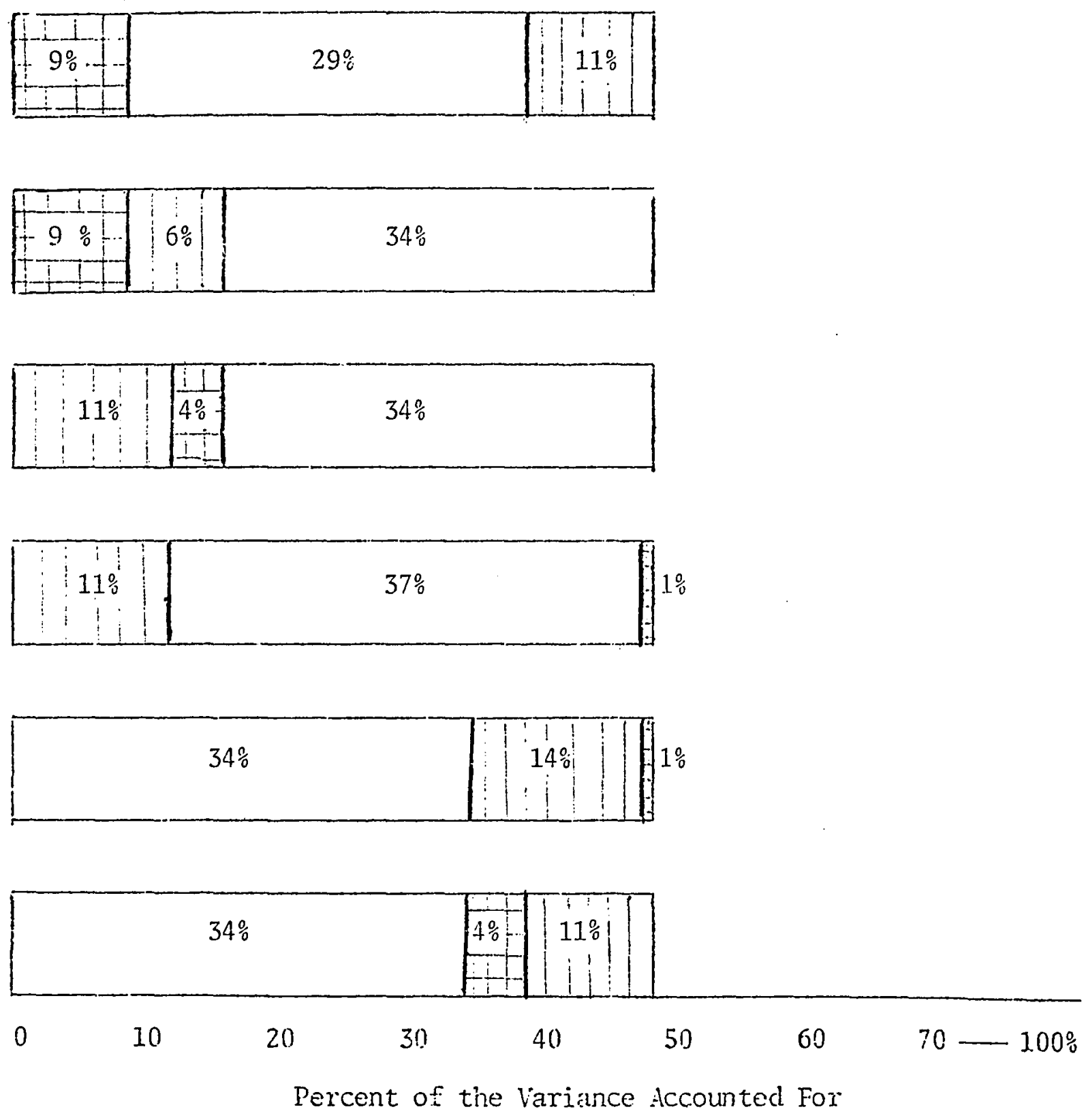

Figure 5. Discriminators (Client, non-client and service history) of cases seen as likely to be adopted by foster parents into two groups: project and non-project cases. Variance accounted for as sets entered in all possible orders. (Sets at the left of Figure are entered first). 
Placeable children were significantly more apt to be picked by the project. This relationship held no matter when the client set entered the analysis. The service history measure age accounts for a significant part of the variation when it went into the analysis after the non-client set, to which it has little relation, but it was not relevant when entered after others.

Discussion of Project Selection

Accounting for the project decision of whether or not the case was suitable for the project has been moderately successful. Forty-nine percent of the variance was accounted for. A child was more likely to be chosen by the project in counties where the caseworkers as a group could find time to do a termination and where the individual child's worker could find tine. Thj as true for both groups, those who were seen as headed for foster parent adoption and new parent adoption. Other non-client discriminators of whether a child entered the project were different for the two groups. Foster parent plan children chosen for the project tended to come from counties where caseworkers as a group had a negative attitude toward termination but nevertheless showed a willingness to terminate. Those headed for adoption by new parents were more likely to by chosen for the project if they lived in a county seen as presenting a high barrier to termination, and if the child's caseworker had a negative attitude toward the termination.

While non-client measures accounts for a larger proportion of the variation, among the client and service history sets of variables, father barriers, overall placeability and age are inportant. Younger children were more likely to be chosen for the project from both groups. 
Children likely to be adonted by new parents whose fathers presented the highest barrier to the child's return were least likely to be chosen for the project. Fathers in this highest barrier category had frequently abandoned the child and termination of parental rights was a straightforward procedure. The decision about the future of children whose fathers presented a major but not severe barrier was not as clear cut. The placement decision for these children would be more difficult and require more effort. The project sought these cases. Overall placeability was a predictor of a child headed for foster parent adointion being chosen for the project with more placeable children being selected.

IS ADOPTION PURSUED FOR CHILDREN

LIKELY TO BE ADOPTED BY FOSTER PARENTS

Until this stage in the process the decisions made have been agency ones and in and of themselves carry no legal commitment. The next decisions can legally change a child's life. They can result in an end to the rights of parents and adoption of the child by other parents.

The indicator of adoption being pursued was when the child became free from his first parent whether this took place through the court ordered temination of parental rights, voluntary relinquishment by the parent or death of the parent. Two analyses explored this decision. One discriminated between cases for whom adoption was pursued or not pursued among those seen as likely to be adopted by foster parents. The second was the same except that cases used were those seen as likely to be adopted by new parents. For these analy'ses project and non-project cases were pooled. Whether or not a case was part of the 
project becane an independent variable in these and subsequent analyses. The number of discriminators was further reduced to 15 for these analyses.

The foster parent adopt analysis will be considered first. Sixty percent of the variation between cases pursued and those not pursued was accounted for with the client set being the most germane. Client measures which were significantly different between grouns were: mother barrier $(F(1,82)=29.58, \underline{p}<.01)$, father barrier $(F(1,81)=12.11$, $\underline{p}<.01)$ and overall placeability of the child $(F(1,80)=5.07, p \leq .01)$. Children who moved toward adoption were likely to have a higher placeability rating and to have parents who presented higher obstacles to their return home.

A difference was found betiveen the groups on bonds to each parent when they were considered separately, Father $(F(1,82)=6.26, \underline{p}<.05)$, Wother $(F(1,82)=4.23, p \times .05)$, independent of the influence of other measures. However, when these variables entered the analysis in a stepwise fashion neither accounted for a significant amount of the variation. The parent-child bonds measures were significantly correlated with variables entering the analysis first and did not add to the variation accounted for after these vere considered.

For both parents a significant negative correlation (Father $\underline{r}=$ -.49 and mother $r=-.56$ ) was found between the child's bonds to that parent and the extent to which the parents presented a barrier to the child's return. High barrier narents tended to have low bonds to the child. The barrier ratings entered the analysis first, since they account for the largest proportion of the variation, and took up variance held in common by barriers and bonds. This decreases the 
variance accounted for by bonds in the discriminant analysis.

Service history accounted for 29 percent of the variation when it entered first. Whether or not a case was chosen for the project was used in the analysis as a discriminator and included in the service history set. Measures from this set accounting for significant portions of the group differences were time in foster care $(F(1,81)=8.21$, p $<.01)$ and whether or not the clild was part of the project $(F(1,82)=$ $20.68,<.01)$. Those in the project who were in foster care a shorter time were more likely to move toward adoption. Age accounted for a significant difference when considered by itself $(F(1,82)=$ 8.99, $\mathrm{p}<.01$ ) but did not significantly contribute to a prediction system containing other measures. Because of a correlation $(\underline{r}=.40)$ between time in foster care and age, age measure did not account for a significant amount of the variation entering in a stepwise way after time in foster care.

The non-client set was the least important, accounting for 1.6 percent of the variation when it entered first. The county climate measure VIII, time for a decision, was significant $(F(1,82)=8.09, \underline{E}<.01)$. If caseworkers as a group within a county felt that they had time for a decision the adoption was more likely to be pursued. Here the caseworker measure, factor VIII, time for a decision, considered by itself accounts for a significant amount of: the variation $(F(1,82)=$ $5.15, \underline{p}(.05)$ but when it entered the analysis in a stepwise fashion after the county climate rating this was not true. The correlation between the two measures was .35 , pointing to variance held in common by these measures. 
TABLE $X$

MANS FOR VARIABLES SIGIIFICAINT TO THE DECISION:

IS ADOPTION PURSUED FOR. THE FOSTER PARENT

ADOP'T SAIPLE?

\begin{tabular}{|c|c|c|c|}
\hline \multirow{2}{*}{$\frac{\text { Variables }}{\text { Service History }}$} & \multicolumn{2}{|c|}{ Adoption Pursued ${ }^{\mathrm{a}}$} & \multirow[t]{2}{*}{ F } \\
\hline & Yes & No & \\
\hline Project/non-project ${ }^{\mathrm{b}}$ & $.65(.48)$ & $.39(.40)$ & $20.68 \div *$ \\
\hline Age in months & $100.35(47.65)$ & $129.42(38.49)$ & $8.89: \div *$ \\
\hline Time in foster care & $65.44(31.24)$ & $91.77(41 . .77)$ & $8.21 \%$ \\
\hline \multicolumn{4}{|l|}{ Client } \\
\hline Iother barrier ${ }^{c}$ & $5.07(.45)$ & $4.17(1.02)$ & $29.58 * *$ \\
\hline Father barrier ${ }^{c}$ & $4.96(.78)$ & $4.28(1.05)$ & $12.11 * *$ \\
\hline Overall p1aceability ${ }^{\mathrm{d}}$ & $1.53(.65)$ & $2.39(3.57)$ & $5.07 * *$ \\
\hline Bonds to mother ${ }^{e}$ & $1.32(.49)$ & $1.64(.93)$ & $4.23^{*}$ \\
\hline Bonds to father ${ }^{e}$ & $1.15(.32)$ & $1.50(.91)$ & $6.26 \%$ \\
\hline \multicolumn{4}{|l|}{ Non-Client } \\
\hline $\begin{array}{l}\text { County Climate VIII: time for a } \\
\text { decision } f\end{array}$ & $55.25(23.4 .3)$ & $4.0 .56(23.4 .3)$ & $8.09 \div \%$ \\
\hline Factor VIII: time for a decision ${ }^{g}$ & $.37(.82)$ & $-.02(.67)$ & $5.16 \%$ \\
\hline \multicolumn{4}{|c|}{ Numbers in parenthesis are standard deviations } \\
\hline \multicolumn{4}{|l|}{$\mathrm{b}_{1}=$ project and $0=$ non-project } \\
\hline \multicolumn{4}{|c|}{$\begin{array}{l}c_{1}=\text { ninimal barrier to child's return to } 6=\text { high barrier } \\
d_{1}=\text { placeable to } 5=\text { not placeable }\end{array}$} \\
\hline \multicolumn{4}{|l|}{$\mathrm{e}_{1}=$ no bonds to $5=$ strong bonds } \\
\hline \multicolumn{4}{|c|}{$\begin{array}{l}\text { fhe child's score on this variable is the percentage of caseworkers } \\
\text { in his county scoring above the state mean on the corresponding factor. }\end{array}$} \\
\hline \multicolumn{4}{|c|}{ g The score for each child is his caseworker's factor score } \\
\hline $\begin{array}{rr}\because & \underline{0}<.05 \\
\therefore * & \underline{\mathrm{p}}<.01\end{array}$ & & & \\
\hline
\end{tabular}


[i] Ciient

Non-C1i:nt

[- Service inston
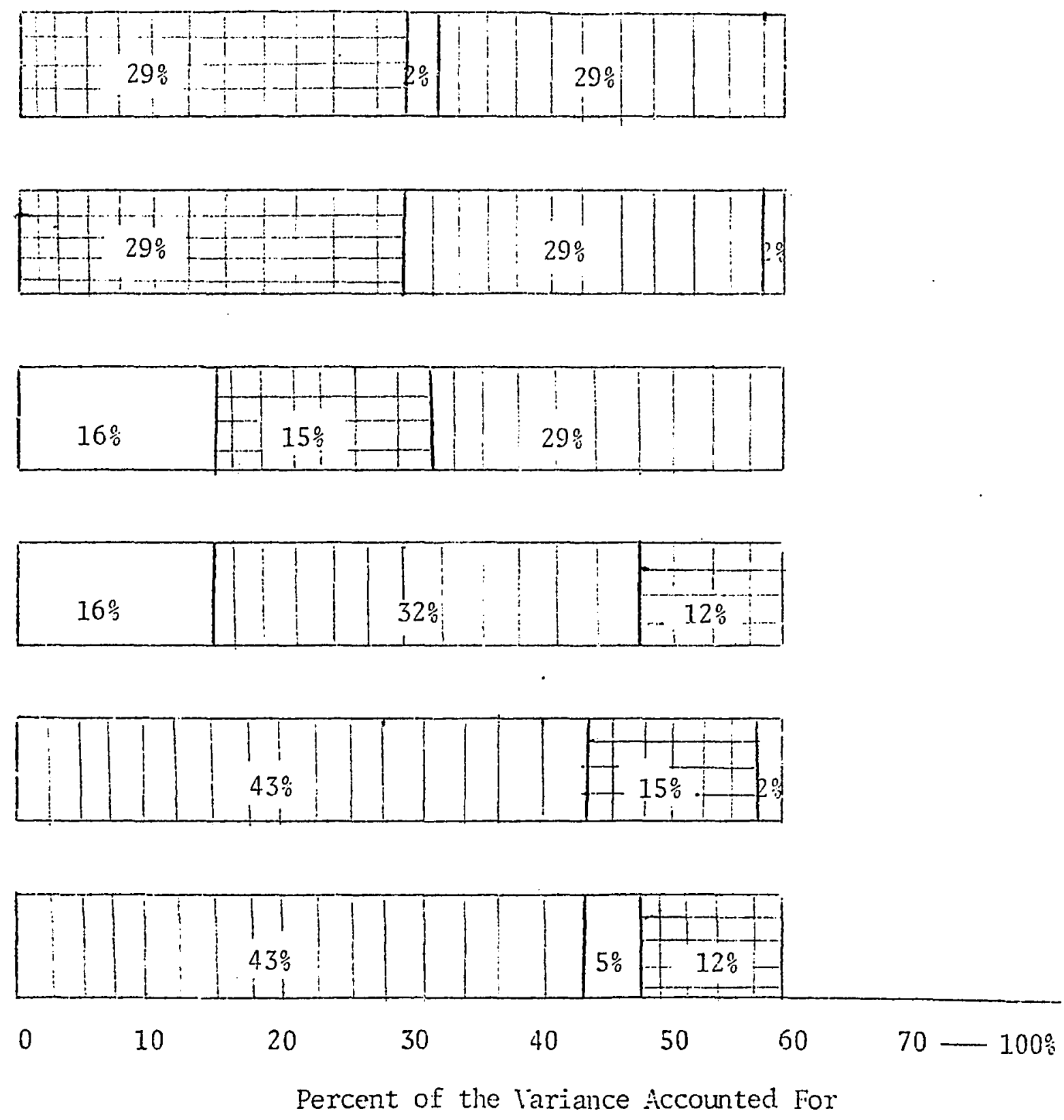

Figure 6. Discriminators (client, non-client and service history) of cases seen as likely to be adopted by foster parents into thio groups: adoption pursued and adontion not pursued. Variance accounted for as the sets entered in all possible orders. (Sets at the left of the figure entered first). 
Considering the relationship of the sets as they entered in different orders, they are all reduced in importance, as is usually the case, when they entered second and third. Non-client measures are greatly reduced when entered after other sets. It appears that measures having to do with the child are more related to whether this legal step is taken than are agency measures. If the child's mother and his father were seen as high barriers to his return it was significantly more likely that adoption would be pursued. Within the service history set project cases were more likely to have adoption pursued for them no matter when the set entered. Younger children tending to head toward adoption was a significant relationship when the set entered first and third but length of time in foster care, a variable correlated with age $(\underline{r}=.46)$, replaces age when the set entered second.

\section{Discussion}

Thether this first legally binding step was taken was best predicted by measures which should have been relevant: the strength of the child's relationship with his parents. Then the court decides whether parents' rights will be terminated it is done on the basis of whether their conduct or condition will permit them to provide a home for the child. When parents voluntarily relinquish their rights it is because they become convinced that they cannot or will not provide a home for the child.

Other measures, age and time in foster care, indicate that neither termination of parental rights nor voluntary relinquishnent was sought unless the child was considered adoptable. Thether the case was part 
of the project was important, indicating that the extra effort helped. Though it was not significant entering the analysis last, after the effects of the other measures had been considered, the caseworker measure Factor VIII, time for decision, was important in understanding what would happen to the child. If the worker had time, adoption was more likely to be pursued.

IS ADOPTION PURSUED FOR CHILDREN LIKELY TO BE ADOPTED BY NEVI PARENTS

In this decision, which is the same as the one presented just before it but made for a different group of children, a similar percentage of the variance ( 57 percent) was accounted for.

Here, as in the analysis of the likely foster parent adopt group, the client set was most prominent, accounting for 44 percent of the variation when entered first. The four variables accounting for significant portions of the variation are: mother barriers to the child's return $(F(1,66)=4.97, \underline{p}<.05)$; overall placeability of the child $(F(1,68)=7.77, \underline{p}<.01)$; bonds of the child to his mother ( $F(1,69)=17.85, \underline{p}<.01)$ and bonds of the child to his father $(F(1,67)=5.97, \underline{p}<.05)$. The group for whom adoption was pursued, that is the children who were free from one parent, had fewer bonds to both their mother and father, were seen as more placeable and tended to have mothers who presented higher barriers to their return home. As would be expected, mother bonds are negatively correlated $(\underline{r}=-.48)$ with mother barriers; that is, mothers who presented higher barriers to the child's return had weaker ties to the child. This resulted in a decrease in the importance of mother barriers in the 
prediction system as it went into the analy'sis in a stepwise way after mother bonds, the variable accounting for the largest proportion of the variance. Even so, it was a significant discriminator.

Both the non-client and the service history sets account for small amounts of the variation, 13 percent and 14 percent respectively. One variable in each set is significant. In the service history set project cases were more likely to move toward adoption $(F(1,69)=$ $7.02, \mathrm{p}<.01)$. Age accounts for a significant portion when considered separately $(F(1,69)=5.54, \underline{p}<.05)$ but when entered in a stepwise fashion after the project case measure it is not significant. The relevant measure in the non-client set is the county climate measure VIII, of time for decision $(F(1,69)=4.77, \underline{\mathrm{p}}<.05)$. Adoption was 1ikely to be pursued, that is the child would be freed from one parent, for cases from counties in which caseworkers felt they had time to pursue termination of parental rights and were comfortable with the idea.

Figure 7 shows the relationship between the three sets as they were forced to enter the discriminant analysis in different orders. Client measures account for well over half the total variation no matter when they entered the analysis. No large change in variance accounted for takes place as this set entered second, then third. One variable within this set, bonds to father, accounts for a significant percent of the variation no matter when it entered. Overall placeability is significant only as the set entered first. Of the two correlated variables, mother bonds is significant when the set is forced to enter the analys is second and mother barrier is significant when the set entered last. Clearly the strength of the mother's relationship to 
her child as measured by bonds to the child and barriers to the child's return was important in determining whether that relationship would be legally ended and arloption would be pursued.

The service history and the non-client set account for very small percentages. Their effect is reduced somewhat in importance when they entered second and third after the effect of other related measures is considered. Within the service history set, the project case measure is important no matter when the set entered. No non-client measure is significant after the set entered first.

Discussion

Comparing the likely foster parent adopt with the new parent adopt group on discriminators of whether or not adoption was pursued, it can be seen that similar measures influenced the decision in both groups. Client measures were most important, with chiliuren whose relationships with their parents were weak being more aipt to move toward adoption. But also irportant were the variables, project case and time for a decision. Project cases from counties where caseworkers had time and inclination to become involved in termination of parental rights were Iiable to have adoption pursued for them.

WHAT IS THE OUTCORE FOR THE CHILD

The outcome for this study was the placement each subject was in twenty-eight months after screening took place or they entered the project. Four outcomes were considered; adontion by foster parents, adoption by new parents, return to parents and foster care. While the primary interest of this study is with comparisons between the foster 
TABLE XI

PEANS FOR VARIABLES SIGIIFICANT TO TTE DECISION:

IS ADOPTION PURSUED FOR THE

NEN PARENT SNPLE?

\begin{tabular}{|c|c|c|c|c|}
\hline \multirow[t]{2}{*}{ Variables } & \multicolumn{3}{|c|}{ Adoption Pursued ${ }^{a}$} & \multirow[t]{2}{*}{$F$} \\
\hline & & Yes & No & \\
\hline Project/non-project ${ }^{b}$ & .82 & $(.39)$ & $.54(.51)$ & $7.02 \% *$ \\
\hline Age in months & 55.08 & $(31.36)$ & $75.54(41.28)$ & $5.54^{*}$ \\
\hline \multicolumn{5}{|l|}{ Client } \\
\hline Mother barriers ${ }^{c}$ & 4.87 & $(.72)$ & $3.85(1.41)$ & $4.97 *$ \\
\hline Overall placeability ${ }^{\mathrm{d}}$ & 1.64 & $(.71)$ & $2.30(1.29)$ & $7.77^{* *}$ \\
\hline Wother bonds ${ }^{\mathrm{e}}$ & 1.57 & $(.69)$ & $2.65(1.47)$ & $17.85^{* *}$ \\
\hline Father bonds $\mathrm{e}^{\mathrm{e}}$ & 1.23 & $(.52)$ & $1.85(1.19)$ & $5.97 *$ \\
\hline \multicolumn{5}{|l|}{ Non-Client } \\
\hline $\begin{array}{l}\text { County Clinate VIII: Time } \\
\text { for decision }\end{array}$ & 56.33 & $(22.06)$ & $45.00(19.16)$ & $4.77 \%$ \\
\hline \multicolumn{5}{|c|}{ a Numbers in parenthes is are standard deviations } \\
\hline \multicolumn{5}{|c|}{$\mathrm{b}_{1}=$ project and $0=$ non-project } \\
\hline \multicolumn{5}{|c|}{$c_{1}=$ minimal barrier to $5=$ high barrier } \\
\hline \multicolumn{5}{|c|}{$\mathrm{d} 1=$ placeable to $5=$ not placeable } \\
\hline \multicolumn{5}{|c|}{$e_{1}=$ no bonds to $5=$ strong bonds } \\
\hline \multicolumn{5}{|c|}{$\begin{array}{l}\text { The child's score on this variable is the percentage of caseworkers } \\
\text { in his county scoring above the state mean on the corresponding factor } \\
: \frac{p}{p}<.05 \\
*: \frac{p}{p}<.01\end{array}$} \\
\hline
\end{tabular}


[Client

[ Noil-Client

ES Service flistory
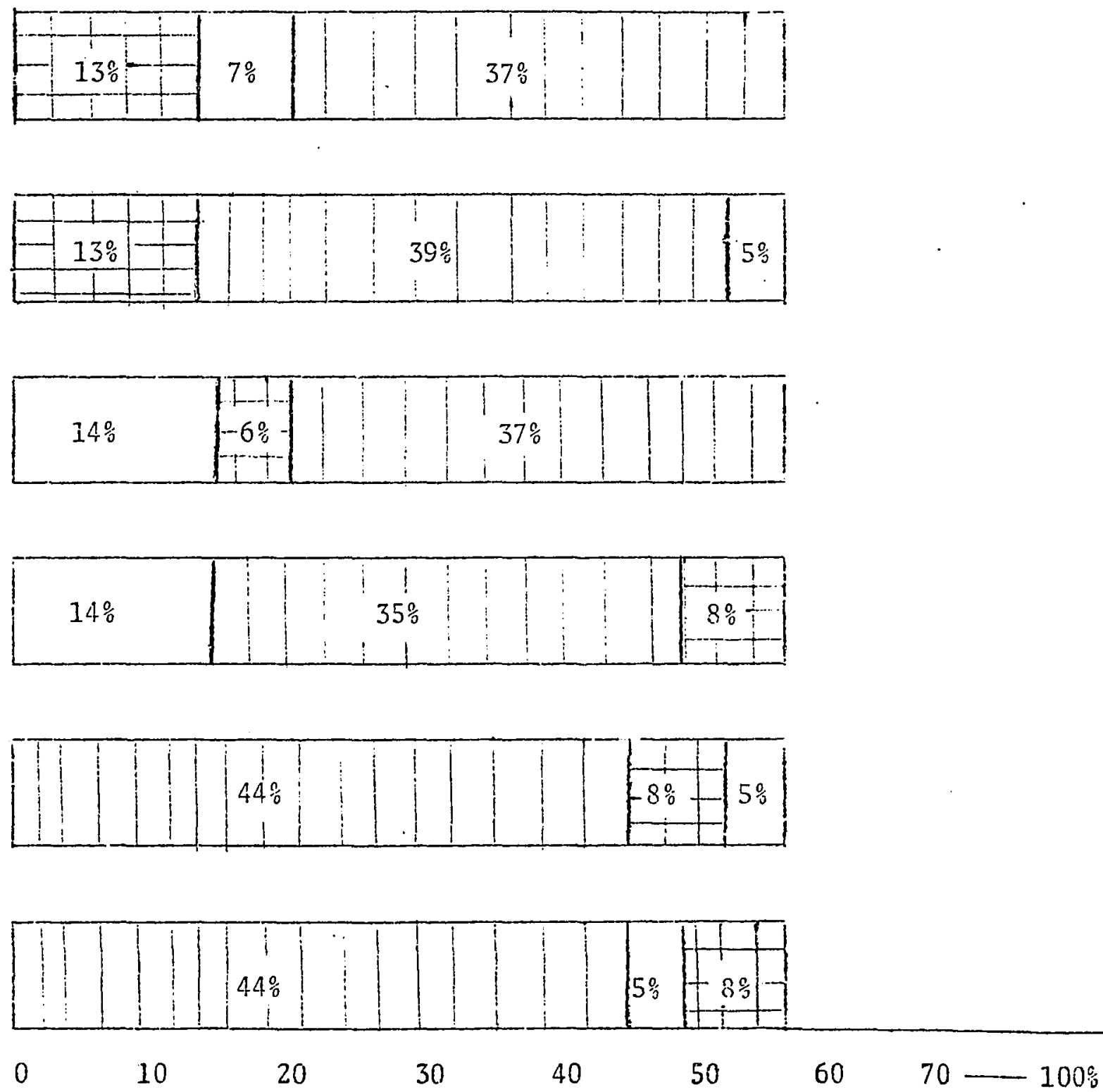

Percent of the Varjance Accounted For

Figure 7. Discriminators (client, non-client and service history) of cases seen as likely to be adopted by neli parents into two groups: adoption pursued and adoption not pursued. Variance accointed for as the sets entered in all possibie orders. (Sets at the left of the figure entered first). 
parent adopt and new parent adopt groups, because so many of the children remained in foster care at the end of the study a discriminant analysis was done in an effort to understand how this happened.

Two analyses were done in an effort to understand factors contributing to outcome. One was discriminant analysis of all four outcone groups. This permitted an assessment of discriminators for all children in the sample. A second analysis discriminated between those actually adopted by foster parents and those adopted by new parents. This permitted a specification of measures which made a difference between just these two groups.

The analysis which discrininates among the four outcome groups will be considered first, followed by the one which discrininates between those adopted by foster parents and those adopted by new parents.

SHOULD THIS CHILD BE ADOPTED BY NEV PARENTS, ADOPTED BY FOSTER PARENTS, REMAIN IN FOSTER CARE, OR RETURN TO HIS SARENTS?

In this analysis a larger percentage of the varjation ( 73 percent) was accounted for then in any of the other analyses. The client set is the largest contributor, accounting for 59 percent of the variation when it entered the analys is first. Variables within the set accounting for a significant portion of the variation when entered in a stepwise fashion are bonds to foster parents $(F(3,151)=22.45, E<.01)$, overall placeability $(F(3,150)=12.49, \underline{p}<.01)$, father barrier (F $\left.(3,143)=4.22, \underline{p^{<}}<.01\right)$ and mother bonds $(F(3,149)=7.88, \underline{p}<.01)$. Children adopted by foster parents or remaining in foster care were judged to have stronger bonds to foster parents than those adopted by new parents or returned to their parents. The adopted children, both adopted by foster parents and new parents, were the most placcable 
and the lowest placeability scores were found in the group remaining in foster care.

The children returned to their parents had stronger bonds to their mothers and had fathers who presented fewer barriers to their return than those in other groups. Nother barrier $(F(3,151)=10.15, \underline{p}<.01)$ and bonds to father $(F(3,151)=6.66, \underline{p}<.01)$ are significant when considered by themselves but not when entered in the analysis in a stepwise fashion. ifother barrier is negatively correlated $(\underline{r}=-.50)$ with mother bonds indicating that a mother considered more j.ikely to have her child returned also had stronger bonds to that child. Father bonds and father barrier were negatively correlated in the same way $(\underline{r}=-.45)$. As has been pointed out before, a variable correlated with one entering a discriminant analysis before it accounts for a smaller percentage of the variation than without the presence of the first. Both mother barrier and father bonds were of this type and did not account for significant portions of the variation when entered in the discriminant, though they were significant when considered separately.

Service history is the next most important set accounting for 29 percent when forced to enter the analysis first. Age is this set's only measure accounting for a significant proportion of the group differences in the discriminant analysis $(F(3.151)=16.88, \underline{p}<.01)$. There is a substantial difference anong each of the four groups with the oldest children remaining in foster care, the second oldest group being adopted by foster parents, the third oldest being returned to their parents and the youngest being adopted by new parents. Time in foster care and whether or not a case was chosen for the project 
are significantly correlated to age $(\underline{r}=.54$ and $\underline{r}=-.29$ respectively). Older children had spent longer in foster care but were not as likely to be chosen for the project. These variables account for a significant proportion of the group differences when considered separately but not when entered stepivise in a discriminant analysis (Time in foster care $(F(3,151)=7.66, \underline{p}<.01)$; Project case $(F(3,151)=4.31$, p $<.01)$.

None of the non-client measures account for a significant: percentage of the group differences.

The interrelationships of the sets as shown on Figure 6 point to the strongest association between client and service history measures. Clearly age, the relevant service history measure, and the client variables are more closely related to each other than either is related to the non-client set.

of the client measures, bonds to foster parents, overall placeability and mother bonds account for a significant part of the group differences no matter when they entered the analysis. Father barrier is significant only when entered first and second.

IS THE OUTCONE FOR TLEE CIILDD

FOSTER PARENT ADOPT OR NEVI PARENT ADOPT?

This is an analysis of tiwo of the outcome groups, those actually adopted by new parents and those adopted by foster parents, regardless of the likely outcome predicted by the caseliorker. In all, 63 percent of the variation between the two groups is accounted for in the analysis. 
TABLE XII

MEANS FOR VARIABLES SIGNIFICANT TO THE DECISION:

WHAT PLACEMENT IS MADE?

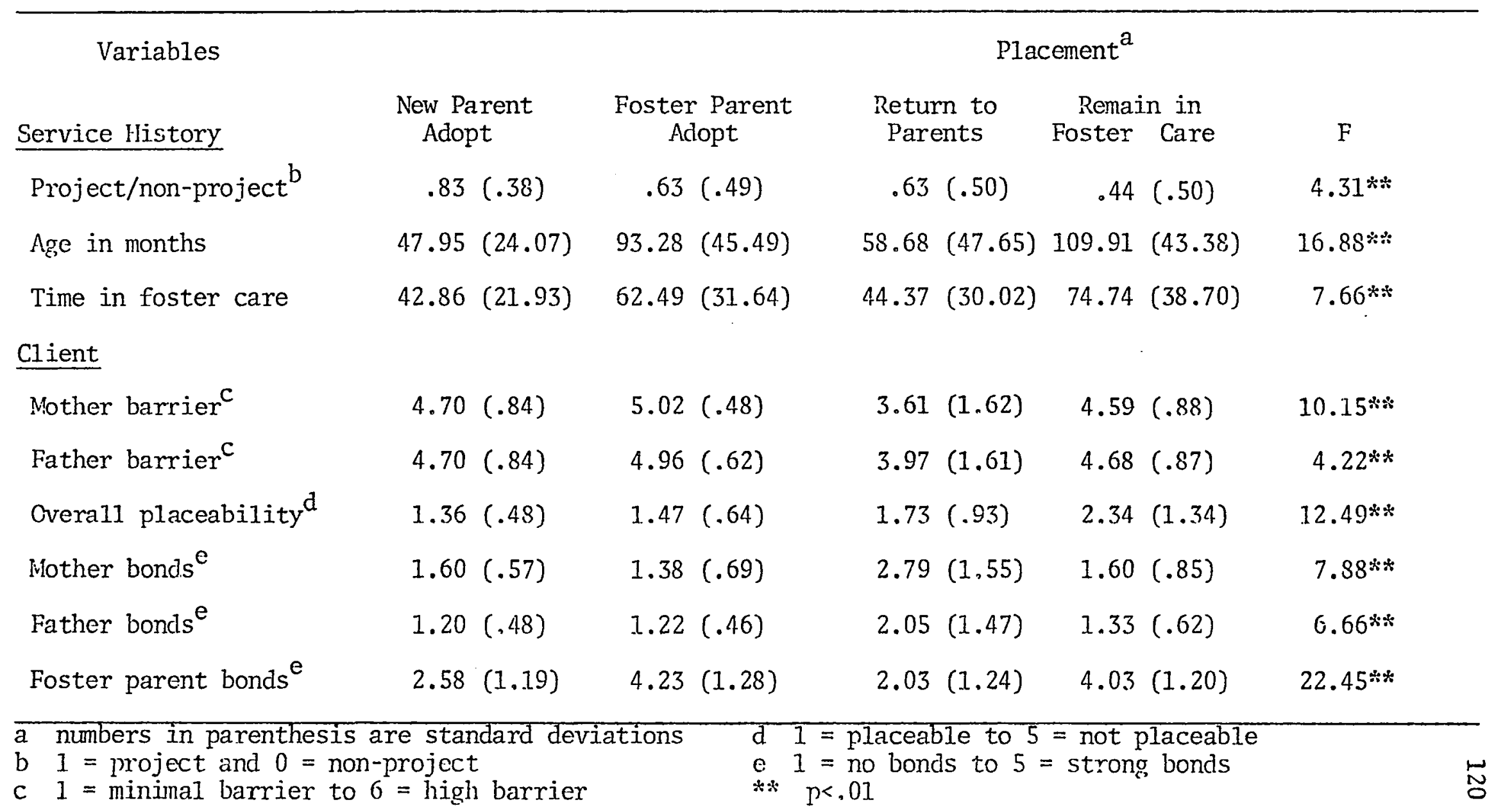


[I Client

[ Non-Client

Service History
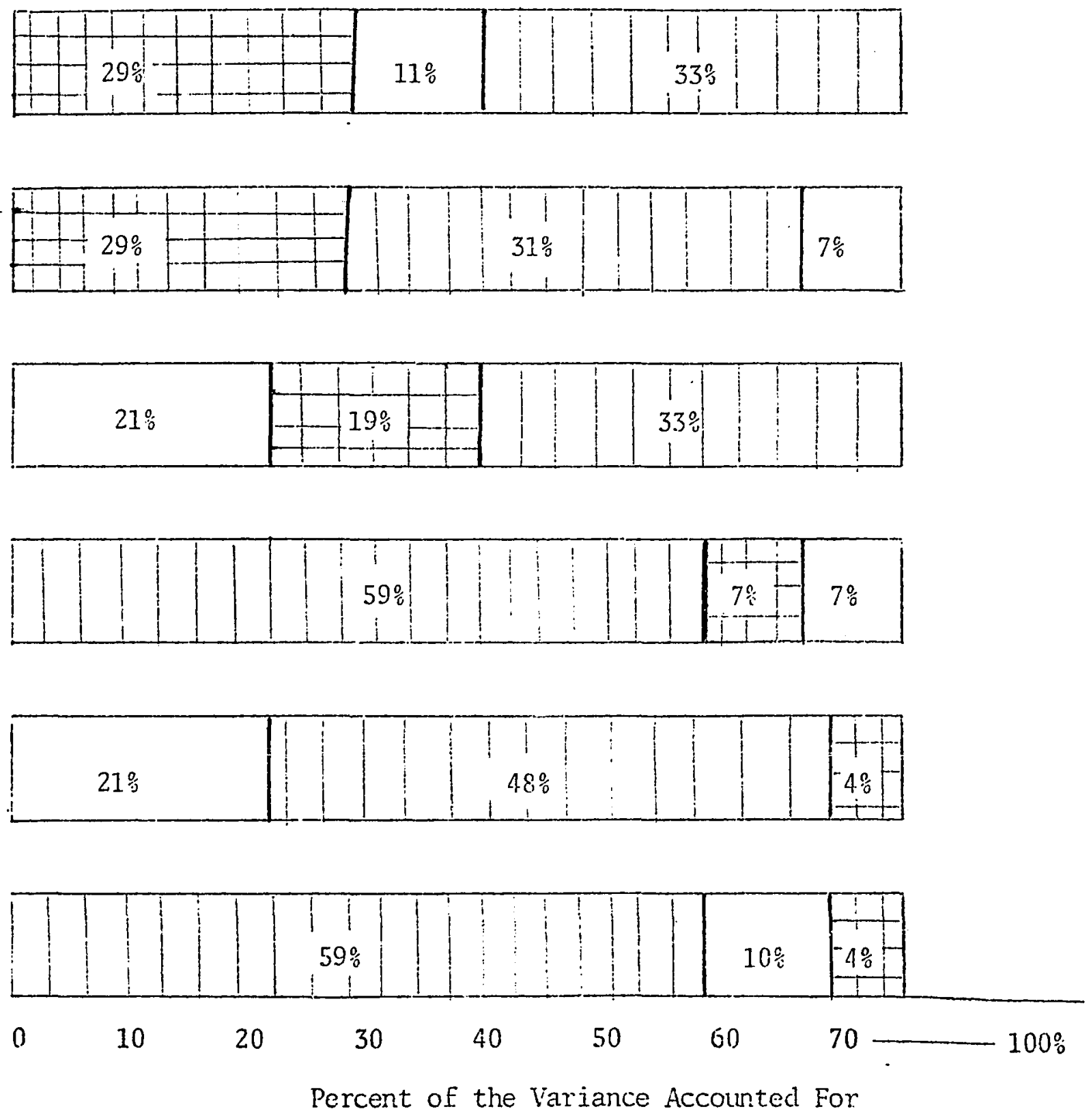

Figure 8. Discriminators (client, non-client and service history) of actual outcome for four grouns: adopted by new parents, acionted by foster parents, retumed to parents and remined in foster care. Variance accounted for as the sets entered in all possible orders. (Sets at the left of the Figure cntered first). 
The client set accounts for the largest part, 40 percent. Variables within the set which account for whether a child was adopted by foster parents or by new parents are bonds to foster parents $(F(1,62)=26.24$, $\underline{p}<.01)$ and overall placeability $(F(1,61)=4.47, \underline{p}<.05)$. Those adopted by foster parents had stronger bonds to those foster parents and were seen as less placeable than the group adopted by new parents. In the presence of stronger bonds a less placeable child could be adopted. Nother barrier accounts for a significant part of the variation only when the client set entered second after the non-cli.ent measures ( $F(1,52=4.74, \underline{p}<.05)$. For the foster parent adopt group the mother presented more of a obstacle to the child's return to her.

The next most important set is service history, accounting for 28 percent when entered in the analysis first. Age is the set's significant measure $(F(1,62)=20.32, \underline{p}<.01)$ with older children being adopted by foster parents. Time in foster care is signifj.cant: when considered separately $(F(1,62)=7.16, \underline{p}<.01$.$) but not when$ included stepwise in the discriminant analysis when it followed age, a variable to which it is correlated $(\underline{r}=.52)$.

The non-client set accounts for a small percent of the variation, 12 percent. County climate II, a generally negative attitude among caseworkers in the child's county, is the only significant measure in this set $(F(1,55)=4.70, \underline{p}<.05)$. This measure is significant only when the set entered after the client measures. Children from counties where caseworkers had a more negative attitude toward termination of parental rights were apt to be adopted by new parents rather 
than foster parents.

Figure 9, showing the relationship among the sets, illustrates that the relationship is stronger between client and service history than it is between either of these sets and the non-client measures. Of the client set, bonds to foster parents is significant no matter when it entered. Overall placeability accounts for a significant percentage of the group differences only when the set is entered first and second. No matter when the set entered, age is the significant service history measure.

\section{$\underline{\text { Discussion }}$}

In the two analyses on outcome, the same set, client measures, is most germane to understanding group differences. The child's relationship with his parents is important to the outcome, children who had strong bonds to their mother and a better relationship with their father were likely to retum to these parents or remain in foster care. If the parents were still involved with the child, he would stay in foster care or return to them. If not, adoption was more likel.y.

For both analyses age and bonds to foster parents are important, with older children tending to be adopted by foster parents or to remain in foster care. Placeability is a significant measure, with the children adopted by new parents having been judiged most placeable. The youngest children were adopted by parents new to them, and the oldest remained in foster care. The second oldest were adopted by foster parents. 
TABLE XIII

MEANS FOR VARIABLES SIGNIFICANT TO THE DECISION:

IS THE PLACEEANT ADOPTION BY FOSTER PARENTS

OR ADOPTION BŸ KEEV PARENTS?

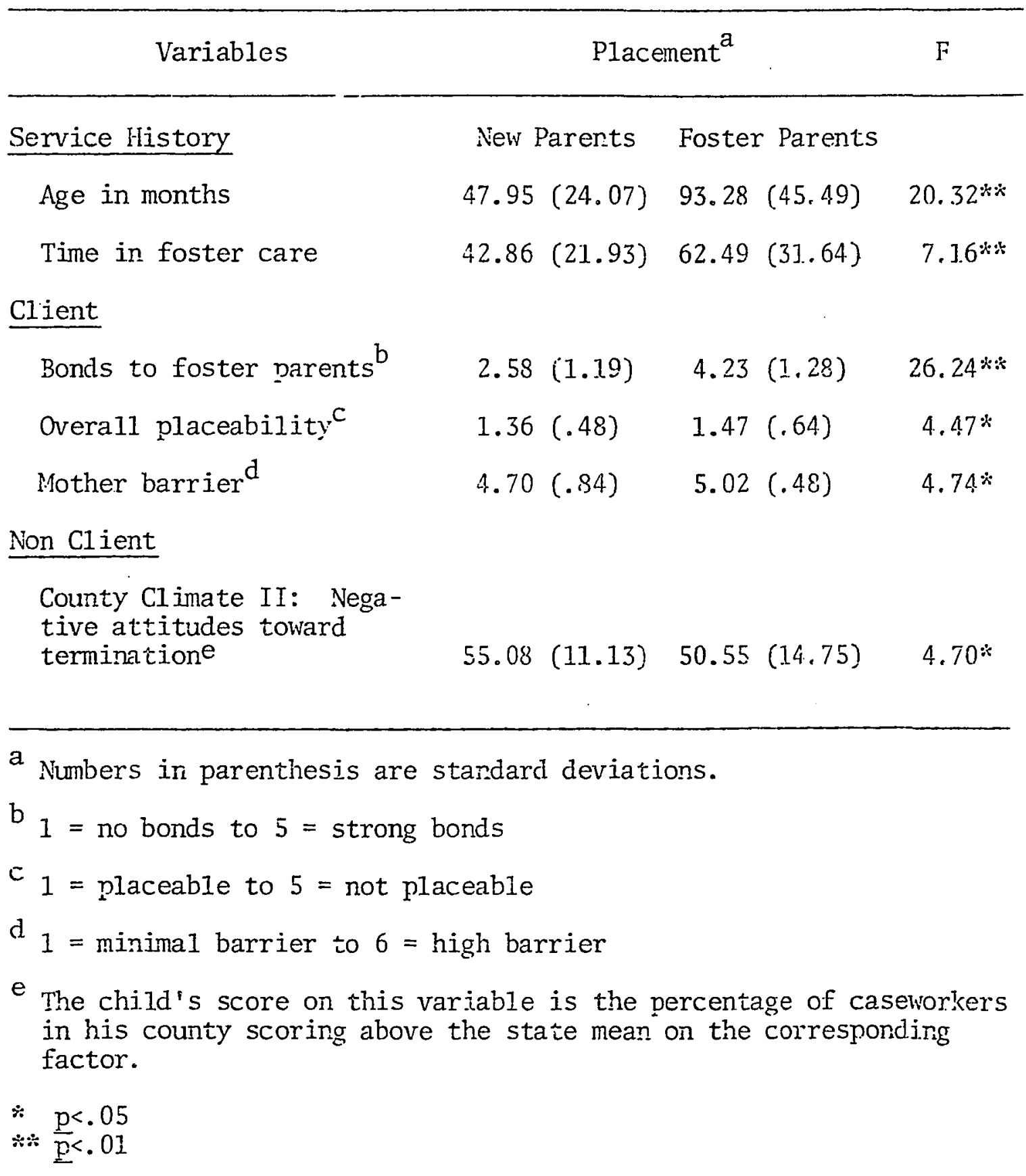


Clicht

$\square$ Non-Clisnt

Fi service llistory
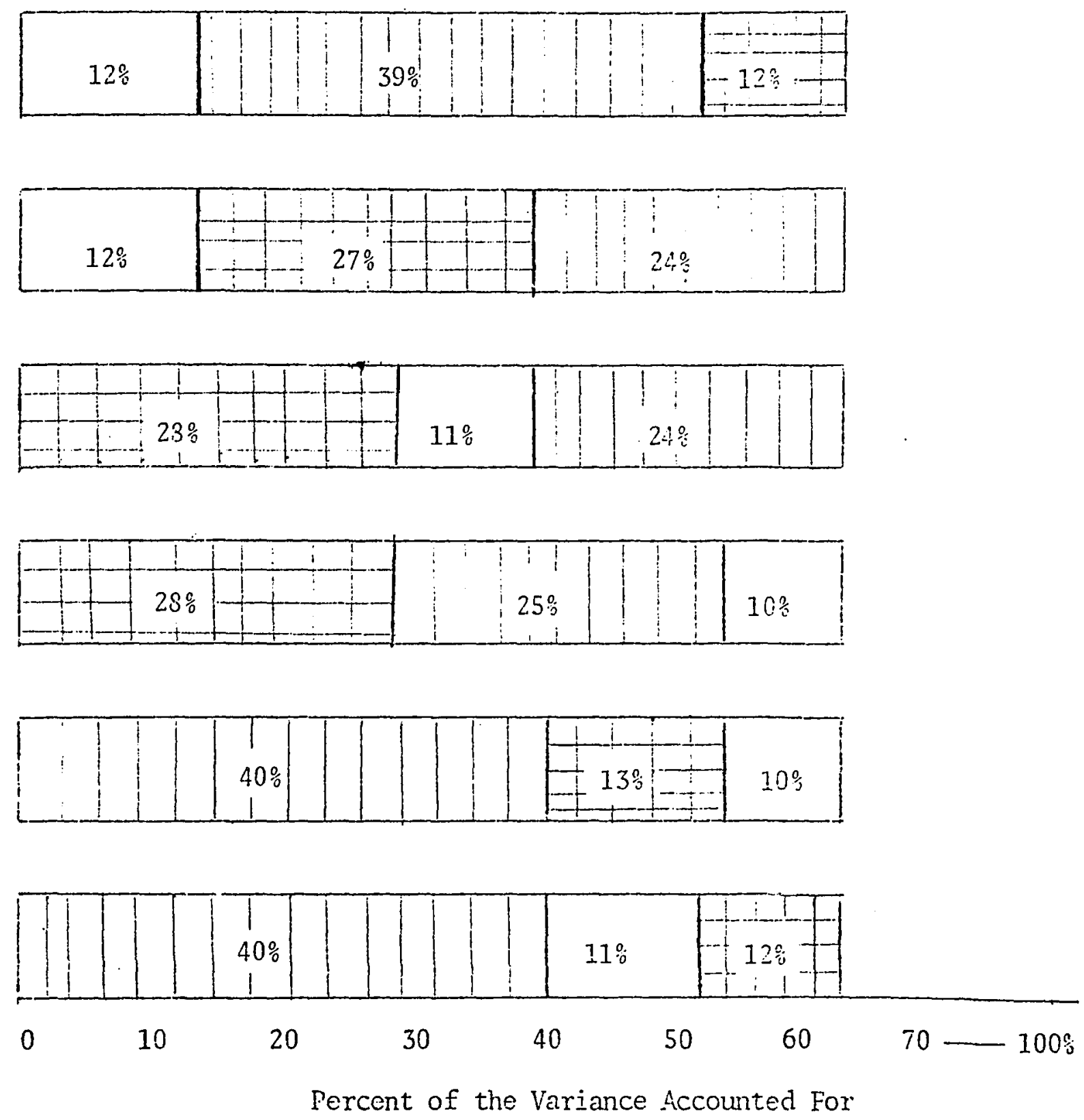

Figure 9. Discriminators (client, non-client and service history) of actual outcome for tiro grouns: adoption by foster parents and adoption by new parents. Variance accounted for as the sets entered in all possible orders. (Sets at the left of the Figure entered first). 


\section{CHAPTER VII}

\section{TIME}

Knowing how long it takes to accomplish the goal of adoption can be germane to deciding whether or not to begin. If this takes too Iong, some children can become unadoptable while efforts are made to achieve adoption. The older child is particularly vulnerable. He may be adoptable when efforts are initiated but if too much time lapses j.t may be impossible to locate parents willing to adopt a child his age. Time is important tu $\mathrm{J}$ for the prospective adoptive parents whose decision may, at least in part, be influenced by the time it might take.

The time dimension was investigated in terms of time to accomplish the goal and what measures account for the time it takes. Each child's status was followed for 28 months beginning with the time special attention was first focused on the case, that is, it was screened and a decision made as to its 1ikely outcome or it became a project case. Dates of key events were recorded and time was calculated to freedom from the first parent, then freedom from the second parent, and finally adoption. In Chapter $\mathrm{V}$ a group of children was described who returned to their parents. Even though this outcome is not directly related to addressing the questions asked by this study, data concerning it are included because this was an important outcome for the study sample. 
TABLE XIV

MEAN AND STANDARD DEVIATION OF TIME, TO REACH PLACEMENT

\begin{tabular}{lccl}
\hline Placement & Number & $\begin{array}{l}\text { Mean Time } \\
\text { in Months }\end{array}$ & $\begin{array}{l}\text { Standard } \\
\text { Deviation }\end{array}$ \\
\hline Foster Parent Adopt & 39 & 14.97 & 7.81 \\
New Parent Adopt & 23 & 12.39 & 6.80 \\
Return to Parent & 17 & 10.47 & 7.67 \\
\hline
\end{tabular}

Table XIV presents the results of the measurement of total time from beginning to the outcome for the three groups, foster parent adopt, new parent adopt and return to parents. The table pools all cases achieving each outcome regardless of how they were freed from their parents or the route taken to get there. The average time taken by each group is similar and there is large variability wi.thin the placements. An analysis of variance was done and no significant difference in time was found among the groups. Thus the cumulative effect of any variations in time taken to achieve the internediate goals is not different for the various outcomes. It took just as long to work with parents to have the child returned home as it did to obtain relinquishment or termination and place the child in an adoptive home.

Some differences can be seen in the time taken to reach decisions along the way (Table XV). It took significantly longer for termination of parental rights to be accomplished for those hacisd for adoption by new parents than for children likely to be adopted by fincter parents. 
TABLE XV

MEAN AND STANDARD DEVIATION TIME TO REACH PLACEMENT

BY IETHOD OF FREEING THE CHILD

\begin{tabular}{|c|c|c|c|c|c|c|c|}
\hline & \multicolumn{7}{|c|}{ PLACENENT } \\
\hline & \multicolumn{3}{|c|}{ Foster Parent Adopt } & \multicolumn{4}{|c|}{ New Parent Adopt } \\
\hline & Number & $\begin{array}{c}\text { Mean Number } \\
\text { of Nonths }\end{array}$ & $\begin{array}{r}\text { Standard } \\
\text { Deviation } \\
\end{array}$ & Number & $\begin{array}{c}\text { Mean Number } \\
\text { of Months }\end{array}$ & $\begin{array}{r}\text { Standard } \\
\text { Deviation } \\
\end{array}$ & $t$ \\
\hline \multicolumn{8}{|l|}{ Freedon from first parent } \\
\hline l'crmination & 22 & 3.32 & 7.30 & 24 & 11.25 & 6.95 & $1.74 *$ \\
\hline Relinquishment & 24 & 5.58 & 8.38 & 18 & 2.94 & 8.30 & \\
\hline \multicolumn{8}{|l|}{ Freedom from both parents } \\
\hline Relinquish-Relinquish & 9 & 9.78 & 7.14 & 7 & 3.71 & 9.18 & \\
\hline $\begin{array}{l}\text { Termination-Relinquish } \\
\text { or Relinquish-Termination }\end{array}$ & 8 & 8.00 & 7.84 & 9 & 8.33 & 8.35 & \\
\hline Termination-Tcrmination & 13 & 3.15 & 6.16 & 18 & 12.67 & 7.45 & $3.80 \div * 6$ \\
\hline
\end{tabular}


It took longer for the new parent adopt group to be freed by termination from the first parent and from the second parent.

To understand how this might have happened other data can be useful as well as a description of termination of parental rights process. Termination of parental rights is the legal action by which the court ends the parent-child relationship. This is the action taken when the court finds that the parents cannot care for the child and they do not voluntarily relinquish their rights as parents. Typicaljy this happens when parents are absent and cannot be located as wej.]. as jn cases where parents are actively contesting the court action. Termination of the parental rights of an absent parent is straightforward and can be accomplished in as little as 3 or 4 months. Among project cases when both parents were absent, freeing the child took 6 months and when both parents were available it took 13 months. For project cases at Jeast termination was faster if the parents had lost contact with the child.

Children headed for adoption by foster parents would be more likely to have absent parents or parents who did not actively contest the action than those headed for adoption by new parents. These children had been in foster care longer than the new parent adopt group allowing more time for the parent to disappear or lose interest.

On ratings of the child's bonds to his biological parents, those headed for adoption by foster parents averaged lower on the strength of the parent-child relationship. The child headed for foster parent adoption remained in foster care longer and had weaker ties to his parents. This implies a situation in which the parent was less interested in continuing a relationship with the child. In this situation 
the dissolution of the legal ties between parent and child was more quickly accomplished.

An indication that these foster parent adopt cases were seen as more straightforward, is that a smaller proportion of those seen as not likely to return home and adoptable were accepted for the project (Chapter V). The project took cases believed to be difficult to move through the network of decisions necessary. It appears that there were fewer of these difficult cases in the foster parent adopt sample. Project decision makers were correct in that it took a shorter time for the termination cases to achieve this goal but the total time taken was not different among placements.

In summary, termination of parental rights was more quickly accomplished for the foster parent adopt group and other evidence would lead one to expect that the rights of these biological parents could be more quickly terminated.

\section{ACCOUNIING FOR TIME}

Efforts to account for the time taken to achieve either of the outcomes of interest here were only moderately successful. A stepwise regression analysis was done for each of the two groups with tjme as the dependent variable and with the following predictors: mother bond, age of the child, foster care population in the county, county clinate I: court as a barrier to termination of parental rights and Factor VIII: time for a decision. Also of interest was the effect on time of whether or not a case was part of the project and the variable measuring the type of parental problem preventing the child's return home. The effects of these measures were analyzed by an analysis of variance and 
a test of mean differences. Measures included in analyses seeking to account for time were those which appeared from previous analyses.

In the regression analysis of the foster parent adont, the only significant measure is the foster care population. It has a negative correlation with time of -.43 and accounts for 18 percent of the variance in time. In counties where the foster care population was larger the time it took to become adopted by foster parents was less. Time is an inverse function of the county's foster care population. Foster care population was the only measure significantly correlated with time. The court as a barrier to termination, county climate I, was negatively correlated $\underline{r}=-.69$ with the foster care population but the correlation of this variable with time is not significant $r=.17$. More populous or urban counties tended to have courts which did not present a high barrier to termination of parental rights, but this was not related to the rapidity with which foster parent adoption might be accomplished. Somehow the acceptance of this newer placement option happened more quickly with fewer barriers in the more populous counties. The foster care population variable did not influence the new parent adopt group in the same way it did here as will be seen below.

Another variable associated with the time is whether or not the case was in the project. Project cases took significantly Ionger (mean 18.04 months) to become adopted by foster parents than did non-project cases (mean $=10.07$ months, $\underline{t}=3.53$ ).

None of the variables is significantly associated with time in the regression analysis of those children adopted by new parents. Once the decision had been made to move toward acoption neither the child's 
age, mother bonds, the factor score related to time for decision, nor the county climate score I: court barriers to termination within the county were associated with how fast the process was completed. AII these variables made a difference in discriminant analys is. The foster care population variable which is significantly associated with the time it took to implement the foster parent adopt decision is not relevant for new parent adopt $(\underline{r}=.04)$.

Children in the project took significantly longer to be adopted by new parents. Project cases took 14 months and non-project cases took six months $(t(2.1)=2.26 ; \underline{p}<.025)$. The project placed 19 children in adoptive homes with new parents whereas the non-project groun consisted of four cases.

\section{DISCUSSION}

To summarize, from the analyses of time it can be seen that both adoption and returning the child to his parents took about a year. Also it appears that the parental rights of parents who had lost contact with their children were terminated more quickly. Efforts to account for the time to attain adoption resulted in identifying project cases as taking longer. Children adopted by foster parents were likely to achieve the goal more quickly if they lived in more populous counties. 


\section{CHAPTER VIII}

\section{CONCLUSIONS AND POLICY CONSIDERATIONS}

This study evaluates a relatively new policy -- adoption by foster parents. The study concludes that adoption of foster children by their foster parents has been shown to be a viable option jn permanent planning for children in foster: care. Compared to adoption by new parents j.t can be accomplished for as many of the children, as qui.ck].y and wi.th no serious negative consequences. Perhaps the greatest strength of adoption by foster parents lies in the fact that it permits the adoption of children who might not be placeable otherwise -- the older, harder-toplace child.

\section{NUMBERS ADOPTED}

Efforts to find a permanent home for children seen as needing adoption by foster parents were as successful as for those headed for adoption by new parents. Approximately the same proportion of children were adopted by foster parents as were adopted by parents new to them. Since the home was already available for children adopted by foster: parents it seemed likely that more adoptions would be accomplj.shed in this group. Certainly the new option is no more risly and so from this standpoint it is a good policy alternative.

Though the number achieving adoption was not different between groups almost half of the children in both groups remained in foster care, though other placements had been predicted for them. It is 
possible that some remained in foster care because it was the best plan for them, but there are indications that some others stayed for reasons not associated with what was in their best interests or the best interests of their parents. The oldest, those in foster care the longest, and least placeable children remained in foster care. For them there were no options for exit. These characteristics are not related to how badly a child needed a permanent home but to the chances of locating a family willing to accept such a child.

From these results it appears that the best chance a child has of leaving foster care is if he leaves soon after entry. This requires intensive efforts to find the most appropriate placement from the day of entry into the system. Cases in this study had been in foster care a year or more before caseworkers were asked to indicate likely outcome. For some, the possibility of exit from foster care seems to have been blocked because they had been in so long. If, at entry into foster care a placement goal was set up, revised later if necessary, and intensive efforts made to achieve this outcome, then reducing the time in foster care would be more 1ilely. A method of monitoring these efforts is suggested in the next section.

Judging from the success of the project in placing more children in permanent plans than were placed outside the project, we must conclude that the goal setting, close monitoring, and special effort pay off. The project chose more difficult cases but managed to more more of them out of foster care. 
TIPSE

From the standpoint of time, foster parent adoption measures up well to adoption by new parents. It took approxinately one year to achieve adoption and the groups were not different. It is difficult to say how long the process should take but in the interests of the child, his potential adoptive parents and even his parents, it shoujd be made as efficient as possible.

There was wide variability in the time it took to reach adoption. It is likely that this can be attributed largely to differences in the ease or difficulty of freeing a child from his parents. If parents are involved with the child yet cannot make the changes necessary to pemit his return to their care, then the time to complete an adoption is longer. Whether a case is intrinsically short or long, giving service provides due process safeguards of the rights of parents. Providing due process and services to parents takes a certain amount of time and this process must run its full course. Yet delays occur which serve no useful purpose in resolving the case. In the results of this study such delays can be seen. In Polk County the court delayed case resolution because of one judge's aversion to the idea of termination of parental rights. Cases headed for foster parent adoption in Jess populous counties took longer than those in the more urban counties for reasons that are not clear but could not have been related to the case itself. Agency policy should be directed torard the elimination of umnecessary delay while at the same time guaranteeing a full exploration cf the possibility of the child returning to his parents. 
While adoption by foster parents can be accomplished as quickly as adoption by new parents, there is evidence that unnecessary delays occur in both. In view of the many opportunities for delays a policy for periodic review of every foster care case seems advisable. Such a process would permit a group outside those most closely involved in the case to go over case plans and progress and evaluate the efforts made to secure a. permanent plan and perhaps offer directjon to facilitate case resolution. Whether the court, the agency, or a citizen group conducted the review, it could provide some assurance that appropriate service is being offered without inappropriate delay.

The lack of this kind of monitoring is evident from the effort to define decisions made for all cases as they move toward adoption. A striking finding is that few decisions were made for all cases. By reading the case studies it can be seen that many judgments were made but the number made and the manner in which they were made varies with the case, the caseworker and the county. The agency did not demand that certain decisions be made for all cases. Those made were mandated by the court: freeing the child from his parents and adoption. Strict1y speaking, even these decisions were not made for every case. Some children were adopted after having been freed from only one parent and without having been freed from the second. In view of the importance of these decisions it is unfortunate that no system was in place to assure that they were made and were in the best interests of the child and his parents. 
WHO IS ADOPTED

Clearly the characteristics of the children adopted by foster parents differ from those of the children adopted by new parents. The former were older, had been in foster care longer, and consjdered less placeable. As a permanent planning option, adoption by foster parents taps a population not easily placed in the other options available, return to parents or adoption by new parents. As a child grows oider and remains in foster care longer his ties to parents become weaker and the option of returning to them is more remote. Parents who seek to adopt through the traditional adoption route usually seek as young a child as possible and one with few problems. Somehow, perhaps because of a deep emotional tie which develops as the child lives in a foster home, these qualities are not critical to adoption by foster parents. This is an important value of adoption by foster parents as a policy alternative. It is a resource for those not likely to be placed in any other way. Variables which influenced decisions made prior to the final outcone were similar to those influencing the final outcome. One difference is in the importance of the non-client measures which should not have been relevant. Although these variables were not gemane to the final decision, they did influence decisions prior to the final one. Non-client measures were most influential in choosing project cases in both the new parent adopt and the foster parent adopt groups. Once the child's caseworker indicated that adoption was likely, the project staff chose cases handled by workers who did not have a negative attitude toward termination of parental rights and were comfortable with 
the idea.

In addition to influencing whether or not a case was accepted for the project, certain non-client measures influence other decisions. They are predictive of the caseworker decision about whether adoption was likely by foster parents or new parents and with the decision as to whether or not the adoption was pursued. Two non-client measures effect the caseworker decision as to who was likely to adopt. Caseworkers who had a negative attitude toward termination of parental rights tended to say foster parents were likely to adopt. Counties in which workers as a group indicated a wijllingness to proceed with termination of parental rights even though an adoptive home might not be available tended to predict that the child would be adopted by foster parents. The foster. home is a readily available resource and the new adoptive home must be located once the child is freed. It appears that among workers for whom the idea of termination is somewhat more aversive and there is a willingness to risk not finding an adoptive home, foster parent adoption could be accepted.

Whether or not adoption was pursued, that is whether the child was freed from at least one parent, was accounised for in part by the measure "time for a decision." If the caseworker saw himself as having time for a decision, adoption was likely to be purused. This attitude held by caseworkers was predictive of whether the relationship of a child and his parent was legally. permanently dissolved. For the new parent adopt group only the county climate time for decision was significant but for foster parent adoptions both county climate and caseworker's attitude of having time for a decision were significant. 
Adoption was more likely to be pursued if caseworkers could accept the idea of termination of parental rights and had time to become involved.

Generally caseworkers who were more reluctant to get involved in termination of parental rights made decisions which favored foster parent adoption. Decisions were influenced by attitudes. The importance of these non-client measures in accounting for decisions made about a child points again to a need for closer consultation, monitoring, and case review so that decisions are made based on the needs of the child and his parents and not on attitudes of the caseworker.

\section{LEGAL SAFEGUARDS FOR PARENTAL RIGHTS}

The soundness of foster parent adoptions as a policy depends on the existence of adequate legal safeguards for parental rights. The best interests of the child as a doctrine provides insufficient reason to transfer rights from parents to others. Oregon's statute providing for termination of parental rights requires court determination on the basis of specific grounds and does provide the due process safeguards necessary for foster parent adoption to be a sound family and child welfare'policy. (O.R.S. 419.523)

Guaranteeing that the rights of parents are fairly dealt with is not entirely in the hands of the social service agency. Agency adoption can not take place until the child is legally free from his parents. Preceding adoption a thorough exploration of the ability and interest on the part of parents to care for the child must be macie. The Oregon statute permitting the termination of narental rights points to three legitinate reasons for taking this action. The 
parents have (1) abandoned or deserted the child which means that they have not contacted him for a specified period; (2) exhibited conduct detrimental to the child and have failed to adjust the circumstances of their life to permit his return; (3) a diagnosed condition preventing the child's return such as mental illness or deficiency. If one of these three situations cannot be established to the satisfaction of the court, then the child is not free to be adopted by anyone.

\section{UNEXPECTED RESULTS}

An unanticipated result for this sample believed headed for adoption was that 11 percent of the sample returned to their parents though the criterion for inclusion in this study was that the child seemed unlikely to return home and was adoptable. Given the value held by our society that a child belongs with his parents if this is at all possible, the first effort must always be to return a child to his parents. The case studies have described the kind of effort made to return the child home. The data indicate that some success was achieved in reaching this goal even for those for whom this was seen least likely.

Another unanticipated finding relevant to both study groups is that 25 children were legally free from their parents but were not adopted. The foster parent. adopt and new parent adopt groups did not differ in the proportion who were freed but not adopted. Clearly the intent was to place these children in adoptive homes. Inile it is possible that some will be placed sometime after the 28 -month period covered by this study, this situation appears to point to the need for more efficient adoptive home finding. Most of the children in this study 
were older than the child typically adopted in the past, had been in several different homes and thus would be labeled hard-to-place. Those remaining in foster care at the end of this study were older and had been in foster care longer than any of the permanently placed groups. While many parents who have traditionally sought to adopt might shy away from these children, innovative programs across the country are managing to locate parents who are willing to adopt the hard-to-place (Unger et al., 1977). Through extensive recruitment of adoptive homes, willingness to risk a failed adoption, and through the development of procedures for successfully re-placing the child from a failed placement into a new adoptive home, the successful adoption of these children has been increased. A closer look at reasons children were freed but not placed would indicate the extent to which such special placement programs would be useful in Oregon. Presumably the goal would be to provide an adoptive home for all children who cannot live with their parents and the availability of the option should not be limited by the characteristics of the child.

\section{OTHER CONSIDERATIONS}

The study done here and reported thus far does not evaluate the real output of the policy completely. A complete assessment would include a look at the cost of the policy, the psychological effects on the child and family of both the process and placement, and the way policy effects other related policies and agency activities. Some information is available from other sources which helps address these issues. 
The effects on the adjustment of the child of being adopted by foster parents (Lahti st al., 1977) discussed more fully in Chapter II, appear to be positive and no different in social adjustment from those of children being adopted by new parents. Adoptions completed are as stable and the child appears to be as well off in a foster parent adopt situation.

While it is not the purpose here to present a complete cost analysis, some relevant data are available from an analysis done for the project. The results of this analysis was that in three years all project costs had been defrayed by savings made by moving chi.].dren out of foster care (Emlen et al., 1977).

One way agency policy can affect adoption by foster parents is if the foster care population changes. The availability of the children for adoption by foster parents depends at least in part on the failure to recognize that foster care is not performing a function for which it was designed. Presumably if foster care is a temporary placement and planning for a permanent placement is started inmediatejy upon the child's entry into care, then fewer children would remain in a foster home so long that adoption by those parents would become the only viable ontion for permanent placement. While the number of children available for adoption by foster parents may vary, it is likely that situations will always exist in which this policy will be in the best interest of the child.

Foster parent adoption policy can effect related policies in that it could decrease the numbers of children adopted by parents new to them. If foster parents frequently take children with the hope of 
adoption, this can reduce the number of children and families available through the traditional adoption channe1s. Though the policy clearly states that this should not happen, it does happen. Results presented in the Follow-up Study of the Oregon Project (Lahti et al., 1977) indicate that 22 percent of the foster parents who adopted saw the placement as permanent from the time the child came to live with them. A case study describes how this happened in one situatjon.

\section{CONCLUSIONS}

Considering the results of this study and the resul.ts of other studies, the idea of adoption by foster parents is concluded to be a sound option. When the child's parents cannot care for him and the child has develoned an emotional attachment to foster parents, a satisfactory permanent home can be found with then. This permits the placement of children less likely otherrise to find a home. The use of this option could be extended as a way of seeking homes for other children who might not otherwise be placeable. If in certain situations with adequate legal safeguards, a child was placed in a home with the recognition on the part of both parencs and agency that adoption was a likely outcome, the use of this type of placement could be expanded to find homes for the hard-to-place. This would require a revision of the policy permitting foster parents to adopt.

By the tine data collection for this study was begun, Oregon's child welfare agency had instituted a policy permitting foster parents to adopt. From a policy of forbidding adontion by foster parents, this change permitted it under certain circumstances. This stated policy was 
that if foster parents wished to adopt and "if this seems a good plan, the caseworker should spell out in the child's summary under 'Type of Home Needed' giving the reasons why this is or is not in the child's best interest" (Note 4). If agreement was reached that adoption was in the best interest of the child, and grounds for termination of parental rights clearly documented, the final decree could be issued in approximately six months. By the time the study was nearing its end in December, 1975, an elaboration of the procedures and conditions had been developed (Appendix). Criteria presented in this later policy statement closely approximate those for adoption by new parents -- that is adoptive parents must be able to show that they can provide a good permanent home for the child. One additional criterion was set for foster parents wanting to adopt which is not and cannot be required of new parents. It is that the child must have been in the home long enough so that those in charge of the adoption could be sure that a good adjustment has been made and an emotional attachment developed.

The important distinction between foster care as a temporary placement and adoption as legally permanent is stressed in the policy statement. At the onset of placement, the foster parents must understand that the placement is temporary and work with the agency in developing an appropriate home for the child. Some foster care placements do become an appropriate home for the child. Some foster care placements do become candidates for adoption, but only later when the child is legally free, has developed a relationship with the foster parents, and the agency has decided that this is in the best interests of the child. 
The new policy, then, does not change the conditions of a child's entry into a foster care home nor the understanding and behavior expected of families who have a foster child in their care. What has been changed is that foster parents can adopt if subsequent events transpire in such a way that adoption is desirable.

If a formal procedure could be developed by which a fanily and child could test their ability to form a relationship before adoption, it is possible that homes could be found for more cinildren particularly those who arc hard-to-place. If a pool of families interested in adopting and willing to take a foster child could be developed, then children seen as likely to be available for adoption could be placed in their care. This could provide a way of tal:ing adrantage of the attraction between parents and children which sometimes results in development of strong ties. 


\section{REFERENCES CITED}

Addis, R.S., Salzberger, F., \& Rab1, E, A survey based on adoption caserecords. London: National Asscciation for Mental Health, 1954.

Aldridge, D.P. Problems and approaches to black adoptions. The Family Coordinator, 1974, 23(4), 407-410.

American Public Welfare Association. Standards for foster family services with guidelines for implementation specifically related to public agencies. Washington, D.C.: Author, 1975.

Andrews, R.G. When is subsidized adoption preferable to long-term foster care? Child Welfare, 1971, 50(4), 194-200.

Babcock, C.G. Some psychodynamic factors in foster parenthood - Part I. Child Welfare, 1965, 44(9), 485-493.

Bell, V. Special considerations in the adoption of the older child. Social Casework, 1959, 40(6), 327-334.

Bohman, M. Adopted children and their families. A follow-up study of adopted children, their background, environment and adjustment. Stockholm: Proprueis, 1970.

Borgatta, E.F., \& Fanshe1, D. Behavioral characteristics of children known to psychiatric outoatient clinics. New York: Child We1fare League of America, Inc., 1965.

Bremner, R.H. Children and youth in America: A documentary history (VoI. 1). Cambridge, Mass: Harvard Liniversity Press, 1970.

Brenner, R. A follow-up study of adoptive families. New York: Child Adoption Research Committee, 1951.

Brieland, D. Children and families: A forecast. Social Work, 1974 , $19(5), 568-579$.

Cautley, P, \& Aldridge, M. Predicting success for new foster parents. Social Work, 1975, 20(1.), 48-52.

Caut1ey, P., Aldridge, M., \& Finifter, B. Successful foster homes: An exploratory study of their characteristics. Wisconsin Dept. of Public Welfare, Jume 1966.

Chema, R., Farley, L., Oakley, F., \& O'Brien, ‥ Adoptive placement of the older child. Child Nelfare, 1970, $49(8), 450-458$. 
Child and Fanily Services of New Hampshire. Reaching out as family advocates. Third summary report of family advocacy program. Manchester: Author, 1972。

Child Welfare League of America, Inc. Child Welfare League of America standards for adoption service: Revised. New York: Author, 1973.

Elonen, A.S., \& Schwartz, E.M. A longitudinal study of emotional, social, and academic functioning of adopted children. Child Wej.fare, $1969, \underline{48}(2), 72-78$.

Fmlen, A. Barriers to planning for children in foster care. Portiand, Ore: Regional Research Institute for Human Services, 1976.

Emlen, A.., Lahti, J., Downs, G., MCKay, A., \& Downs, S. Overcoming barriers to planning for children in foster care. Portland, Ore: Regional Research Institute for Human Services, 1977.

Faj.rweather, M.E. Early placement in adoption. Chi.J WeJfare, J.952, 31( $(3), 3-8$.

Falk, L.L. A comparative study of transracial and inracial adoptions. Child Welfare, $1970, \underline{49}(2), 82-88$.

Fanshe1, D. A study in negro adoptions. New York: Child Welfare League of America, Inc., 1957.

Fanshel, D. Foster parenthood: A role analysis. Finneapolis: University of Minnesota Press, 1966.

Farishel, D. Far from the reservation. Metachen, NJ: The Scarecrow Press, Inc., 1972.

Farshe1, D. \& Shinn, E. Children in foster care: A Iongitudinal investigation. New York: Columbia University Press, 1978.

Gentile, A. Subsidized adoption in New York: How law works--and some problems. Child Welfare, 1970, 49(10), 576-580.

Gi11, M. The foster care/adoptive family: Adoption for children not Iegally free. Child Welfare, 1975 , 54(10), 712-720.

Glickman, E. Child placement through clinically oriented casework. New York: Columbia University Press, 1957.

Goldstein, J., Freud, A., \& Solnit, A.J. Beyond the best interests of the child. New York: The Free Press, 1974.

Hegarty, C.M. The family resources program: One coin, two sides of adoption and foster family care. Child Welfare, 1973, 52(2), 91-99. 
Herzog, E., Sudia, C., Harwood, J., \& Newcomb, C. Families for black children: The search for adoptive parents. Washington, D.C.: DHEW, Office of Child Development, Children's Bureau, 1971.

Jacobson, E., \& Cockerum, J. As foster children see it: Former foster children talk about foster family care. Children Today, 1976, $\underline{5}(6), 32-36$.

Jaffee, B., \& Fanshe1, D. How they fared in adoption. New York: Co1umbia University Press, 1970.

Jenkins, S. Duration of foster care: Some relevant antecedent variables. Child Welfare, 1969, 48, 440-455.

Kadushin, A. Adopting older children. New York: Columbia University Press, 1970. (a)

Kadushin, A. Single parent aduptions. An overview and some relevant research. Social Service Review, 1970, 44(3), 263-274. (b)

Kadushin, A. Child welfare services (2nd ed.). New York: Macmillan, 1974.

Kraus, J. Predicting success of foster placements for school age children. Social Work, 1971, 16(1), 63-72.

Lahti, J., Green, K., Emlen, A., Zadny, J., Clarkson, O.D., Kuehne1, M., \& Casciato, J. A follow-up study of the Oregon project. Portland, Ore: Regional Research Institute for Human Services, 1978.

Lawder, E.A., Lower, K.D., Andrews, R.G., Sherman, E.A., \& Hill, J.G. A follow-up of adoptions: Post-placement functioning of adoption families. New York: Child lielfare League of America, Inc. 1969.

MCCoy, J. Identity as a factor in the adoptive placement of the older child. Child Welfare, 1961, 40(7), 14-18.

Maas, H.S. The successful adoptive parent applicants. Social Work, $1960, \underline{5}(11), 14-20$.

Maas, H.S. Children in long-term foster care. Child Welfare, 1969, $\underline{48}(6), 321-333$.

Maas, H.S., \& Engler, R.E., Jr. Children in need of parents. New York: Columbia University Press, 1959.

Mande11, B.R. Where are the children? Toronto: Lexington Books, 1973.

Meier, E.G. Current circumstances of former foster children. Child Welfare, 1965, 44(6), 207-213. 
Neely, A.J. Adoption by foster parents. Child Welfare, 1969, 48(3), $163-164$.

Neilson, J. Tayari: Black homes for black children. Child Welfare, 1976, 55 (1), 41-50.

Oregon Revised Statutes. 109.041 (1).

Oregon Revised Statutes. 419.523.

Paulson, M., \& Grossman, S. Child-rearing attitudes of foster home mothers. Journal of Community Psychology, 1974, 20(1), 11-14.

Petersen, J., \& Pierce, A.D. Socioeconomic characteristics of foster parents. Child Welfare, 1974, 53(5), 295-304.

Pringle, M.L., \& Bossive, F. Early prolonged separation and emotional maladjustment. Child Psychology and Psychiatry, 1965, 1, 37-48.

Rein, M., Nutt, T., \& Weiss, H. Foster family care: Myth and reality. In A. Schorr (Ed.), Children and decent people. London: George Allen and Unvin Ltd., 1974.

Roe, A., \& Burks, B. Adult adjustment of foster children of alcoholic and psychotic parentage and the influence of the foster home. Memoirs of the Section on Alcohol Studies, 1945, 3.

Rutter, M. Parent-child separation: Psychological effects on the children. Journal of Child Psychology and Psychiatry, 1971, 12. 233-260。

Seglow, J., Pringle, M.K. , \& Wedge, P. Growing up adopted. England and Wales: National Foundation for Educational Research, 1972.

Shireman, J.F., \& Johnson, P.R. Single persons as adoptive parents. Social Service Review, 1976, 50(1), 1.03-116.

Shireman, J.F., \& Watson, K. Adoption of real children. Social Work, $1972, \underline{17}(7), 29-38$.

Skodak, M., \& Skeels, H.M. A follow-up study of children in adoptive homes. Journal of Genetic Psychology, 1945, 66, 21-58.

Skodak, M., \& Skeels, H.M. A follow-up study of 100 adopted children. Journal of Genetic Psychology, 1949, 프, 85-125.

Smith v. Organization of Foster Families for Equality and Reform, $97 \mathrm{~S}$. Ct. 2094 (1977).

Stanley v. Illinois, 405 U.S. 645 (1972).

State v. Jamison, 251 Or. 114, 444 P.2d.15 (1968). 
Stephenson, P.S. The emotional implications of adoption policy. Comprehensive Psychiatry, 1975, 16(4), 363-367.

Stone, H.D. Reflections on foster care: A report of a national survey of attitudes and practices. New York: Child Welfare League of America, Inc., 1969.

Tizard, B., \& Rees, J. A coinparison of the effects of adoptions, restoration to the natural mother, and continued insticutionalization on the cognitive development of four-year-old children. Child Development, 1974, 45(1), 92-99.

Triseliotis, J. In search of origins: The experiences of adopted people. London: loutledge \& Kegan, 1973.

Lnger, C., Dwarshuis, D., \& Johnson, E. Chaos, madness, and unpredictability... Placing the child with ears like Uncle Harry's (The Spaulding approach to adoption). Chelsea, Michigan: Spaulding for Children, 1977 .

United States Department of Health, Education and Welfare, Office of Human Development. Model State Subsidized Adoption Act and regulacions. (DHEN Publication No. OHD-76-30010). Washington, D.C.: Author, 1976.

Watson, K. Subsidized adoption: A crucial investment. Child Welfare, 1972, 51 (4), 220-230.

Witmer, H., Herzog, E., Weinstein, E., \& Sullivan, M.E. Independent adoptions: A follow-up study. New York: Russel.J. Sage Foundation, 1963.

Wolins, M. Selecting foster parents. New York: Columbia Lniversity Press, 1963. 


\section{REFERENCE NOTES}

1) Pike, V. Personal communication, October 5, 1977.

2) Pargeter, J. Personal communication, November 15, 1977.

3) Children's Services Division. Social services for children and families with children. Out of print, monthly publication. State of Oregon, Department of Human. Resources, 1.973.

4) Children's Services Division. Oregon CSD Staff ilanual. Unpublished. 1973. 
APPERDIX

OREGOIN CHILDREN'S SERVICES IIVISION

POLICY ON ADOPTION BY FOSTER PARENTS

\author{
Effective: December 1, 1975 Title: DNISION POLICY \\ Family Services Sec. \\ Expires: $\quad$ Author: Barbara Spencer \\ T0: All State Staff, Regional N!anagers, \\ Supervisors and Caseworkers \\ SUBJECT: $\quad$ Policy on Adoption by Foster Parents \\ CBSOLEFIE NIATERIAL: :None
}

Discussion

Adoption and foster care are two distinct services provided for children invclving different relationships and responsibilities. It must be kept in mind that from its onset foster care is temporary by nature whereas adontion is pemanent and uitimately results in a permanent legal relationship between chi]d and parents. To fail to delineate the temporary nature of foster care and the permanent nature of adoption at the onset and during the course of a foster home placement is unfair to child, natural parents and foster parents. Foster narents who accept a child with adoption in mind nomally cannot share the child with the agency and natural parents, and sharing is essential if the agency is to plan appropriately for the child. Under no circumstances should a child be placed in foster care with the foster parents being led to believe adoption by then may be possible, with the exception of foster-adopt situations which are only to be planned through the Adop- 
tion Unit. While we must recognize some foster home placements do appropriately become adoptive planning, this decision can only be made at a later date when the child has been in the foster home for a period of time and (1) the child is legally free for adoption or could readily be legally freed, (2) a relationship and comitment betiveen child and foster parents has developed, (3) the agency has thoroughly considered the situation and a decision has been made.

\section{POLICY STATEMENT}

When it appears a child will not be returning to his own home and other permanent plans are being considered and the foster parents express interest in adopting, their interest should imnediately be evaluated along with other permanent planning options. This will need to be done on a case-by-case basis considering at all. times the best interest of the child. An early agency decision as to the suitability of acioption by the foster parents should be made on a local levei utilizing the knowledge of casework, supervisory, aministrative staff, other disciplines as indicated, and with consultation from the manager of the Adoption Unit of Central Office, if necessary. Under no circumstances should this decision be made by one individual.

CRITERIA FOR CONSIDERING FOSTER PARENTS' INTEREST IN ADOPTION

1. The child is legally free for adoption or can be readily freed.

2. The child has been in the foster home for a sufficient period of time to establish that a good adjustment has been made, that a solid emotional attachnent is developing betreen child and foster parents which would make acceptance of another 
family difficult for the child, the foster parents have made a commitment to the child; or, if the child by virtue of age and extended length of time in the foster home would not be able to accept another home, keeping in mind that length of stay in itself does not constitute an inability for the child to move.

3. Foster parents have demonstrated good parenting ability and are capable of meeting the child's needs now and as he grows older.

4. Both foster parents are highly motivated toward making this a permanent relationship.

5. Foster parents' ages are appropriate to the age of the child. The general guideline should be that the foster parents should be no older than 60 when the child reaches 21 .

6. Foster parents have no known handicapping physical condition which predictably may reduce their life expectancy.

7. Foster parents can realistically assume financial responsibility for the child. No family will be excluded because of income alone.

8. The child is emotionally or physically handicapped and foster parents have demonstrated an ability to accept and deal with child's problems.

9. The foster parents are capable of protecting the child from natural parents' interference, should this occur. 
10. Consultation with the manager of the Adoption Unit has established no other adoptive home is currently available that could better meet the child's needs.

The above criteria must be considered in combination as no single criterion is sufficient to base a decision upon. Criterion (3) must be established in all cases.

PROCEDURE

While procedure needs to be flexible and leave room for individual regional differences, it must include certain basic elements:

1. Early identification by the social service worker of adoptable children and of their foster parents who appear an appropriate resource to be explored.

2. As soon as it appears adoption may be possible and the foster parents express an interes 1 in adopting, the case must be reviewed by the social service worker and supervisor.

3. If an adoption request by foster parents is being evaluated by social service worker and supervisor, a staff meeting should be held including the child's social service worker, supervisor, regional adoption worker and foster home certification worker, branch manager or his designee, and other disciplines when appropriate.

The purpose of this staffing is to establish:

a. Adoption is an appropriate plan to consider for the child. 
b. The child is legally free for adoption or can be freed quickly.

c. Evaluation or analysis of the circumstances that give rise to consideration of the foster home as an adoption resource.

d. Evaluation of the strengths and weaknesses in the foster home for the particular child as well as motivation of both foster parents.

4. A decision should be made as to the direction in planning, who will carry out the decision and in what time frame. The decisions and its reasons must be documented in the case record.

5. If the child is legally free and the decision is that the foster parents should adopt, the decision will be documented and referred to the manager of the Adoption Unit in Centrai Office who will ascertain that all areas needing consideration have been covered and will then refer the foster parents to an adoption worker who will take their application to adopt ard complete the necessary home study to assure the family meets minimum standards for an adojtive home as per usual procedure.

6. If the local cecision finds adoption by the foster parents an unsuitable plan, the manager of the Adoption Unit in Central Office will be advised in writing of the reasons, with a copy to the regional manager. If the manager of the Adoption Unit determines the reasons are valid, no adoptive study will be 
completed and the appropriate steps will be taken to move the child if the foster parents are unable to help hin move into an adoptive home. An adoptive home will be selected by the usual procedure. If after reviewing the local decision the manager of the Adoption Unit in Central Office questions its validity, the child will not be moved and an adoptive study of the family will be cormleted which will then be staffed in regular adoption committee.

7. If the foster parents disagree with a local decision not to allow them to adopt, they will be given the opportunity to make application to adopt, and to be considered in adoption committee with other suitable homes for the child.

Nothing in this policy statement is intended to eliminate the need for an adoptive home study or the usual process in completing an adoption. 